\title{
EVALUATION OF EXIT SIGNS IN CLEAR AND SMOKE CONDITIONS
}

\author{
NEW NIST PUBLICATION
}

December 1990

\section{Belinda L. Collins \\ Mubarak S. Dahir}

Center for Bullding Technology

Daniel Madrzykowski

Center for Fre Research

U.S. DEPARTMENT OF COMMERCE National Instltute of Standards and Technology

Galthersburg, MD 20899 



\section{EVALUATION OF EXIT SIGNS IN CLEAR AND SMOKE CONDITIONS}

\section{Belinda L. Collins} Mubarak S. Dahir

Center for Bullding Technology

Daniel Madrzykowski

Center for Fre Research

U.S. DEPARTMENT OF COMMERCE Natlonal Instltute of Standards and Technology

Galthersburg, MD 20899

August 1990

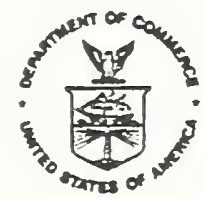





\section{Abstract}

The present paper provides a short review of the research literature on the visibility of exit signs, directional markings, and emergency lighting. It also presents a study which assessed the visibility of several types of exit signs including conventional and electroluminescent (EI) in both clear and smokey conditions. A two-part evaluation was performed. In the first, signs were measured photometrically in clear conditions with two different photometers in a laboratory to determine their luminance under dark conditions and with an ambient room illuminance of $54 \mathrm{~lx}(5 \mathrm{fc})$. Analysis of these data indicated very wide variations in luminance (from about 0.9 to $1350 \mathrm{~cd} / \mathrm{m}^{2}$ ) as a function of sign type. In the second part of the study, the visibility of the signs in both clear conditions and smoke was assessed psychophysically. A total of 21 observers participated in the assessment of visibility. Analysis of the data indicated that overall sign luminance was one of the primary determinants of visibility in smoke conditions, while uniformity was also an important contributor. The data indicated that some EL signs can be effective in clear conditions and in smoke (particularly if their luminance is above about $10 \mathrm{~cd} / \mathrm{m}^{2}$ ). Consideration of the results indicated that somewhat different characteristics of the signs seemed to determine their visibility for clear conditions than smoke, with uniformity (or sign configuration) playing a larger role in clear conditions, and luminance being more critical in smoke. Finally, the data indicated the need for further research in which the effects of color, sign configuration, and luminance are varied parametrically.

Keywords: Color, contrast, egress, electroluminescent, emergency lighting, exit, luminance, sign, smoke, optical density, uniformity, visibility. 
This report summarizes research conducted from August 1989 to June 1990, under contract Number E8789M198 with the U.S. Army Corps of Engineers.

\section{ACKNOWLEDGEMENTS}

The authors wish to acknowledge the assistance provided by Mr. Charles Bulik, Ms. Anna Dato, Mr. Jay McElroy, Mr. Peter Goodin, and Mr. Jim Meade during the course of the experiment and data analysis. In addition, the authors deeply appreciate the insightful review provided by Mr. Michael Ouellette of NRC Canada. The willing participation of the observers is also gratefully recognized. Finally, the authors wish to thank the sign manufacturers for the signs that they supplied for the experiment.

\section{DISCLAIMER}

Any commercial products or trade names mentioned in this report are included for informational purposes only, and do not constitute an endorsement or recommendation by the National Institute of Standards and Technology or the U.S. Army. 
Abstract . . . . . . . . . . . . . . . . . . . iii

1. Introduction . . . . . . . . . . . . . . . . . . . 1

1.1 Background . . . . . . . . . . . . . . . . . 1

1.1.1 Visibility Research . . . . . . . . . . . . . 1

1.1.2 Emergency Lighting and Markings . . . . . . . . . 11

1.1.3 Standards for Exit Signs . . . . . . . . . . 17

1.2 Experimental Approach . . . . . . . . . . . 23

2. Photometric Evaluation . . . . . . . . . . . . . 24

2.1 Procedure . . . . . . . . . . . . . . . 24

2.1.1 Stimuli................. . . 24

2.1.2 Approach .. . . . . . . . . . . . 24

2.2 Photometric Results .. . . . . . . . . . . . 25

3. Visibility Assessment . . . . . . . . . . . . . . 38

3.1 Experimental Approach . . . . . . . . . . . 38

3.1.1 Apparatus . . . . . . . . . . . . . . 38

3.1.2 Smoke Production and Optical Density Measurement .. . . . . . . . . . 38

3.1.3 Observers . . . . . . . . . . . . 42

3.1.4 Procedure. . . . . . . . . . . . . . . . . 42

3.2 Results of the Visibility Assessment . . . . . . . . 43

4. Conclusions and Recommendations . . . . . . . . . . . 63

5. References ................... . . . 66

Appendix A. Instructions and Research Participant Agreement Form. . 70 


\section{List of Figures}

Figure 1. Measurement Locations for Photometry of Exit Signs. . . 26

Figure 2. Chromaticity of Letters and Background of All Exit Signs. . . . . . . . . . . . . . . . . . . . 31

Figure 3. Exit Sign Array for Smoke Tests . . . . . . . . . . . . 39

Figure 4. Diagram of Experimental Test Facility. . . . . . . . . 41

Figure 5. Optical Density as a Function of Time Showing the Dispersal Between the Three Sets of Signs. . . . . . . 45

Figure 6. Comparison of Mean Sign Luminance and Visibility Ratings . . . . . . . . . . . . . . . . . . 46

Figure 7. Boxplot Comparing Time to Disappear in Smoke with Initial Sign Luminance. . . . . . . . . . . . . . . . . 48

Figure 8. Time to Disappearance as a Function of Optical Density of Smoke.................... 49

Figure 9. A Comparison of Optical Density and Luminance for all Signs as Measured During Clear and Smoke Calibration. . 50

Figure 10. Rated Visibility Comparing Low and High Ratings for the First and Fourth Smoke Condition. . . . . . . . . . 52 
Table 1. Luminance and Chromaticity of Exit Signs as Measured with Laboratory Photometer and Spectroradiometer in Darkened Room. . . . . . . . . . . . . . . . . .

Table 2. Photometric Results for Exit Signs Obtained with Handheld Luminance Meter in Dark and Illuminated Environments................ . . 33

Table 3. Data From the Visibility Experiment . . . . . . . . . . 44 Table 4. Frequency of Selection of Specific Signs as Best and Worst in Both Clear and Smokey Conditions. . . . . . . 54

Table 5. Reasons for Selecting Signs Given By All Observers . . 55

Table 6. Comments by Observers in Smoke Experiment . . . . . . . 60 



\section{Introduction}

The present study describes an assessment of the visibility of several types of exit signs in both clear and smokey conditions. A two-part evaluation was performed. In the first, signs were measured photometrically in clear conditions in a laboratory following the UL 924 procedure. In the second, the visibility of the signs in smoke was assessed psychophysically using human observers.

\subsection{Background}

\subsubsection{Visibility Research}

A number of researchers have evaluated the appearance or visibility of exit signs in clear and smokey conditions. An extensive analysis was performed at NRC Canada by Rea, Clark and Ouellette (1985) who evaluated the visibility of thirteen exit signs using both photometric and psychophysical evaluation procedures. In their experiment, 16 volunteers made threshold observations of the visibility of the exit signs in smoke. Two of the signs were chemiluminescent (tritium powered) self-illuminated signs, while the remaining eleven were illuminated with either fluorescent or incandescent bulbs.

Rea, et al. (1985) evaluated the effects of exit sign type, threshold visibility criterion and ambient smoke chamber illumination. Sixteen observers, six of whom were color deficient, viewed all 52 conditions once. Observers sat in a viewing booth about $5.2 \mathrm{~m}$ (17.06 ft) from the sign (behind a transparent plastic window). On a given trial, observers indicated if they could just see a sign or also read it. Thus, two visibility criteria, detectability and readability, were used during the experiment. If a sign were judged to be either detectable or readable, smoke was added to the chamber until the sign was obscured. The smoke density for which a sign was just below threshold was taken as the critical smoke density. Observers evaluated all signs in a cosmetic oil smoke produced by a smoke generator. Ambient lighting in the chamber was provided by a pair of $\mathrm{F} 40 \mathrm{cool}$ white fluorescent lamps which provided an illuminance of $75 \mathrm{~lx}(6.97 \mathrm{ft})$ at $1.5 \mathrm{~m}(4.92 \mathrm{ft})$ above the smoke chamber floor. The luminance of the signs was also measured at several points on the sign face. About 4-8 hours were required for the entire experiment.

A detailed analysis of the data indicated significant effects of the sign type, sign luminance, evaluation criterion, and ambient illuminance in the testing chamber. The data analysis indicated generally that greater smoke density was required to mask the visibility of signs with higher luminances. In other words, brighter signs were more visible in smoke. Greater smoke density was also required for the detectability threshold than the readability threshold. Furthermore, when ambient illuminance (at $75 \mathrm{~lx}$ ) was provided in the chamber, sign visibility was reduced, although the effect was greater for certain signs. The presence of ambient illumination also increased the amount of sign luminance required to reach the readability threshold as compared with the detectability threshold. 
Rea, et al. (1985) commented that removing the supplementary ambient illumination reduced the scattered light and enabled the signs to become more visible. It also enhanced the difference between readability and detectability. As a result, the authors suggested that scattered light from luminous (background) areas of a sign will reduce its readability more than its detectability. In addition, scattered light seemed to reduce the readability of low contrast signs more than high contrast signs, as well as the readability of smaller text.

Clark, Rea and Ouellette (1985) reported that the general sign luminance varied from 14 to $1277 \mathrm{~cd} / \mathrm{m}^{2}(4.09-372.74 \mathrm{fL})$ for incandescent and fluorescent signs, and 0.18 to $0.61 \mathrm{~cd} / \mathrm{m}^{2}(0.05-0.18 \mathrm{fL})$ for the tritium signs without external illuminance. Although both detectability and readability generally increased with overall luminance, there was considerable variability for a given luminance level, with three signs with luminances of $170,391,1272 \mathrm{~cd} / \mathrm{m}^{2}(49.6,114.13371 .28 \mathrm{fL})$ being the "best" performers. The chemiluminescent (tritium induced) signs, which had the lowest luminances, proved to be the most difficult to read. On the other hand, a sign which used one $7 \mathrm{~W}$ and one $9 \mathrm{~W}$ fluorescent lamp, with red lettering (upper and lowercase) was the most detectable and readable. Another sign using two incandescent (25W) bulbs in red was next, followed by a third sign which used only one $9 \mathrm{~W}$ fluorescent with white letters on a luminous red background. These signs had the highest luminance of any of the signs studied. In addition, abnormal color vision proved to be an important factor, with four protan ${ }^{1}$ observers performing significantly more poorly. Protans had more trouble with red signs (as might be expected from their loss of long wavelength sensitivity). While protans found the signs with the highest luminances to be more visible, their critical smoke density was markedly lower than for color-normal observers. Analysis of the data indicated that the reduction in luminous efficiency for red signs on dark backgrounds was about 208 for protans.

Clark, et al. (1985) reported that the red signs were slightly less affected by scattering due to the cosmetic smoke used. They concluded that "sign brightness was found to strongly influence visibility; the brighter the sign the more visible it was through smoke" (p.79). They also suggested that extraneous ambient illumination near a sign should be extinguished to increase visibility. The authors pointed out that while smoke may scatter red wavelengths less, such long wavelengths are less detectable by protans (about 2.58 of Caucasians). They stated that "For protans, therefore, it would be better if exit signs were green. More importantly perhaps, materials used for green sign faces will probably transmit more visible radiant energy to all occupants than will the

1 There are three major classes of color deficiency - protanopia, deuteranopia, and tritanopia. Protan defects are characterized by loss or alteration in the long wavelength (red) photopigment; deutan defects are characterized by loss or alteration in the medium wavelength (green) photopigment; and tritan defects (very rare) are characterized by loss or alteration in the short wavelength (blue) photopigment (See Hurvich, 1981, for a fuller discussion of color deficiency). 
materials used for red signs. All things considered then, it is probably better not to have red exit signs. Nonetheless, it is impossible to make sensible statements about color without proper experimentation and adequate specification of the optical properties of the signs and smoke, as well as the visual capabilities of people" (p.80).

Based on the findings from the visibility study, Rea, Ouellette, and Clark (1985) recommended increasing the brightness of the sign itself while reducing scattered light from other sources including downlights. They also suggested that cutout (stencil-face) signs should be more visible than panel-face signs. Noting that many factors affect sign "brightness", they suggested that "translucent green materials will be brighter to more people than translucent red materials for the same light source" (Rea, et al., 1985 p. 296). Although a white or colorless exit sign might be more visible, the authors agreed that an exit sign must be discriminated from its surroundings. Because green or red lights are rarely used in interior lighting for hallways and rooms, red or green signs become unique and hence more distinguishable. The authors commented that a possible solution for problems imposed by high sign luminance would be the "smart" sign that increases in brightness under smokey conditions. At the same time, ambient lighting in the vicinity of the sign could be dimmed or extinguished. They also pointed out that while many specifications for exit signs contain recommendations for minimum or maximum luminance, letter size and spacing, color, and/or mounting height, the research basis for them is rarely specified. In addition, studies of exit sign visibility have often failed to define the optical properties of the smoke used or the sign itself or the visual capabilities of the observer. Sign color and brightness are often not explicitly defined and the response methodology is often inadequate.

Rea, et al. (1985, p.19) suggested that in clear conditions, brighter signs are likely to be more visible and stated that "color can help people discriminate between an exit sign and another white, luminous source, like a ceiling fixture". They suggested further that "unevenly lit lettering will probably be more difficult to read in smoke than uniformly lit letters. Luminous surrounds and downlights will also reduce one's ability to read the exit sign lettering because of the scatter they produce (p.20)." Clark (1988) reiterated that the addition of illumination sources in the field of view may substantially reduce the visibility of nearby exit signs in smoke. Furthermore, because relatively little smoke is needed to obscure exit signs, they should be as bright and as distinctive as possible. Clark commented that the visibility of exit signs would be improved if ambient light is reduced to low levels and pointed away from the exit sign. Downlights located at the bottom of the sign may also increase light scatter and decrease visibility. Rea (1985) reiterated that brighter signs generally need more smoke for obscuration, and discussed the need for "smart" fixtures which could increase sign brightness while decreasing ambient illumination in smoke conditions.

In a subsequent study, Ouellette (1988 a,b) evaluated the effect of luminance of the sign legend and background. Suggesting that previous research had demonstrated that signs with trans-illuminated letters and 
opaque backgrounds performed better, he assessed the effect of various combinations of trans-illuminated and opaque letters and backgrounds. In Ouellette's experiment, twelve color-normal subjects (aged 22-48 years) viewed three types of exit signs at two levels of smoke density with and without ambient illumination. Their task was to adjust the brightness of the sign to a threshold of "just readable".

Three rectangular signs containing the word "EXIT" were studied with letters which subtended $0.36^{\circ}$ at a distance of $2 \mathrm{~m}$. Sign A was a red transilluminated sign with an opaque background; sign $B$ was opaque with a red transilluminated background; and Sign $C$ had red transilluminated letters with a white transilluminated background. All signs were quite uniform in transmittance. The design of the experiment was such that two levels of smoke density were studied for three sign types both with and without ambient illumination. Subjects repeated these twelve conditions three times. They were seated $2 \mathrm{~m}$ (6.56 ft) from the sign and dark adapted for $10 \mathrm{~min}$. before testing. In the experiment sign luminance was provided by a projector which illuminated the back of the exit sign panel with a range of illuminances from 0.6 to $19000 \mathrm{~lx}(0.06$ to $1765.8 \mathrm{fL})$. The subject's task was to vary the projector illuminance, and hence sign brightness, by selecting different neutral density slides until the sign was just readable. Signs were viewed in nominally white smoke. Ambient lighting at an illuminance of $0.55 \mathrm{~lx}(0.05 \mathrm{fc})$ could be provided on the front of the sign. (This illuminance represents emergency ambient lighting conditions).

Ouellette found that smoke density had the greatest effect on sign readability. In addition, the presence of ambient illumination, even as low as $0.55 \mathrm{~lx}(0.05 \mathrm{fc})$, also reduced sign readability. Two measures of sign intensity were taken; illuminance at the rear of the sign, and luminance of the front panel. Illuminance was determined for the center rear of the sign while luminance was reported in terms of the brightest luminance of text and background. (Sign luminance was determined with the colored filter in place). The luminance required for sign $C$ was greater than that required for sign $A$. This latter result is consistent with the idea that signs with illuminated backgrounds and text (such as sign C) produce a veil in smoke which reduces their readability. Yet sign $C$ was somewhat less affected by increases in smoke density. It should be noted that Ouellette's criterion of "adjust brightness until just readable" was somewhat different from that used by Rea, et al. The latter had used two criteria -- detectability and readability -- with smoke densities controlled by the experimenter.

Wilson (1990) evaluated the effectiveness of four types of exit signs in support of revisions to the Australian Standard for Emergency Lighting in Buildings (AS 2293-1979). Five different types of exit signs, all combinations of green and white, were included initially: an externally illuminated exit sign; two internally lit signs, one with the letter illuminated, and one with the background illuminated; an edgelit sign; and a tritium self-illuminated sign. 
Photometric evaluation of the signs indicated the following range of luminances in $\mathrm{cd} / \mathrm{m}^{2}$ :

\begin{tabular}{||c|c|c||}
\hline \multicolumn{2}{|c|}{ LETTER } & BACKGROUND \\
\hline \hline A-Externally lit & 11.5 & $2.7 \mathrm{~cd} / \mathrm{m}^{2}$ \\
\hline B-Internally lit & $373-720$ & $60-154 \mathrm{~cd} / \mathrm{m}^{2}$ \\
\hline C-Internally lit & $38-80$ & $230-629$ \\
\hline D-Edgelit & $3-573$ & $1-56$ \\
\hline E-Tritium & 0.9 & 0.43 \\
\hline
\end{tabular}

All signs except the tritium sign were illuminated with fluorescent lamps.

Wilson evaluated the visibility of four of the exit signs in clear and smokey conditions with twelve observers. The tritium sign was rejected from further visibility evaluation following the photometric measurements and a trial appraisal which indicated that its performance was so poor that it should not be included.

In Wilson's evaluation, each exit sign was evaluated in clear and smokey conditions as well as with and without external room illumination. Room illumination was provided by four single tube fluorescent lamps. Observers were located approximately 18-20 m (59-66 ft) from the signs. Two types of assessments were performed. In the first, observers viewed all four signs simultaneously and rank-ordered them in terms of effectiveness. In the second, observers assessed each sign individually on a rating scale of perceived effectiveness. Each assessment was performed for signs in clear conditions with and without room illumination.

The results indicated clearly that the two internally lit signs performed significantly better than the externally lit or edgelit signs for all conditions. The performance of the externally lit sign was poorest, especially for clear conditions with the room illumination on. As a result, Wilson (1990, p.16) commented that "The appraisals suggest that externally illuminated exit signs are significantly less effective than internally illuminated exit signs, particularly in the presence of smoke". He suggested restricting their use to areas that can extinguish or exclude smoke automatically, specifying the maximum distance of the external source from the sign, and increasing the minimum illuminance requirement.

Inspection of the results also revealed that an internally lit sign with illuminated letters remained visible for a longer time when smoke density was increased than a similar sign with an illuminated background. Wilson concluded (1990, p.16) that "The performance of exit signs and of emergency lighting systems in smoke warrants further study particularly since in the worst case smoke is likely to be present in at least a part of the escape route when the evacuation of the building is required". 
Schooley and Reagan (1980a) discussed the problem of reading exit signs in terms of sign contrast, observer visual acuity, and threshold illumination. These basic visual parameters are affected by such factors as letter size and separation, sign luminance (both text and background), illuminance, and distance. These authors state that calculations of visual angles and likely viewing distances suggest that object size should be set to about $0.05 \mathrm{~mm}$ ( $1.25 \mathrm{in}$ ). They calculated visual angle according to the following formula:

$$
\begin{aligned}
& \text { Visual angle }=3438 \mathrm{~d} / \mathrm{D} \\
& \qquad \begin{array}{l}
\mathrm{d}=\text { object size, perpendicular to line of sight } \\
\mathrm{D}=\text { distance to the object }
\end{array}
\end{aligned}
$$

Howett (1983) used a similar formula to calculate letter stroke width needed for sign legibility as a function of observer visual acuity. Use of these formulas depends on the maximum distance at which the sign is to be read (visual angle), observer visual acuity, sign contrast, and overall illuminance.

Schooley and Reagan (1980a) noted that visual acuity is the reciprocal of visual angle and is determined by background luminance. Thus, the smallest visual angles are resolvable only at the highest luminances and vice versa, such that an angle of $2^{\prime}$ would be required for an object lit to a luminance of $0.034 \mathrm{~cd} / \mathrm{m}^{2}(0.01 \mathrm{fL})$, while a visual angle of only 0.4 " would be required for a similar object lit to a luminance of $342600 \mathrm{~cd} / \mathrm{m}^{2}$ $(100,000 \mathrm{fL})$. Assuming that a sign receives $53.8 \mathrm{~lx}(5 \mathrm{fc})$ of room illuminance under normal illumination conditions, its luminance should be around $10.28 \mathrm{~cd} / \mathrm{m}^{2}$ ( $3 \mathrm{fL}$ ). If it is internally illuminated, a luminance of $0.21 \mathrm{~cd} / \mathrm{m}^{2}(0.06 \mathrm{fL})$ is reasonable for the sign. Calculations show that for a luminance of $0.21 \mathrm{~cd} / \mathrm{m}^{2}(0.06 \mathrm{fL})$, the expected visual acuity of 0.8 is equal to that required to detect a $31.8 \mathrm{~mm}$ (1.25 in) object at 1027.8 $\mathrm{cd} / \mathrm{m}^{2}$ (300 fL). For observers with less than normal acuity this object (or sign) should still be resolvable at $38.18 \mathrm{~m}$ (125 ft).

Schooley and Reagan then calculated minimum contrast using the formula ( $\mathrm{L}_{\circ}$ - $I_{b}$ )/ $I_{b}$ where $L_{0}$ is object luminance and $L_{b}$ is background luminance, for signs with $10.28 \mathrm{~cd} / \mathrm{m}^{2}$ and $0.21 \mathrm{~cd} / \mathrm{m}^{2}$ ( 3 and $0.06 \mathrm{fL}$ ) letter luminance. They concluded that a contrast (apparently 0.5 ) which would be detectable for observers with normal acuity should allow people to discern letters up to $45.7 \mathrm{~m} \mathrm{(150} \mathrm{ft)} \mathrm{for} \mathrm{these} \mathrm{two} \mathrm{signs.} \mathrm{Schooley} \mathrm{and} \mathrm{Reagan} \mathrm{pointed} \mathrm{out}$ that smoke could reduce this distance substantially. They concluded that four factors must be quantified to assess the legibility of an exit sign. These include: dimensional properties such as letter height, width and spacing; letter and background luminances for the intended ambient illumination; observer to sign distance; and optical transmittance along this distance. In addition, the age and visual acuity of the observer should be determined.

In a second experiment, Schooley and Reagan (1980b) conducted a series of experimental evaluations of the visibility of exit signs using five 
observers. Three sign types were used; a radioactive isotope self-powered sign, an unlit electric sign, and a lit electric sign (with two $25 \mathrm{~W}$ incandescent bulbs). The latter was a panel-face sign which used a diffuse fiberglass panel for the background. An interior corridor (10 ft wide, $12 \mathrm{ft} \mathrm{high,} \mathrm{and} 399 \mathrm{ft}$ long ( $3 \mathrm{~m} \times 36.6 \mathrm{~m} \times 121.6 \mathrm{~m}$ ) was used. For normal conditions, it was lit to between 53.8 and $538 \mathrm{~lx}$ ( 5 and $10 \mathrm{fc}$ ) with $58.1 \mathrm{~lx}(5.4 \mathrm{~lx})$ incident on the exit sign which was mounted at 1.5 $\mathrm{m}$ ( $5 \mathrm{ft}$ ) on the end wall. In the first of four tests, the maximum distance at which the three signs could be seen, distinguished and read was determined. Luminance for the internally lit sign was reduced to $5 \mathrm{fL}$ $\left(17.1 \mathrm{~cd} / \mathrm{m}^{2}\right)$ from the normal $48.5 \mathrm{fL}\left(166.2 \mathrm{~cd} / \mathrm{m}^{2}\right)$. Observers walked toward the sign and indicated the distance at which the sign met each of the three viewing criteria. In the second test, a darkened corridor was used and the legibility of the two illuminated signs was determined at different sign distances and luminances. In the third test the three viewing criteria were assessed for all three signs in smoke provided by a smoke candle. The internally lit sign was also assessed at 25 and $55 \mathrm{fL}$ $\left(85.7\right.$ and $\left.188.4 \mathrm{~cd} / \mathrm{m}^{2}\right)$. In the final test, the legibility of each sign at $75 \mathrm{ft}(22.9 \mathrm{~m})$ in smoke was determined.

The results indicated that all three signs were detectable at means of about $300 \mathrm{ft}(91.4 \mathrm{~m})$, distinguishable at $225 \mathrm{ft}(68.6 \mathrm{~m})$, and legible at $150 \mathrm{ft}(45.7 \mathrm{~m})$ under clear normal lighting conditions. When the corridor was darkened, the unlit electric sign was not visible, but the selfluminous sign was legible at $125 \mathrm{ft}(38.1 \mathrm{~m})$, as compared with $75 \mathrm{ft}$ (22.9 m) for the lit electric sign. (No luminance was given for the selfluminous sign, however.) Schooley and Reagan (1980b, p.32) claimed that "increasing brightness of the electric sign did not have a major influence on improving legibility and indeed could be detrimental when certain thresholds are exceeded... a blurring phenomenon occurred which reduced legibility when the brightness exceeded 10-20 fL $\left(34.3-68.6 \mathrm{~cd} / \mathrm{m}^{2}\right)$." When smoke was added to the normally lit corridor, the three signs became legible at only about 40-50 ft (12.2 - $15.2 \mathrm{~m})$, with essentially similar performance. Increasing the luminance of the electric sign to $25 \mathrm{fL}$ increased its visibility to $125 \mathrm{ft}(38.1 \mathrm{~m})$ and its legibility to $50 \mathrm{ft}$ $(15.2 \mathrm{~m})$ in smoke, however. Yet, the authors concluded that the performance of the self-luminous sign is acceptable compared with that of the internally illuminated electric exit sign. One of their criteria was that of energy conservation, although they did not evaluate the performance of an internally lit fluorescent sign. Furthermore, the data were based on only five observers, one of whom was protanopic.

When Cohn (1978) evaluated conditions for emergency egress in buildings, he identified three areas of concern for exit signs; namely, sign illumination level; readability of sign; and visibility of arrows. In a short experiment, six subjects viewed white, green, yellow, red and blue exit lights mounted in both a well-lit and dark office. The observers judged the lights for visibility and identifiability as an exit indicator. Cohn reported that a yellow light was most effective, followed by green and then by red, although he reported no luminance measures for the lights. He claimed that subjects had difficulty in identifying the word "EXIT" from $80 \mathrm{ft}(24.4 \mathrm{~m})$, although his procedure was not clearly 
explained. Cohn also criticized the lettering used for exit signs, saying that the ratio of the stroke width to height of dark letters on a light background should be about $1: 5$ and $1: 10$ for light letters on a dark background. Yet, the stroke width on most exit signs ranges from 0.5 to 0.75 in. $(12.7-19.0 \mathrm{~m})$ with 6 in. $(152 \mathrm{~mm})$ letters for a ratio of $1: 12$ to $1: 8$ regardless of letter and background color. Because of these inconsistencies he stated that colored signals (similar to stoplights) would be preferable. Green signals, in particular, should be more detectable in smoke. His final recommendation was to replace the word "EXIT" with a green light or to combine "EXIT" with an arrow of equal or greater size. These recommendations have not been implemented, however.

Collins and Lerner (1983) evaluated the performance of exit symbols in a laboratory setting which simulated smoke conditions. In their study, 42 participants viewed 108 symbol slides of which 18 were actually exit symbols. Participants were familiarized with a random set of 9 of the 18 symbols before beginning the experiment. Three different viewing conditions simulated the degrading effects of smoke (including veiling luminance, reduced luminance, and blur) with luminance of the symbol slides set at $0.085,0.06$, and $0.032 \mathrm{~cd} / \mathrm{m}^{2}(0.025,0.018,0.009 \mathrm{fL})$. These conditions were produced by combinations of neutral density filters and supplementary veiling luminance. The authors found more errors as the viewing conditions were degraded, as expected, although some symbols were affected more than others by the degradation. Symbols which were most affected included complex ones with which participants were unfamiliar. At least three symbols performed reasonably well under all viewing conditions, regardless of familiarization, with one being "better" than the rest. The authors recommended that this symbol, showing a person and an open door, be considered for use in the United States. It has subsequently been adopted in NFPA 171. Data from this study suggests that veiling luminance and degraded viewing conditions reduce the visibility of all exit symbols, although the effect is greater for some symbols than other. Unfortunately, the relative visibility of symbols and the word EXIT was not compared in this experiment. Such an experiment should be done before symbols are used to replace EXIT signs, although the dual use of symbols and words has proved successful in highway situations.

Edmondo and Macey (1968) evaluated the effectiveness of lighting and directional signs for emergency egress on Navy ships. In the first experiment, they constructed an observation tunnel for viewing lights in smoke. Fifteen observers viewed each of five light sources five times in smoke, with a transmission of 7 to $13 \%$ per foot. Analysis of the data indicated that a quartz iodine lamp was the most visible, although it did not meet U.S. Navy specifications. The next most visible lamps were a Navy battle lantern and a xenon flasher. In a second study, subjects negotiated their way through a maze in smoke using both lights and markers as guides. Both the battle lantern and the xenon flash lamp were tested in the second experiment, along with retroreflective tape and tactile arrows. Flashlights were used with the tape, as needed. Analysis of the data indicated that the most errors (in terms of wrong turns in the maze) were made for the situation with no markers. The longest time, however, was for the tactile arrows, although the fewest errors were made for this 
condition. Apparently it was very difficult to discriminate the arrows from the surface on which they were mounted. The time to negotiate the maze was shortest for the battle lantern, while the number of errors was also among the lowest. The use of $6 \mathrm{ft}(1.8 \mathrm{~m})$ spacings for the lantern was more effective than the $12 \mathrm{ft}(3.6 \mathrm{~m})$ spacings used for the xenon flashers. As in other studies, there was less smoke near the floor, suggesting that light sources should be mounted low on the passageway bulkhead, no more than $2 \mathrm{ft}(0.6 \mathrm{~m})$ from the deck and no more than $6 \mathrm{ft}$ $(1.8 \mathrm{~m})$ apart. The authors recommended using retroreflective tape on ladders and hatches in the beam of the battle lantern to increase the visibility in the exit pathway.

Bono and Breed (1965) used the obscuration of a series of exit signs to assess the effects on smoke produced by a larger set of building materials. Subjects rated the visibility of an array of six exit signs. The center two signs (located $5 \mathrm{ft}(1.5 \mathrm{~m}$ ) above the ground in the 2 by 3 array) were used as the reference point for the visual, photographic, and physical measures of smoke density. The time and density required for smoke to obscure these signs was determined for the different building materials. A scale of 0 to 5 , in which " 0 " meant "entirely unobscured" and "5" meant "totally obscured" was used to rate smoke density. These measures were also related to physical measures of smoke density. The signs included conventional internally illuminated signs in red and green on white with 4.5 in $(114.3 \mathrm{~mm})$ letters located $12 \mathrm{ft}(3.6 \mathrm{~m})$ from the observers. Inspection of the obscuration data revealed wide differences in the time to obscuration with smoke from some plastic and polyvinyl materials totally obscuring the exit signs in less than a minute. The authors pointed out that changes in room volume, air flow, and ventilation would all affect the time to obscuration. Unfortunately, no details are given of the number of subjects or the photometric characteristics of the exit signs. Nevertheless, these data do provide an indication of differences in the ability of real building materials to obscure exit signs located only $12 \mathrm{ft}(3.6 \mathrm{~m})$ from the observer, in some cases extremely rapidly.

Beyreis and Castino (1974) evaluated the effectiveness of three types of exit signs in clear and smokey conditions. Signs included tritium, phosphorescent and electric internally lit signs. All signs had 6 in (152 $\mathrm{mm})$ high letters with a 0.75 in $(19.1 \mathrm{~mm})$ stroke width. For clear conditions, the luminance of the electric sign was adjusted to be equivalent in visibility to that of an unlit exit sign with $5 \mathrm{fc}$ (53.8 $1 \mathrm{x}$ ) of external illumination on the face. In smoke conditions, the luminance was adjusted to give a visibility equivalent to the self-luminous sign at full life. An unspecified number of observers viewed the signs. Results from the clear condition indicated that the electrically illuminated sign was visible and legible at $300 \mathrm{ft}(91.4 \mathrm{~m})$. The tritium signs were legible at $75 \mathrm{ft}(22.9 \mathrm{~m})$ for the half-life sign and $100 \mathrm{ft}(30.5 \mathrm{~m})$ for the fulllife sign, but neither was visible at $300 \mathrm{ft}(91.4 \mathrm{~m})$. Self-luminous arrows were legible at only $25 \mathrm{ft}(7.6 \mathrm{~m})$ in clear conditions. The effects of smoke were assessed at a fixed distance of $12 \mathrm{ft}(3.6 \mathrm{~m})$ in a smoke filled chamber. Observers were adapted to about $5 \mathrm{fc}$ (53.8 $1 \mathrm{x}$ ) ambient illumination. The optical density at which the electric signs 
were legible was greater $(0.152 / f t)$ than for the tritium sign $(0.095 / f t)$. When the brightness of the electric sign was reduced to be nearly equivalent to the tritium sign, legibility and visibility occurred at the same smoke density for both. The authors reported little effect of the backscattering of incident light when it was directed into the smokey room over the heads of the observers. It should be pointed out that the number of observers and their visual capabilities were not specified. In addition, signs were viewed at only $12 \mathrm{ft}(3.6 \mathrm{~m})$, even though NFPA specifies a maximum viewing distance of $100 \mathrm{ft}(30.5 \mathrm{~m})$. Furthermore, the performance of the electric sign was comparable to that of the tritium sign only when it had been dimmed. The performance of the tritium sign in clear conditions was markedly poorer, with a legibility distance of less than one-third that of the electric sign.

Rasmussen, Garner, Blethros and Lowrey (1979) evaluated the visibility of eight exit signs in smoke simulating an aircraft cabin. The signs were viewed at a distance of $1956 \mathrm{~mm}$ (77 in). Four levels of background luminance were assessed - 31, 89, 140, and $158 \mathrm{~cd} / \mathrm{m}^{2}(9.1,25.9,40.9,46.1$ $\mathrm{fL}$ ), while eight levels of sign height and width were evaluated - 3.2 to $211.5 \mathrm{~mm}(0.13-8.33 \mathrm{in})$ in height, and 0.38 to $25.4 \mathrm{~mm}(0.01$ to 1 in) in stroke width. After subjects adapted to the prevailing luminance, smoke was exhausted from the chamber until the subject could identify the sign correctly. The authors found that relatively similar smoke densities obscured the signs at the three higher luminances, while slightly less smoke was required for obscuration at the lowest luminance. Similarly, larger signs consistently required greater smoke density for obscuration, although the results for the six larger signs (above $13.4 \mathrm{~mm}(0.53 \mathrm{in}$ ) in height) were quite similar. Rasmussen, et al suggested that smoke effectively reduced sign luminance and hence apparent brightness to between 0.03 and 0.11 percent of clear air conditions. They concluded that signs which meet or exceed the FAA recommendation of $89 \mathrm{~cd} / \mathrm{m}^{2}(26 \mathrm{fL})$ will be visible in smoke densities of 3 to 3.55 (total optical densities). Increasing sign size above a certain minimum did not appreciably increase readability.

Demaree (1982) evaluated typical and innovative aircraft emergency lighting and signage systems in smoke conditions. He noted that the FAA requires the average illuminance to be not less than $0.05 \mathrm{fc}(0.5 \mathrm{~lx})$ on the centerline of the main aisle or the armrests. Passenger exit signs must be internally illuminated with a background luminance of $25 \mathrm{fL}$ ( 85.6 $\left.\mathrm{cd} / \mathrm{m}^{2}\right)$. In a series of tests, Demaree found that smoke can rapidly and significantly obscure cabin illumination and signs (in as little as 45 sec), as well as decrease overall illumination. The obscuration is clearly a function of the distance from the floor - signs 90 in $(2.3 \mathrm{~m})$ above the floor were obscured in $45 \mathrm{sec}$; signs that were only 24 to 45 in. $(0.6-1.14 \mathrm{~m})$ were barely visible at $120 \mathrm{sec}$. As a result, Demaree recommended locating illumination sources below 61.5 in $(1.56 \mathrm{~m})$. Although Demaree's results did not indicate any significant effect of increasing sign luminance on visibility, he only examined three luminance levels $\left(25,50\right.$ and $75 \mathrm{fL}$ or $\left.85.6,171.3,256.9 \mathrm{~cd} / \mathrm{m}^{2}\right)$. The signs with the greater luminance remained visible about 10 to $15 \mathrm{sec}$ longer. than the 25 fL $\left(85.6 \mathrm{~cd} / \mathrm{m}^{2}\right)$ signs, although the density of smoke determined the 
absolute time course for visibility. Demaree found that lighting in the armrests remained visible longer than ceiling or bulkhead lighting, and claimed that floor-mounted electroluminescent lighting would provide the maximum visibility. Thus in one test condition, ceiling lights were obscured in $68 \mathrm{sec}$, while the floor lights were not obscured until $156 \mathrm{sec}$ for the same amount of smoke.

Teal (1983) evaluated eleven potential emergency lighting systems in terms of ease of use and cost of retrofit, as well as ability to improve emergency lighting in dense smoke. He found that self-illuminated markers and exit signs would be substantially less expensive than incandescent lights and signs in terms of initial and life-cycle costs.

Jin and Yamada (1985) evaluated the effects of irritating smoke on visibility. They reported that the visibility of internally lit signs in black smoke was slightly greater than in white smoke. They also determined that signs of $2000 \mathrm{~cd} / \mathrm{m}^{2}$ (584 fL) were more visible than signs of $500 \mathrm{~cd} / \mathrm{m}^{2}(146 \mathrm{fL})$, and observed a linear relationship between the product of the visibility of the sign at the obscuration threshold and the smoke density. In a second experiment, they found that when observers walked through irritating white smoke, the visibility of the exit sign decreased more sharply than with a less irritating black smoke. Similarly, walking speed dropped from about $1.2 \mathrm{~m} / \mathrm{s}$ to about $0.4 \mathrm{~m} / \mathrm{s}$ as smoke density increased. The effect occurred at a much lower smoke density for irritating smoke (with an extinction coefficient of only 0.5 as compared with 1.0). An experiment on visual acuity in smoke also indicated a marked decrease with increasing extinction coefficient, with an accompanying increase in eye blink rate. Thus, when the smoke was relatively thick, its irritating effects reduced visibility beyond its ability to obscure the sign physically.

\subsubsection{Emergency Lighting and Markings}

Another consideration for exit signs and markings is that of the time to exit a building successfully during an emergency. Numerous studies have attempted to determine minimum illumination required for safe egress as well as the type of markings which aid such egress. These will be reviewed in the following section.

Boyce (1985) investigated the time required for subjects to escape from a large open-plan office into a corridor for five emergency and one normal lighting conditions. Illuminance on the floor of the office ranged from about 6.28 to $0.0021 \mathrm{~lx}(0.58$ to $0.00019 \mathrm{fc})$, and from 7.19 to $0.012 \mathrm{~lx}$ (774 to $0.0011 \mathrm{fc}$ ) in the corridor. Boyce obtained three measures of subject performance - time for egress, hesitancy, and opinions of the difficulty of the task. Boyce found that subjects' performance deteriorated as room illuminance decreased. Both the total time to leave the space as well as the time to initiate movement from the space increased, particularly for the condition with the lowest illuminance. Boyce did not report a significant increase in speed or delay time when room illuminance was increased from $7 \mathrm{~lx}(0.65 \mathrm{fL}$ ) to normal (about $580 \mathrm{~lx}$ or $53.9 \mathrm{fc}$ ) on the office floor). The number of collisions with obstacles 
(such as chairs, wastebaskets, desks) increased as illuminance decreased, particularly from 0.15 to $0.0021 \mathrm{~lx}(0.014$ to $0.00019 \mathrm{fc})$, while subjects' movements were classified as more hesitant. Similarly, rated difficulty increased as illuminance decreased, particularly to the lowest two levels 0.0021 and $0.011 \mathrm{~lx}(0.00019$ and $0.0010 \mathrm{fc})$. Boyce found no significant differences to this pattern when he examined the performance of older observers, more familiar observers, or groups of four observers. Boyce (p. 65) concluded that "at illuminance condition 4 (mean illuminance 0.012 lx or $0.0011 \mathrm{fc}$ ) people move hesitantly, collide with obstacles and consider the emergency lighting very unsatisfactory. At illuminance condition 3 (mean illuminance $0.16 \mathrm{~lx}$ or $0.014 \mathrm{fc}$ ) movement becomes easier but there are still some subjects who move hesitantly and who collide with obstacles. The emergency lighting is considered neutral as far as satisfaction is concerned." Boyce concluded that the British standard of $0.2 \mathrm{~lx}(0.018 \mathrm{fc})$ on the floor is reasonable only as an absolute minimum, and that use of a mean illuminance of $1 \mathrm{~lx}(0.09 \mathrm{fc})$ is likely to improve speed and certainty of movement through such spaces. Increases in illuminance above a mean of $1 \mathrm{~lx}(0.09 \mathrm{fc})$ did not improve performance further in Boyce's experiment. Boyce noted that the occurrence of smoke would likely reduce the illuminance on the escape route and scatter any available light; thereby rendering the situation much more difficult.

In a second experiment Boyce (1986) evaluated the effects of a 5 sec delay in the changeover from normal to emergency lighting conditions. The goal was to determine if there was any effect of the delay on peoples' ability to traverse the space under a given illuminance. As in the previous experiment, Boyce assessed movement time, hesitations, collisions and rated difficulty. Boyce confirmed the effect of illuminance reported earlier; namely, that lower illuminances reduce speed, and increase collisions and rated difficulty. He also found that the 5 sec delay tended to improve performance more than an immediate changeover to the emergency lighting condition. When subjects were instructed to remain at their desk until they felt able to move without hesitation over the escape route, Boyce found that they tended to wait longer at their desk but move more quickly than in $5 \mathrm{sec}$ delay or immediate switchover conditions. Unfortunately at the lowest illuminance level, the delay to initiate movement was so long that the faster movement speed could not compensate. Delay in initiating movement reduced hesitations and collisions but did not remove them. Nonetheless, "there is little doubt that delaying movement for a short period leads to a significant improvement in all these aspect of performance (Boyce, 1986, p.14). Boyce related these results to the adaptation state of the subject, noting that because it takes longer to adapt to lower levels of illuminance, the 5 sec delay allows time for the subject's eyes to become more fully adapted. Levels of $0.012 \mathrm{~lx}(0.0011 \mathrm{fc})$ took much longer for subjects to adapt to, judging by their average delay of $40.45 \mathrm{sec}$ to initiate movement. In contrast, delay in starting for an illuminance $0.16 \mathrm{~lx}(0.014 \mathrm{fc})$ was only $6.95 \mathrm{sec}$. Boyce concluded that neural adaptation is a reasonable basis for setting emergency lighting criterion. "Specifically, it can be suggested that any emergency lighting criteria should be set at such a level that people can completely adapt to it from any likely prevailing luminance within a few seconds using neural adaptation" (Boyce, 1986, p. 17). 
Sime (1984) analyzed egress data from a fire in a recreational facility to determine which route was selected. He found that people tended to select the route they were most familiar with, even though it was not the designated fire exit or the most direct way out of the building. Panic did not appear to be a major element in directing behavior; rather lack of information about the fire and the whereabouts of party members was. Sime stated that familiarity with a particular exit is the determinant of its use, and could lead to the use of an exit which is inappropriate or further away. Providing exit signs and markings may not help an unfamiliar user, particularly if those routes are restricted from normal use (e.g. "fire exit only"). In a subsequent paper, Sime (1985b) expanded this discussion to include the role of familiarity with other occupants in a further development of his model of movement in fire emergencies. Thus, analysis of the data from this fire indicated a tendency for group members to come together before leaving the building, as well as a tendency to use the route by which they entered the building. He found that his model predicted egress behavior much better than the panic model. Failure to provide adequate information about the extent of the fire and the best exit routes (even though 'unfamiliar') resulted in serious delays in beginning the evacuation. Finally Sime (1985b) discussed the perception of time available for egress in fires and noted that by the time a fire is noticed, many escape options have been seriously reduced or cut off. Thus, relying on an escape criterion of a certain amount of time such as 2.5 min does not include the time to initiate movement. Sime commented that "The key to improving the margin of safety undoubtedly lies as much in efficient forms of information and communication about the state of the fire at different stages, as in the building's design" (1985b, p. 10).

Jaschinski (1982) evaluated emergency lighting provisions in a study of peoples' movement under normal and emergency lighting conditions. In a series of experiments, subjects negotiated their way through one of 10 paths in a large room, following the exit signs under six conditions of emergency illuminance ranging from 0.24 to $7.7 \mathrm{~lx}(0.022-0.72 \mathrm{fc})$ at 20 $\mathrm{cm}$ above the floor, and two of normal illuminance. Two types of German exit signs ("NOTAUSGANG") were used, one non-luminous with a contrast of 0.57 and one luminous with a contrast of 0.7 and mean luminance of $40 \mathrm{~cd} / \mathrm{m}^{2}$ $(11.7 \mathrm{fL})$. Signs were green on white. Two different age groups participated, one younger (between 18 and 30) and one older (between 50 and 70). Performance measures included escape time, subjective evaluation, and ability to perform simple arithmetic operations (such as addition) accurately. This latter task was chosen to evaluate "spare mental capacity" as an indicator of task difficulty. Analysis of the data indicated that speed of movement dropped significantly for older subjects at illuminances below $4 \mathrm{~lx}(0.18 \mathrm{fc})$ and for younger subjects at illuminances below $2 \mathrm{~lx}(0.37 \mathrm{fc})$. Error rates for the arithmetic task also increased while subjective evaluations were less favorable at the lower illuminance. When performance was assessed as a function of sign type, Jaschinski found that when the emergency illuminance was only 0.24 Ix $(0.022 \mathrm{fc})$, escape time and error rates were higher, while subjective evaluation was less favorable than at higher illuminances, regardless of age group. A subsequent study confirmed that time to escape and subjective evaluation were less affected by low levels of emergency 
lighting when luminous signs were used. Jaschinski found, however, that performance was relatively unaffected by the prevailing room illuminance $(250-10001 x$ or 23.2 to $92.9 \mathrm{fc})$. He commented (p.370) that "Each of our performance measures shows a substantial improvement as the emergency lighting is increased from $0.24 \mathrm{~lx}(0.022 \mathrm{fc})$, whereas little if any improvement occurs between about 2 and $41 \mathrm{x}^{\prime \prime}(0.18$ to $0.37 \mathrm{fc})$. He recommended $2 \mathrm{~lx}(0.18 \mathrm{fc})$ for general use with an increase to $4 \mathrm{~lx}(0.37$ fc) if many elderly people are involved. While levels below this, such as $0.3 \mathrm{~lx}(0.027 \mathrm{fc})$, may not result in many collisions, walking speed can be reduced by as much as $30 \%$. Finally he cautioned that his findings apply to surroundings with mean reflectance of about 50\%. Reflectances below this obviously will reduce mean wall and floor luminance.

In an early investigation, Simmons (1975) evaluated several issues related to the quality of emergency lighting. He defined the three major factors which determine lighting quality as mean illuminance at floor level, diversity in illuminance on the escape path, and apparent brightness (or glare) from individual luminaires. In an experimental assessment of illuminance levels, Simmons had subjects walk through a network of corridors into which six grey cubes had been placed. He measured speed through the corridor and number of collisions as a function of seven different horizontal illuminances ( 6 emergency and 1 normal) on the floor for 10 subjects. All subjects experienced all conditions. Analysis of the data indicated that a level of $0.28 \mathrm{~lx}(0.026 \mathrm{fc})$ resulted in total avoidance of obstacles and could be considered a minimum "safe" illuminance. Comparison with speed of movement data for $300 \mathrm{~lx}(27.9 \mathrm{fc})$, however, indicated that speed is noticeably slower at $0.28 \mathrm{~lx}(0.026 \mathrm{fc})$ than $300 \mathrm{~lx}(27.9 \mathrm{fc})$. It is unfortunate that simmons did not test an illuminance between $0.28(0.026 \mathrm{fc})$ and $300 \mathrm{~lx}(27.9 \mathrm{fc})$. Evaluation of the effect of diversity in illuminance showed no significant effect. A final experiment on the effects of a glare source directly in the field of view ahead also showed no significant effect. The author theorized that this occurred because the light source was not directly in view when the occupants were searching the escape route for obstacles. He reanalyzed his data to consider the effect of the same glare source on an adjacent sign. This analysis provided a formula for relating source intensity to the average emergency illuminance to provide a glare limit for ensuring the legibility of signs under emergency conditions. Use of such a formula would limit illuminance levels near exit signs and markings, as recommended by Rea, et al (1985).

When Taylor and Sucov (1974) evaluated the choice of routes in a room, they found that at least $67 \%$ of the subjects selected the right-hand path. If the illumination ratios were greater than 1,708 of the subjects chose the brighter of the two paths. Illuminances included $1,3,10,30$ or 100 fc $(10.76,32.28,107.6,322.8,10761 \times 1 \mathrm{ft}$ from the end of the corridor) for one path versus $1 \mathrm{fc}(10.76 \mathrm{~lx})$ for the other path. Subjects had some tendency to follow the brighter path more if it were on the right. These data have important implications for egress marking in that they suggest that both brightness and location (left or right) influence the choice of routes through an area. It may be that "left" paths require more illumination, or more salient markings than "right" paths. 
Ouellette and Rea (1989) re-evaluated the research on illuminance requirements for emergency lighting in an attempt to resolve some of the discrepancies between the different research results. They noted that three different operational definitions of safety have been used by various authors. These include: the ability to move through a space without colliding with obstacles; time to egress; and subjective impressions of the emergency lighting. Yet, the amount of illumination may affect each aspect differently. Ouellette and Rea listed the many factors which could determine emergency lighting requirements. These include: occupant factors such as age, familiarity with the space; and extent of crowding; lighting factors such as illuminance uniformity; and space characteristics such as escape route length, exit signs, clutter, and changes in level.

Ouellette and Rea compared five studies of emergency lighting on the basis of escape route, mean illuminance and location, subjects, prior exposure (or adaptation level), crowd size, and dependent variables such as egress time, collision, delay and subjective response. When they compared the mean number of collisions, they found that these decreased rapidly once an average illuminance of $0.5 \mathrm{~lx}$ on the floor was reached. This conclusion applied to results by Simmons (1975), Jaschinski (1982), Boyce (1985), and Nitikin (1973).

When Ouellette and Rea examined the results for egress time as a function of floor illuminance, they found a somewhat different pattern. In this analysis, the dependent variable was average speed, or time to move successfully through the egress route. When Ouellette and Rea plotted average speed as a function of floor illuminance for the results of Jaschinski, Simmons and Boyce, they found that speed for people of similar age was consistent in the three studies. Furthermore, speed increased with floor illuminance, even up to normal ambient levels ( $300 \mathrm{~lx}$ or more). The reduction in escape speed for younger subjects was $12 \%$ at $51 \mathrm{x}, 20 \%$ at $1 \mathrm{~lx}$, and 308 at $0.2 \mathrm{~lx}$, relative to normal walking speed at $300 \mathrm{~lx}$.

The authors concluded that "studies which measure safety in terms of the number of collisions with large obstacles in the escape pat consistently show good performance at illuminance levels as low as $0.5 \mathrm{~lx}$. Although obstacles can be avoided at these low levels, people are still more hesitant as reflected in average walking speed, a potentially important measure of safety during emergency evacuation. Any reduction in average illuminance below $300 \mathrm{~lx}$ will compromise average walking speed to some degree. Thus the recommendation of minimum illuminance levels, becomes a value judgment on resolving a compromise between inferred occupant safety and the cost of illuminance" (Ouellette and Rea, 1989, p.40). The authors concluded that a recommendation of $0.51 \mathrm{x}$ minimum and $5 \mathrm{~lx}$ average along the escape route appears reasonable for avoiding obstacles and not seriously compromising walking speed.

Still another approach to improving emergency lighting and egress markings is the use of photoluminescent markings. A series of papers by Webber and his colleagues at the Building Research Establishment in the UK discussed the role of lighting and path markings for emergency conditions in 
buildings. Webber (1987), Webber and Hallman (1987, 1988, 1989) and Webber, Hallman, and Salvidge (1988) conducted a series of studies on the use of photoluminescent markings. The studies were conducted in a simulated L-shaped corridor with a single change in elevation in addition to a staircase. The markings simulated a painted baseboard on the corridor, and risers on the stair. Webber and his colleagues measured walking speed for 84 subjects as a function of different illuminance levels and photoluminescent markings. The photoluminescent pigments used are activated primarily by ultraviolet radiation in both natural and artificial sources. These authors found that mean speeds declined markedly for illuminances below $0.21 \mathrm{x}(0.018 \mathrm{fc})$ for both the corridor and the stairs. Furthermore, the mean speeds with photoluminescent markings was comparable to that at $0.2 \mathrm{~lx}(0.018 \mathrm{fc})$ in the corridor and slightly faster on the stair (Webber, 1987). Webber and Hallman (1987) reported that all subjects were adapted to normal room lighting $500 \mathrm{~lx}$ $(46.5 \mathrm{fc})$ which was extinguished to one of five emergency lighting conditions. Mean speed was slowest for $0.02 \mathrm{~lx}(0.0018)$ for both the corridor $(0.55$ to $0.6 \mathrm{~m} / \mathrm{s})$ and stair $(0.24 \mathrm{~m} / \mathrm{s})$. The authors reported that on stairways, movement with an illuminance of $1 \mathrm{~lx}(0.09 \mathrm{fc})$ was faster, appeared easier, and showed less likelihood for stumbles or falls than that with $0.2 \mathrm{~lx}(0.018 \mathrm{fc})$. They suggested consequently that increasing emergency illuminance to $1 \mathrm{~lx}(0.09 \mathrm{fc})$ could be beneficial. Use of photoluminescent material yielded results comparable to $0.2 \mathrm{~lx}$ $(0.018 \mathrm{fc})$, although subjects expressed a preference for the photoluminescent markings.

Webber and Hallman (1988) reported results for the use of photoluminescent EXIT and directional signs with green backgrounds. At the conclusion of an experiment in which each subject completed two corridor and two stairway tests, subjects were asked to recall if they had seen any signs and where. Only 258 recalled seeing the signs on the stairs as compared with $75 \%$ who recalled the corner sign (exit plus arrow where they turned from one corridor into the next). At least 658 recalled the 'end of corridor' sign while only 23-36\% recalled the 'start of corridor' signs. Webber and Hallman also found that the use of non-uniform lighting in which one area was most brightly lit ( $1 \mathrm{~lx}$ or $0.09 \mathrm{fc}$ ). to serve as a "beam" was less successful as judged by slower movement and lower satisfaction ratings. The authors commented that performance for the photoluminescent markings could be improved if more markings were used.

Webber, Hallman, and Salvidge (1988) discussed results for a comparison of both photoluminescent markings and British minimum illuminance conditions for a subset of 24 subjects. This analysis indicated that mean speeds were faster for 5 of the 6 sections of the stairway route when photoluminescent markings were used. Furthermore the difficultly of negotiating the stairway was rated as lower while satisfaction with the lighting was rated as higher when compared with the standard of $0.2 \mathrm{~lx}$ $(0.018 \mathrm{fc})$ illuminance. On the other hand, photoluminescent markings were not as successful for corridor markings as the $0.2 \mathrm{~lx}$ standard. The greatest difficulty arose in an area where there were no markings on the corridor. Webber et al commented that there is a need for guidelines on the placement and use of such marking material. 
Preliminary data suggested that using either fluorescent or incandescent sources at 100-200 $\mathrm{lx}(9.29-18.59 \mathrm{fc})$ for ambient illumination provided sufficient excitation for the photoluminescent markings and signs, although the use of fluorescent lamps resulted in somewhat greater and longer lasting luminance for the markings. Excitation of the markings depended on initial excitation illuminance and spectral power as well as the presence of diffusers and duration of illumination. Nonetheless, the rate of decay for the photoluminescent markings approximated that for dark adaptation for human observers. Finally, Webber and Hallman (1989) provided guidance for using photoluminescent markings as an alternative or supplement to emergency lighting. Such markings can identify the location of exit doors, directional information, route markings, stair characteristics and changes in elevation;-mark protruding objects; and indicate location of emergency equipment. Those authors suggested the use of eye (or waist) level and floor level markings, with continuous markings as much as practicable. They concluded that the success of the material in BRE field tests indicates the need for standardized test methods and procedures for determining the luminance of photoluminescent material and performance in emergency egress situations.

\subsubsection{Standards for Exit Signs}

The Life Safety Code of the National Fire Protection Association (NFPA) provides specifications for exit signs and lighting for emergency egress in NFPA 101-26 (1988). This code states that "the floors of means of egress shall be illuminated at all points including angles and intersections of corridors and passageways, stairways, landings of stairs, and exit stairs to values of not less than $l \mathrm{fc}(10.76 \mathrm{~lx})$ measured at the floor" (5-8.1.3) The only exception is for public assemblies where the illuminance may be reduced to $0.2 \mathrm{fc}(2.1 \mathrm{~lx}$ ) during a performance. Under guidance for marking means of egress, the code states that "Exits shall be marked by an approved sign readily visible from any direction of exit access" (5-10.1.2), with the only exception being a main exterior door which is readily identifiable as an exit. Signs are to be placed such that no point in the access to the exit is more than $100 \mathrm{ft}(30.5 \mathrm{~m})$ from the nearest visible sign. Signs are to be "located and of such size, distinctive color, and design as to be readily visible and shall provide contrast with decorations, interior finish or other signs. No decorations, furnishings, or equipment that impair visibility of an exit sign shall be permitted..."(5-10.1.5). Signs are required to have plainly legible letters at least 6 in $(152 \mathrm{~mm}$ ) high with a stroke width of not less than 0.75 in $(19.1 \mathrm{~mm})$. Every sign is to be illuminated by a reliable source. Externally illuminated signs are to be lit by not less than $5 \mathrm{fc}(53.8 \mathrm{~lx})$ and have a contrast ratio of not less than 0.50 . Internally illuminated signs shall have a visibility equivalent to such an externally illuminated sign. The only exception is approved self-luminous or electroluminescent signs with evenly illuminated letters which may have a minimum luminance of $0.06 \mathrm{fL}\left(0.21 \mathrm{~cd} / \mathrm{m}^{2}\right)$ and which are to be used for low level exit signs located 6 to 8 in (152 to $203 \mathrm{~mm}$ ) above the floor.

The Underwriters Laboratory (UL) 924 (1989) Standard for Emergency Lighting and Power Equipment provides procedures for determining the 
provides procedures for determining the visibility of exit fixtures and lights. In the 924 standard, the minimum size for exit.letters is specified as 6 in $(152 \mathrm{~mm}$ ) with the minimum width of each stroke being 0.75 in $(19.1 \mathrm{~mm})$, the minimum width of all letters except "I" being 2 in $(50.8 \mathrm{~mm})$, and the minimum spacing between letters being 0.38 in $(9.5 \mathrm{~mm})$. As the letter height increases, the stroke width, letter width; and spacing should increase proportionately. If an arrow is provided it should be located no less than 0.38 in $(9.5 \mathrm{~mm})$ from any letter in the sign. It should be located outside the legend, and most importantly the direction of travel should not be easily changed. The standard thus precludes sign constructions in which arrow direction could be easily (or inadvertently) switched during relamping or cleaning. Similarly, any openings on the sign that are neither letters nor arrows should be covered up to avoid indicating an unintended direction of travel.

The UL 924 standard provides two means of determining the visibility of an exit sign and arrow. The first is a gray scale visibility test; the second is by a luminance measurement visibility test. The standard requires that the legend and arrow be visible even when not internally illuminated. A determination of visibility should be made for normal ambient lighting on the sign face. UL further specifies a contrast ratio of no less than 0.5 for the exit sign (and arrow) under both normal and emergency lighting conditions.

The grey scale visibility test is used to determine the visibility equivalence of a candidate sign with a reference sign under normal operating conditions. To perform the grey scale test, the sign should be located in the center of the back wall of a flat-black test enclosure which should be divided in half by a separate wall. The visibility of the candidate sign located $5 \mathrm{ft}(1.5 \mathrm{~m})$ from the observer is compared with that of an externally illuminated white metal reference sign ( $85 \%$ reflectance and $0-5 \%$ gloss). This reference sign should contain the word "EXIT" in flat black in the standard format for 6 in letter height. The reference sign should be illuminated by an incandescent lamp (type R-14) with a frosted 25 W 120 volt bulb located 50 in $(1.3 \mathrm{~m})$ from the sj.gn. Illuminance of the sign should be $5 \mathrm{fc}(53.8 \mathrm{~lx})$. UL allows the reference sign to be identical with the candidate sign if it has a minimum contrast ratio of 0.5 when externally illuminated at $5 \mathrm{fc}(53.8 \mathrm{~lx})$. When the visibility comparison is made, there should be no other illuminance in the room. The comparison is a visual one, made by viewing both candidate and reference sign simultaneously through a photographic grey scale. The density is gradually increased from the clear end to a point of greater density until the reference sign fades from view. The test sign should be equal to or greater in visibility than the reference sign over the entire grey scale. UL cautions that the judgment should be made for the entire sign and not for single letters.

UL provides an alternative to the grey scale test in which the luminance of the sign is measured. For this test, the candidate sign should be placed on a vertical black surface and externally illuminated to $5 \mathrm{fc}$ or $3 \mathrm{fc}$ ( 53.8 or $32.3 \mathrm{~lx}$ ) with the type R-14 reflector lamp mentioned above. Luminance of both letters and sign background is to be measured at 23 
locations. These areas should consist of circles no larger than 0.38 in. $(9.5 \mathrm{~mm})$, in diameter. A distance of at least 0.69 in. should be maintained between the target area and the edge of the legend and/or background. UL specifies a series of measurements and calculations for each illumination condition including:

a) luminance of each of the 23 points;

b) average luminance of each letter and of all background points;

c) average luminance of all letters;

d) contrast ratio for the sign using the average luminance of the background and the legend according to the formula;

$$
\begin{aligned}
C=\left(L_{g}-L_{1}\right) / L_{g}, \text { where, } \\
C=\text { contrast ratio, } \\
L_{g}=\text { greater luminance (average of measures), } \\
L_{1}=\text { lesser luminance (average of measures). }
\end{aligned}
$$

UL 924 specifies repeating these measures with an energized sign with no other source of illumination in the room. All contrast ratios shall be no less than 0.5 .

UL 924 also provides specifications for determining the luminance and contrast for various combinations of translucent and opaque letters and backgrounds of energized signs. For signs with translucent letters and opaque backgrounds, or the reverse, the average luminance for each letter must be equal to or greater than that for the same letter in a sign externally lit with 5 fc (or 3 fc under emergency conditions). The maximum luminance value shall be less than or equal to $300 \mathrm{fL}$ (1027.8 $\mathrm{cd} / \mathrm{m}^{2}$ ) with a maximum to minimum luminance ratio between any energized and non-energized area of the sign of not greater than 40 . For an energized fixture with both translucent letters and background, the average luminance of each letter, border, and letter/border combination should be equal to or greater than the same element when the sign is externally illuminated. Similarly the average luminance of the background for the energized sign must be equal to or greater to the sign when externally illuminated. For translucent signs, UL specifies a maximum luminance value (for any single measurement point) of less than or equal to $800 \mathrm{fL}$ $\left(2740 \mathrm{~cd} / \mathrm{m}^{2}\right)$ with a maximum to minimum luminance ratio of 40 for the letters, background, and border. UL 924 also provides specifications for measuring signs with 3 different types of borders around the individual letters of the legend. These include those with borders less than 0.10 in $(2.54 \mathrm{~mm})$; those with letters less than $0.10 \mathrm{in}$; and those with both letters and borders greater than 0.10 in. UL 924 also provides measurement procedures for the luminance of arrows with at least 5-7 measurements recommended for the body of the arrow and at least 11 for the background. Contrast shall also be equal to or greater than 0.5 . The standard also gives provisions for calculating the average contrast for various combinations of letters and borders.

To determine that the contrast of the exit sign is equal to or greater than 0.50 , the luminance of the letters and background should be measured 
for circular areas no larger than 0.38 in $(9.5 \mathrm{~mm})$ in diameter. At the same time, a distance of at least 0.06 in $(1.6 \mathrm{~mm})$ should be maintained between the edge of the measurement area and the edge of the letters and sign frame. If such a distance cannot be maintained the diameter of the measurement area should be reduced so that a distance of at least its radius can be maintained. If this is not possible, the measurement should be disregarded. Finally, UL 924 specifies that lamps used in exit signs should conform to UL 1570 for fluorescent fixtures or UL 1571 for incandescent fixtures. Tests are to be conducted with the appropriate maximum rated voltage $(120,240 \mathrm{~V})$ or as specified.

The Japanese Standard for Self-Luminous Safety Signs (JIS Z9115, 1979) provides test methods and procedures for determining the effectiveness of self-luminous signs, including provisions for determining scotopic luminance, as well as the amount of radiation emitted. Similar procedures for testing phosphorescent signs are given in JIS Z9100 (1987). The latter includes examples of exit and directional indicators, including symbols, as well.

An Australian standard (AS 2293, 1983) specifies the general use of white lettering on green backgrounds with a minimum letter height of $100 \mathrm{~mm}$ (3.9 in) and width of $12 \mathrm{~mm}$ ( $0.47 \mathrm{in})$. Provisions for a directional arrow are also given. It specifies that internally illuminated signs shall have a background luminance of not less than $8 \mathrm{~cd} / \mathrm{m}^{2}(2.3 \mathrm{fL})$, with a ratio of legend to background luminance of not less than 4:1. If the legend and background are reversed in color, so that the legend is green and the background opaque (white), the sign luminance should be between 2 and 25 $\mathrm{cd} / \mathrm{m}^{2}(0.6$ to $7.3 \mathrm{fL}$ ). Variation in the legend and background luminance should not be more than 5:1. An illuminance of not less than 50 1x (4.65 fc) is required for externally illuminated signs. The position of any external luminaire should be such as to cause no reduction in sign contrast and be screened from the direct view of people moving through the area.

Bullen (1988) reviewed the history and current status of emergency lighting requirements in the UK, and pointed out that detailed provisions are given in the British standard (BS 5266). Webber (1985) discussed provisions for emergency lighting given by the British Standards Institution (BSI), the International Commission on Illumination (CIE), and the Illuminating Engineering Society of North America (IESNA). Webber pointed out that the UK recommendation for emergency lighting of a $0.2 \mathrm{~lx}$ $(0.018 \mathrm{fc})$ minimum on the centerline is about a fiftieth of the US recommendation of $1 \mathrm{fc}(10.76 \mathrm{~lx})$. Conversely, the size (about $4 \mathrm{in}$ ) required for EXIT signs in the UK results in signs which subtend a visual angle of one half to two thirds the size recommended for the US. Further comparison of US and UK standards revealed that the UK recommendation for the luminance of internally lit signs is about 3 times that of the US. Both standards specify a luminance for self-luminous signs which is 1-2 times lower than that for conventionally lit signs. In a review of the literature on walking speeds, Webber concluded that speeds range from 0.70 to $1.3 \mathrm{~m} / \mathrm{sec}$ for normal lighting ( $0.51 \mathrm{x}$ and above) depending on the population studied. Below $0.05 \mathrm{~lx}$ walking speeds drop to 0.21 to 0.3 
$\mathrm{m} / \mathrm{sec}$. When the visibility of exit signs in smoke is considered, analysis of data for US style sign suggest that the legibility distance (ability to read the sign) is reduced from the recommended $30.5 \mathrm{~m}$ (100 ft) to about 10 $\mathrm{m}$ (32.8 ft) when the optical density of the smoke is between 0.05 and 0.01 $\mathrm{od} / \mathrm{m}$. Webber (1985, p.68) noted that consideration of work on disability glare and smoke modeling leads to the conclusion "that when luminous signs are exposed to smoke, they are more legible when the smoke is not lit by the corridor lighting than when so lit. The general validity of this conclusion and the magnitude of the effect in practice clearly needs confirmation from practical tests."

The National Building Code of Canada (1990) specifies that the minimum requirement for lighting exits, public corridors, and access corridors to exits is an average illuminance of not less than $501 \mathrm{x}$ at floor or tread level. The minimum requirement for emergency lighting is an average level of not less than $10 \mathrm{~lx}$ at the floor or tread level. These requirements apply to exits; access to exits; corridors used by the public, patients, or students; underground walkways; and public floor areas meeting specified occupancy requirements.

The code also provides specifications for exit signs stating that every EXIT sign shall be visible from the approach to the exit; display the word EXIT or SORTIE in plain and legible letters; and be illuminated continuously while the building is occupied. It specifies the use of (a) red letters or background on a contrasting background or letters with a minimum letter height of $114 \mathrm{~mm}$ (4.5 in) with a $19 \mathrm{~mm}(0.75 \mathrm{~lx})$ stroke width for internally lit signs; or (b) white letters (background) on a red background (letters) with a minimum letter height of $150 \mathrm{~mm}$ (5.9 in) and a $19 \mathrm{~mm}$ (0.75 in) stroke width for externally illuminated sign. No specifications (maximum, mean, minimum) are given for either external sign illuminance or internal sign luminance.

The Commission Internationale de I'Eclairage (CIE) (1981) published a Guide on the Emergency Lighting of Building Interiors in which it defined three categories of emergency lighting: escape, safety, and standby. Escape lighting is used to enable building occupants to leave an interior safely during an emergency. Horizontal illuminance at floor level on the center line of the escape route is set at not less than $0.21 \times(0.018 \mathrm{fc})$, although the guide indicates that a minimum of $11 \times(0.09 \mathrm{fc})$ may be preferable. A uniformity ratio of 40:1 along the center line of the egress route should not be exceeded. Safety lighting is used in situations where failure of normal lighting could place people in danger. Safety lighting should not provide less than $5 \%$ of the illuminance given by the normal building lighting. It is not intended to replace escape lighting. Standby lighting is used for non-dangerous activities which must be carried out even during failure of normal lighting. Standby lighting should not be less than $10 \%$ of the normal requirement, and should be provided within $15 \mathrm{sec}$ of power failure. This type of lighting is rarely covered by codes and regulations.

Escape lighting is required to provide three things: indicate the escape route clearly and unambiguously, illuminate obstructions in the path of 
egress and facilitate movement through the exits, and ensure that fire fighting equipment and fire alarm call points can be located. Escape routes must be clearly indicated by appropriate signs and markers. The CIE recommended use of pictographs and suggested that their size be at least 1/300 of the maximum distance from which the sign would be viewed. Contrast, either color or brightness, should be sufficient to make the sign easy to see, but not cause disability glare. The recommended minimum luminance for the pictograph is at least $15 \mathrm{~cd} / \mathrm{m}^{2}$ with a maximum of 300 $\mathrm{cd} / \mathrm{m}^{2}(87.6 \mathrm{fL})$. Recommendations for the placement of emergency luminaires along the path of egress are given. The guide also suggests marking all permanent hazards with a light color to increase their visibility under emergency conditions.

The IESNA Handbook (1987) also provides recommendations for emergency lighting and signage. Along with the CIE it also defines emergency, safety and standby lighting. The IESNA defines an exit sign as "a graphic device including words and symbols that indicates or identifies an escape route or the location of or direction to an exit or emergency exit" ( $p$. 246). These signs should be illuminated when the building is occupied to identify all possible escape routes. They should be placed no more than $30.5 \mathrm{~m}$ (100 ft) apart. Supplementary directional information should be provided as needed. Illumination can include external lamps, internal lamps or self luminous sources such as tritium. Exit signs must be illuminated during a building emergency from a power source that is independent of the main power supply. The IESNA (1987, p. 2-47) notes that "Where codes exist, an illuminance of $53.8 \mathrm{~lx}(5 \mathrm{fc})$ on the face of the sign is often specified. Illuminance is an inappropriate parameter for internally illuminated signs; however, research is currently ongoing to establish meaningful standards."

The IESNA notes that the graphic characteristics of the word "exit" are generally given as 6 in (150 mm) height; 0.75 in (19 mm) stroke width; 2 in $(50 \mathrm{~mm})$ letter width (except "I"); and 0.375 in (10 mm) character spacing. Maximum sign spacing is $100 \mathrm{ft}(30 \mathrm{~m})$ or less, with visibility being critically affected by smoke or other light scattering particles (such as dust). The handbook notes that sign visibility is also determined by contrast, color, adaptation, and lighted vs. opaque backgrounds, although it provides no specific recommendations for any of these parameters. Other factors to be considered include glare and veiling reflections from external emergency or ambient illumination. Exit signs are generally mounted with the bottom of the sign between 2 and 2.3 m ( 6.5 and $7.5 \mathrm{ft}$ ) above the floor, to allow people to pass underneath and see the sign over the heads of other people during egress. Supplemental signs may be mounted near the floor (at $200 \mathrm{~mm}$ or $8 \mathrm{in}$ ) for use during fire and smoke emergencies to reduce the problems caused by smoke layering. Signs should be uniformly lit, with a variation of not more than \pm 5 over the face of the sign. Signs within an area should be similar in color and design to aid in identification. Finally, the IESNA recommends a minimum average of $5 \mathrm{~lx}(0.5 \mathrm{fc})$ at floor level for emergency lighting with $30 \mathrm{~lx}(3 \mathrm{fc})$ for exit doors.

In Standard Drawings No 40-06-04 (1985, 1986), the U.S. Army Corps of 
Engineers provides specifications for several different types of exit signs. All specifications call for exit signs with 6 in (150 mm) letters with 0.75 in $(19 \mathrm{~mm})$ stroke width with red letters. Both panel-face and stencil-face types are specified, along with either fluorescent or incandescent sources. Arrows may be provided either through or below the letters, with a distinctive arrowhead and optional tail. Type 602 (1985) calls for an aluminum stencil-face with a red diffuser with $20 \mathrm{~W}$ incandescent lamps for normal use, and two 20W DC lamps for emergency use. Type 604 (1986), an exit sign with a self-contained battery, is specified to have red letters on a white diffuser, with two $20 \mathrm{~W}$ incandescent lamps for normal use with two additional $5 \mathrm{~W}$ DC lamps. for emergency use. Provision are also given for wiring, mounting hardware, and battery characteristics. Type 605 (1985) provides for either two 20W incandescent or two $8 \mathrm{~W}$ fluorescent lamps with an aluminum stencil-face with red letters. Downlights are to be provided as part of the sign. Finally, Type 606 provides for an edgelit exit sign with either two 20W incandescent or two $8 \mathrm{~W}$ fluorescent lamps. Again red letters are specified, with a background of clear acrylic plastic.

The preceding review of the literature has indicated general agreement on the size, configuration and spacing of letters in exit signs, but considerable disagreement on specifications for the color and luminance, of the signs as well as for the level of general illuminance in the path of egress. Relatively little research has been done to determine characteristics for optimum sign visibility in smoke.

\subsection{Experimental Approach}

The present study was an evaluation of conventional and electroluminescent (EL) exit signs from both a photometric and visibility standpoint. It was thought that the electroluminescent signs might have greater visibility because of their greater uniformity. As a result, twelve signs - eight electroluminescent and four conventional - were selected for the evaluation. The effectiveness of the signs was assessed in two different ways. First, the luminance of each individual sign was measured in detail to compare the different signs photometrically. Second, the visibility of each sign was determined for observers at a fixed distance in both clear and smokey conditions. This procedure allows the signs to be compared psychophysically. Data from both procedures are reported in sections 2 and 3 ; conclusions are drawn in section 4. 


\section{Photometric Evaluation}

\subsection{Procedure}

\subsubsection{Stimuli}

As noted above, twelve EXIT signs were selected for the evaluation. Two signs were incandescent, two were fluorescent, and eight were electroluminescent (EL). The eight EL signs were supplied by three different manufacturers - two each from each of two manufacturers, and four from the third. The incandescent and fluorescent signs were equipped with stencil and panel-faces, meaning that the letters were illuminated for the stencil-face, while the background was illuminated for the panelface. The electroluminescent signs also included examples of stencil and panel-faces. All signs met the UL 924 (1989) specifications of 6 -in (152 $\mathrm{mm}$ ) height with 0.375 in $(50.8 \mathrm{~mm})$ spacing and stroke width of 0.75 in $(19.1 \mathrm{~mm})$. One incandescent and one fluorescent sign were red; the other two were green. Three EL signs were red; three were green; one was bluegreen, and one was red on green.

\subsubsection{Approach}

In the photometric evaluation, the luminance of 23 points on each exit sign was measured approximately according to the luminance measurement test suggested in UL 924 (1989). Two different photometers were used - a laboratory photometer and a hand-held luminance meter. The luminance of each sign was measured first in a dark environment with both instruments, and then the luminance was measured in a $5 \mathrm{fc}(53.8 \mathrm{~lx})$ environment with the luminance meter. All measures were made in the NIST Illumination Color Laboratory. All signs were energized for all measures. Because four of the EL signs could be operated in both conventional and emergency mode, photometric measurements were made for both types of operation with the laboratory photometer. In addition the chromaticity of the exit signs was measured with a spectroradiometer in the smoke facility described in section 3. Chromaticity measures were made on 3-5 points per sign about $5 \mathrm{ft}(1.5 \mathrm{~m})$ from the sign in a darkened facility.

Both the photometer and the luminance meter were located about $5 \mathrm{ft}$ ( 1.5 $\mathrm{m})$ from the sign which was mounted about $5 \mathrm{ft}(1.5 \mathrm{~m})$ from the ground. Both meters were mounted on tripods to stabilize measurements. The spot size measure on the sign subtended no more than 0.38 in $(9.5 \mathrm{~mm})$ as indicated by UL 924. Luminance was measured at 20 points on the letters 8 points on the "E", 5 points on the "X", 3 points on the " $I$ " and 4 points on the " $T$ ". The luminance of the background was measured at 23 points adjacent to the letters as shown in figure 1.

When room illumination was used for the ambient illumination measures, it was supplied by an incandescent lamp located $5 \mathrm{ft}(1.5 \mathrm{~m})$ in front of the sign to provide a relatively even distribution of illuminance (minimize hot spots and glare) across the face of the sign. Illuminance on the sign was maintained at 5 fc (53.8.1x). 


\subsection{Photometric Results}

The luminance data obtained with the laboratory photometer with all signs internally illuminated under dark conditions are given first. Both the means and standard deviations of the luminance for each letter and for the immediately adjacent background are presented in table 1 . In addition, contrast between the average luminance for each letter and background was calculated according to the following formula (IESNA, 1987):

$$
\begin{aligned}
C=\left(L_{g}-L_{1}\right) / L_{g} \quad \text { where } L_{1} & =\text { lesser luminance } \\
\text { and } \mathrm{L}_{g} & =\text { greater luminance }
\end{aligned}
$$

The overall mean luminance, standard deviation, calculated contrast, and chromaticity for all letters and their background are also presented for each sign.

Inspection of table 1 reveals considerable variation in luminance between signs. The four "conventional" signs (signs 1 to 4 ) had the highest average luminances, with that for sign 4, a panel-faced fluorescent sign being substantially greater than the other three. Sign 3 was evaluated in two configurations -. $3 G$ which used a green diffusing panel for the letters, and $3 R$ which used a red diffusing panel for the letters. As might be expected, the luminance of the letters was greatest for stencilfaced signs, while the luminance of the background was greatest for panelfaced signs. Thus, signs 1 and 3 , both stencil-faced, had mean letter luminances $^{2}$ of $22.9,324.9(3 \mathrm{R})$, and $140.9 \mathrm{~cd} / \mathrm{m}^{2}$ (3G) respectively, while signs 2 and 4, both panel-faced, had mean background luminances of 297.7 and $1186.4 \mathrm{~cd} / \mathrm{m}^{2}$. (Variation in background luminance for the stencil-faced signs is most likely due to spill from the illuminated letters to the metallic surround.) The overall contrast for the panel-faced was lower (about $0.77,0.87$ ), while the variation in uniformity, as indicated by the increased standard deviation, was higher. As noted above, Sign 3 was measured with two different color filters - a red ( $3 R$ ) and a green (3G). It was tested in both configurations in the visibility experiment, as well. The luminance for the letters in the red configuration was substantially higher $\left(324.9 \mathrm{~cd} / \mathrm{m}^{2}\right)$ than for the green $\left(140.9 \mathrm{~cd} / \mathrm{m}^{2}\right)$. The chromaticity coordinates in table 1 and figure 2 reveal tnat the "red" signs were quite similar while the "green" signs varied substantially. Figure 2 presents the chromaticity of the letters in the upper plot, and that of the background in the lower plot.

As compared with the conventional signs, the luminance of the electroluminescent signs was uniformly lower, although there was considerable variability among these signs as well. The mean luminance of sign 9 was the lowest, only $0.924 \mathrm{~cd} / \mathrm{m}^{2}$ for the letters, while that for signs 6 and 8 was the greatest, about $23 \mathrm{~cd} / \mathrm{m}^{2}$. Operating signs $6,7,10$, and 12 in emergency mode increased their mean luminance substantially as compared

2 All photometric measurements in the following sections are presented in SI units. The following conversion factors can be used to translate to IPS units: $10.76 \mathrm{~lx}=1 \mathrm{fc} ; 3.426 \mathrm{~cd} / \mathrm{m}^{2}=1 \mathrm{fL}$. 
Figure 1. Measurement Locations for Photometry of Exit Signs.

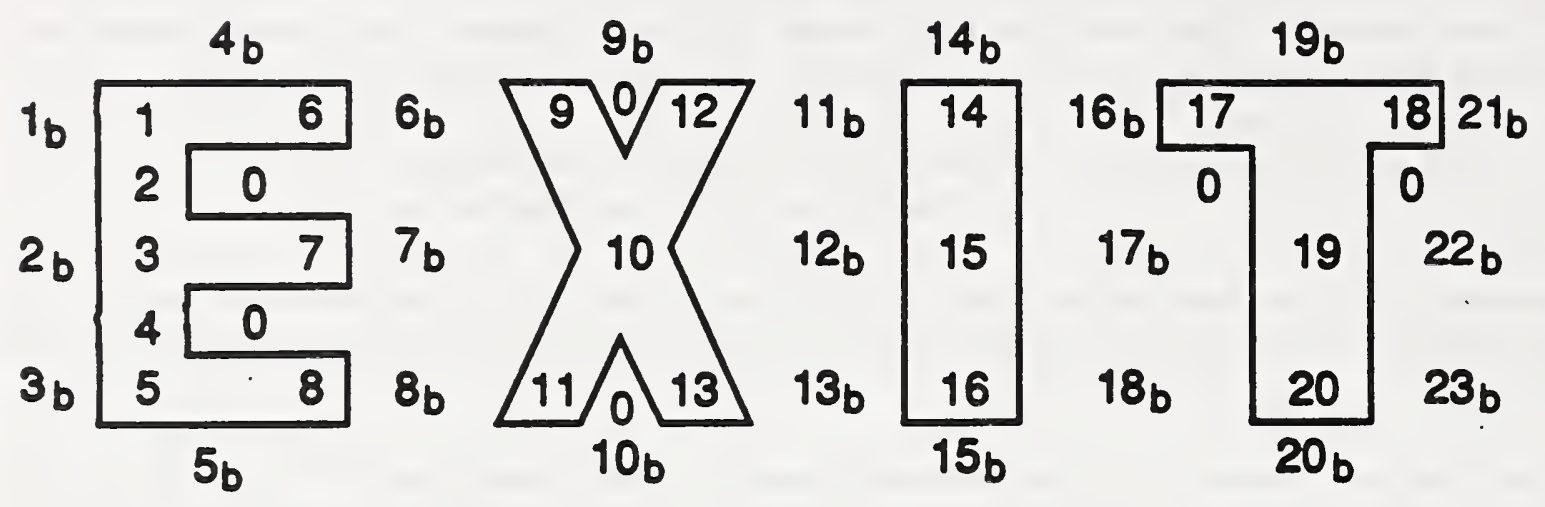

Luminance was measured at 20 points on the sign letters, and at 23 points on the background. Points $1-8$ were then averaged to determine the luminance of the "E", while background points $1-8_{b}$ were averaged to determine its luminance; points $9-13$ were averaged for the " $\mathrm{X}$ ", and points $9-13_{b}$ for its immediate background; points $14-16$ were averaged for the "I" and points $14-16_{b}$ for its immediate background; and points 17-20 were averaged for the " $\mathrm{T}$ ", while points $17-23_{\mathrm{b}}$ were averaged for its background. An averaged luminance value was then calculated for the sign as a whole. 
Table 1. Luminance and Chromaticity of Exit Signs as Measured with Laboratory Photometer and Spectroradiometer in Darkened Room.

Sign 1 (Incandescent Stencil, Green Letters)

\section{Letter Background Contrast} $\mathrm{cd} / \mathrm{m}^{2}$

E-Avg 18.7

E-Std

$X-A v g$

$X$-Std

$I-$ Avg

I-Std

T-Avg

T-Std

11.1

19.0

8.5

30.8

20.3

23.3

20.5

$0.1 \quad 0.995$

0.1

0.1

0.992

0.1

0.4

0.988

0.4

0.1

0.0

0.996

$0.1 \quad 0.994$

Avg

21.5

15.2

0.2
Sign 2 (Incandescent PaneI-Face Red Letters).

Letter Background Contrast $\mathrm{cd} / \mathrm{m}^{2}$

$\begin{array}{llll}E-A v g & 72.0 & 400.1 & 0.820\end{array}$

E-Std $\quad 46.6 \quad 742.1$

$X$-Avg $\quad 85.7 \quad 309.0$

X-Std $\quad 43.5 \quad 250.0$

I-Avg $\quad 123.3 \quad 59.4$

I-Std $\quad 77.5 \quad 49.0$

T-Avg $\quad 59.2 \quad 422.3$

T-Std $\quad 39.1 \quad 595.9$

$\begin{array}{llll}\text { Avg } & 80.6 & 342.6 & 0.765\end{array}$

Std $\quad 54.4 \quad 572.1$

Summary Chromaticity Data

Summary Chromaticity Data

$\begin{array}{llll}x & y & \end{array}$

Ltr 0.23650 .6547

Bkg 0.34390 .3121

$\begin{array}{lll}0.0914 & 0.3781 & \text { Ltr }\end{array}$

$0.22710 .3092 \quad B k g$

0.69250 .3004

$\begin{array}{llll}x & y & \end{array}$

$\begin{array}{llll}x & y & \end{array}$

0.723

0.518

0.860

0.3453

0.3593
Sign 3 (Fluorescent Stencil) Green Letters

$\begin{array}{lrrr}\text { E-Avg } & 102.5 & 0.6 & 0.994 \\ \text { E-Std } & 74.9 & 0.4 & \\ \text { X-Avg } & 146.9 & 0.9 & 0.994 \\ \text { X-Std } & 119.8 & 0.4 & \\ \text { I-Avg } & 212.4 & 1.2 & 0.994 \\ \text { I-Std } & 177.5 & 1.1 & \\ \text { T-Avg } & 156.5 & 0.7 & 0.996 \\ \text { T-Std } & 173.9 & 0.4 & \\ & & & \\ \text { Avg } & 140.9 & 0.8 & 0.995 \\ \text { Std } & 134.2 & 0.6 & \end{array}$

Sign 3 (Fluorescent Stencil) Red Letters

\begin{tabular}{cccc} 
E-Avg & 264.0 & 1.4 & 0.995 \\
E-Std & 186.1 & 1.0 & \\
X-Avg & 318.7 & 2.3 & 0.993 \\
X-Std & 214.7 & 1.9 & \\
I-Avg & 524.5 & 5.0 & 0.990 \\
I-Std & 388.3 & 4.5 & \\
T-Avg & 304.8 & 1.4 & 0.995 \\
T-Std & 287.0 & 0.9 \\
\multicolumn{4}{c}{} \\
Avg & 324.9 & 2.0 & 0.994 \\
Std & 268.4 & 2.3 \\
Summary & Chromaticity Data \\
x & y & \\
O.6745 & 0.3193 & 0.4921 & 0.3494
\end{tabular}


Table 1. Continued.

$$
\begin{gathered}
\text { Sign } 4 \text { (Fluorescent Panel, } \\
\text { Red Letters) }
\end{gathered}
$$

Letter Background Contrast

$\begin{array}{lrrr}\text { E-Avg } & 168.6 & 1405.9 & 0.880 \\ \text { E-Std } & 105.8 & 2285.3 & \\ \text { X-Avg } & 218.3 & 1332.3 & 0.836 \\ \text { X-Std } & 142.8 & 1075.5 & \\ \text { I-Avg } & 302.1 & 181.4 & 0.400 \\ \text { I-Std } & 206.8 & 254.6 & \\ \text { T-Avg } & 32.4 & 1826.2 & 0.982 \\ \text { T-Std } & 29.1 & 2602.5 & \\ & & & \\ \text { Avg } & 173.8 & 1358.1 & 0.872 \\ \text { Std } & 152.1 & 2094.3 & \end{array}$

Summary Chromaticity Data

$\begin{array}{llll}\mathrm{x} & \mathrm{y} & \mathrm{u} & \mathrm{v}\end{array}$

$\begin{array}{lllll}\text { Ltr } & 0.6558 & 0.3229 & 0.4715 & 0.3483\end{array}$

$\begin{array}{lllll}\text { Bkg } 0.4873 & 0.4207 & 0.2755 & 0.3568\end{array}$
Sign 5 (EL Thin Panel, Red Letters)

Letter Background Contrast

$\begin{array}{llll}\text { E-Avg } & 6.1 & 0.0 & 0.992 \\ \text { E-Std } & 0.2 & 0.0 & \\ \text { X-Avg } & 5.5 & 0.1 & 0.990 \\ \text { X-Std } & 0.2 & 0.0 & \\ \text { I-Avg } & 5.3 & 0.2 & 0.958 \\ \text { I-Std } & 0.2 & 0.3 & \\ \text { T-Avg } & 5.3 & 0.0 & 0.995 \\ \text { T-Std } & 0.3 & 0.0 & \end{array}$

$\begin{array}{llll}\text { Avg } & 5.7 & 0.1 & 0.988\end{array}$

$\begin{array}{lll}\text { Std } & 0.4 & 0.1\end{array}$

Summary Chromaticity Data

$\begin{array}{cccc}\mathrm{x} & \mathrm{y} & \mathrm{u} & \mathrm{v} \\ 0.6618 & 0.3348 & 0.4650 & 0.3528 \\ 0.4332 & 0.3861 & 0.2561 & 0.3423\end{array}$

0.43320 .3861

0.2561

\section{Sign 6 (EL Stencil-Face) \\ Green Letters \\ Non-Emergency Mode}

$\begin{array}{llll}\text { E-Avg } & 4.8 & 0.0 & 0.993 \\ \text { E-Std } & 0.3 & 0.0 & \\ \text { X-Avg } & 4.8 & 0.0 & 0.992 \\ \text { X-Std } & 0.2 & 0.0 & \\ \text { I-Avg } & 5.0 & 0.2 & 0.963 \\ \text { I-Std } & 0.2 & 0.2 & \\ \text { T-Avg } & 5.0 & 0.0 & 0.996 \\ \text { T-Std } & 0.1 & 0.0 & \\ & & & \\ \text { Avg } & 4.9 & 0.1 & 0.990 \\ \text { Std } & 0.2 & 0.1 & \end{array}$

Ltr

Bkg
Sign 6 (EL Stencil-Face)

Green Letters

Emergency Mode

$\begin{array}{lrll}\text { E-Avg } & 22.2 & 0.1 & 0.996 \\ \text { E-Std } & 3.0 & 0.0 & \\ \text { X-Avg } & 23.3 & 0.1 & 0.995 \\ \text { X-Std } & 2.0 & 0.0 & \\ \text { I-Avg } & 25.7 & 0.8 & 0.967 \\ \text { I-Std } & 3.0 & 1.1 & \\ \text { T-Avg } & 24.8 & 0.1 & 0.997 \\ \text { T-Std } & 2.6 & 0.0 & \end{array}$

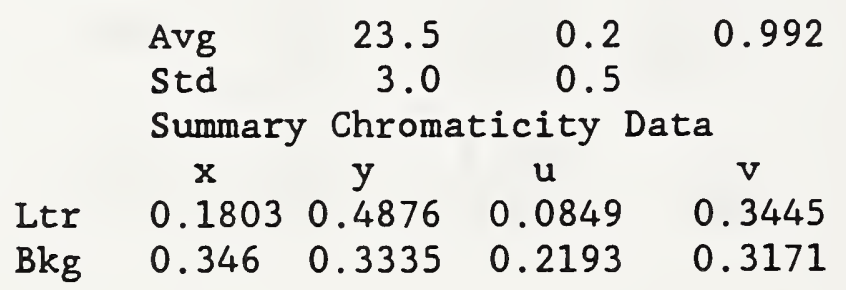

Sign 7 (EL Panel-Face, Red Letters and Green Background) Non-Emergency Mode

$\begin{array}{llll}\text { E-Avg } & 0.1 & 2.9 & 0.967 \\ \text { E-Std } & 0.0 & 2.8 & \\ \text { X-Avg } & 0.1 & 4.0 & 0.975\end{array}$

Sign 7 (EL Panel-Face, Red Letters and Green Background) Emergency Mode

$\begin{array}{llrl}\text { E-Avg } & 0.3 & 10.1 & 0.971 \\ \text { E-Std } & 0.1 & 9.8 & \\ \text { X-Avg } & 0.3 & 13.6 & 0.977\end{array}$


Table 1. Continued.

Sign 7 Continued

$\begin{array}{llll}\text { X-Std } & 0.0 & 2.7 & \\ \text { I-Avg } & 0.1 & 2.0 & 0.949 \\ \text { I-Std } & 0.0 & 2.1 & \\ \text { T-Avg } & 0.1 & 4.2 & 0.976 \\ \text { T-Std } & 0.0 & 2.9 & \\ & & & \\ \text { Avg } & 0.1 & 3.4 & 0.971 \\ \text { Std } & 0.0 & 2.9 & \end{array}$

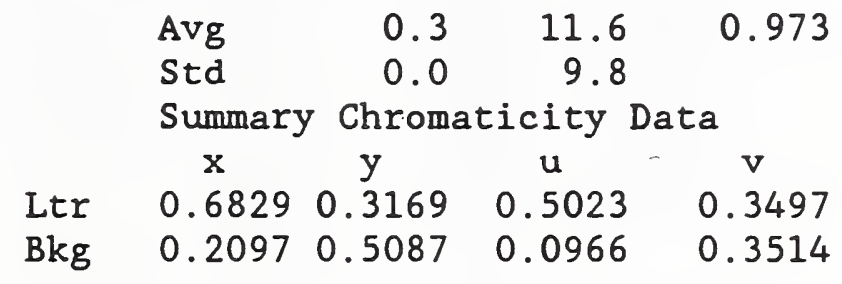

Sign 8 (EL Thin Panel Blue-Green Letters)

Sign 9 (EL Red Background Green Stenciled Letters)

$\begin{array}{lrllllll}\text { E-Avg } & 24.3 & 0.1 & 0.997 & \text { E-Avg } & 0.9 & 0.0 & 0.992 \\ \text { E-Std } & 0.5 & 0.0 & & \text { E-Std } & 0.0 & 0.0 & \\ \text { X-Avg } & 22.5 & 0.1 & 0.996 & \text { X-Avg } & 0.9 & 0.0 & 0.990 \\ \text { X-Std } & 1.0 & 0.0 & & \text { X-Std } & 0.0 & 0.0 & \\ \text { I-Avg } & 21.4 & 0.6 & 0.971 & \text { I-Avg } & 0.9 & 0.0 & 0.962 \\ \text { I-Std } & 1.7 & 0.8 & & \text { I-Std } & 0.1 & 0.0 & \\ \text { T-Avg } & 20.2 & 0.1 & 0.997 & \text { T-Avg } & 1.0 & 0.0 & 0.994 \\ \text { T-Std } & 1.2 & 0.0 & & \text { T-Std } & 0.0 & 0.0 & \end{array}$

$\begin{array}{lrrrrrrr}\text { Avg } & 22.6 & 0.1 & 0.994 & \text { Avg } & 0.9 & 0.0 & 0.988 \\ \text { Std } & 1.9 & 0.3 & & \text { Std } & 0.1 & 0.0 & \end{array}$

Summary Chromaticity Data

Summary Chromaticity Data
$x$
y u v

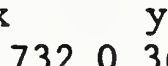

Ltr $0.17320 .3667 \quad 0.0982 \quad 0.3119$

$\begin{array}{lllll}\text { Bkg } 0.5053 & 0.4385 & 0.2787 & 0.3628\end{array}$

$\begin{array}{ccccc} & \mathrm{x} & \mathrm{y} & \mathrm{u} & \mathrm{v} \\ \text { Ltr } & 0.2185 & 0.5209 & 0.0992 & 0.3546\end{array}$

Sign 10 (El Stencil-Face, Red Letters) Non-Emergency Mode

$\begin{array}{llll}\text { E-Avg } & 0.6 & 0.0 & 0.993 \\ \text { E-Std } & 0.0 & 0.0 & \\ \text { X-Avg } & 0.6 & 0.0 & 0.992 \\ \text { X-Std } & 0.0 & 0.0 & \\ \text { I-Avg } & 0.6 & 0.0 & 0.960 \\ \text { I-Std } & 0.0 & 0.0 & \\ \text { T-Avg } & 0.6 & 0.0 & 0.994 \\ \text { T-Std } & 0.0 & 0.0 & \\ & & & \\ \text { Avg } & 0.6 & 0.0 & 0.989 \\ \text { Std } & 0.0 & 0.0 & \end{array}$

Sign 10 (E1 Stencil-Face, Red Ltrs) Emergency Mode

\begin{tabular}{|c|c|c|c|}
\hline$E$-Avg & 3.5 & 0.0 & 0.995 \\
\hline E-Std & 0.1 & 0.0 & \\
\hline$X-A v g$ & 3.5 & 0.0 & 0.993 \\
\hline$X-S t d$ & 0.3 & 0.0 & \\
\hline$I-A v g$ & 3.5 & 0.1 & 0.960 \\
\hline I-Std & 0.2 & 0.2 & \\
\hline$T$-Avg & 3.4 & 0.0 & 0.996 \\
\hline T-Std & 0.2 & 0.0 & \\
\hline Avg & 3.5 & 0.0 & 0.990 \\
\hline Std & 0.2 & 0.1 & \\
\hline \multicolumn{4}{|c|}{ Summary Chromaticity Data } \\
\hline $\begin{array}{c}x \\
0.6371\end{array}$ & $\begin{array}{c}y \\
0.3153\end{array}$ & $\begin{array}{c}u \\
0.4625\end{array}$ & $\begin{array}{c}v \\
0.3434\end{array}$ \\
\hline 0.5057 & 0.4475 & 0.2749 & 0.3649 \\
\hline
\end{tabular}


Table 1. Continued.

Sign 11 (EL Stencil-Face, Green Letters and Red Background E-Avg Letter $\frac{\text { Background }}{8.0} \frac{\text { Contrast }}{0.996}$

$\begin{array}{llll}\text { E-Std } & 0.2 & 0.0 & \\ \mathrm{X}-\text { Avg } & 8.5 & 0.0 & 0.995\end{array}$

X-Std $\quad 0.1 \quad 0.0$

$\begin{array}{llll}I-A v g & 8.4 & 0.3 & 0.965\end{array}$

I-Std $\quad 0.1 \quad 0.4$

$\begin{array}{llll}\text { T-Avg } & 8.6 & 0.0 & 0.997\end{array}$

T-Std $\quad 0.1 \quad 0.0$

$\begin{array}{llll}\text { Avg } & 8.5 & 0.1 & 0.992 \\ \text { Std } & 0.2 & 0.2 & \end{array}$

Summary Chromaticity Data

$\begin{array}{llll}x & y & u & v\end{array}$

$\begin{array}{lllll}\text { Ltr } & 0.2378 & 0.5561 & 0.1035 & 0.3627\end{array}$

$\begin{array}{lllll}\text { Bkg } 0.3953 & 0.3648 & 0.2401 & 0.3323\end{array}$

Sign 12 (EL Panel-Face Green Letters Sign 12 (EL Panel-Face Green Letters

on Green Background)

Non-Emergency Mode

$\begin{array}{llll}\text { E-Avg } & 0.2 & 3.2 & 0.933 \\ \text { E-Std } & 0.0 & 2.8 & \\ \text { X-Avg } & 0.2 & 4.2 & 0.940 \\ \text { X-Std } & 0.0 & 2.8 & \\ \text { I-Avg } & 0.2 & 2.1 & 0.901 \\ \text { I-Std } & 0.0 & 2.3 & \\ \text { T-Avg } & 0.2 & 4.4 & 0.945 \\ \text { T-Std } & 0.0 & 3.3 & \end{array}$

$\begin{array}{llll}\text { Avg } & 0.2 & 3.6 & 0.938\end{array}$

Std

$0.0 \quad 3.0$

on Green Background)

Emergency Mode

$\begin{array}{lrrr}\text { E-Avg } & 0.8 & 10.9 & 0.927 \\ \text { E-Std } & 0.2 & 10.3 & \\ \text { X-Avg } & 0.9 & 16.3 & 0.945 \\ \text { X-Std } & 0.1 & 7.8 & \\ \text { I-Avg } & 0.8 & 7.7 & 0.901 \\ \text { I-Std } & 0.0 & 9.0 & \\ \text { T-Avg } & 0.9 & 15.6 & 0.941 \\ \text { T-Std } & 0.1 & 11.6 & \end{array}$

$\begin{array}{llll}\text { Avg } & 0.8 & 13.1 & 0.936\end{array}$

$\begin{array}{lll}\text { Std } & 0.1 & 10.6\end{array}$

Summary Chromaticity Data

$\begin{array}{ccccc} & \mathrm{x} & \mathrm{y} & \mathrm{u} & \mathrm{v} \\ \text { Ltr } & 0.0991 & 0.6675 & 0.0830 & 0.3694 \\ \text { Bkg } & 0.2106 & 0.4994 & 0.0758 & 0.3496\end{array}$


Figure 2. Chromaticity of Letters and Background of All Exit Signs. Chromaticity of Exit Signs

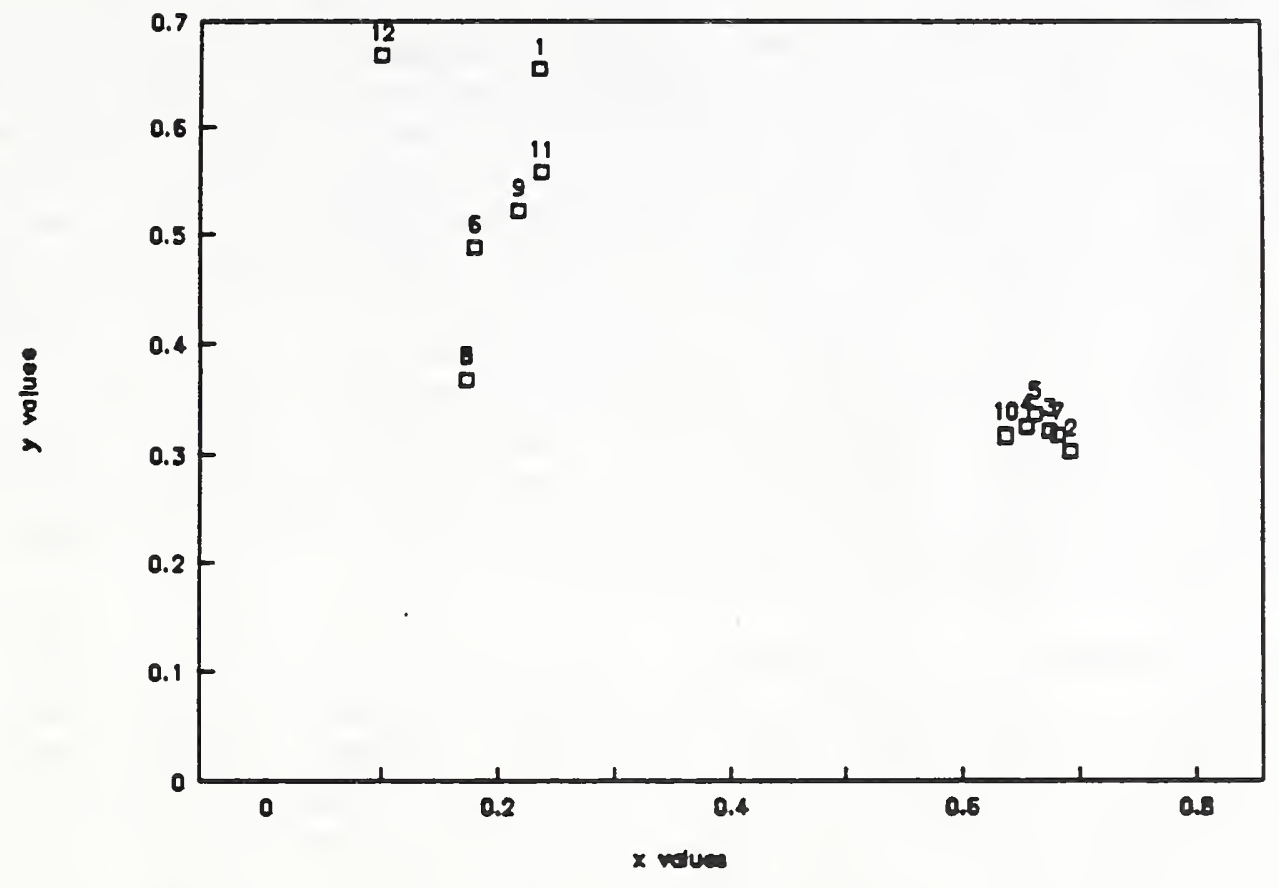

Chromaticity of Exit Signs

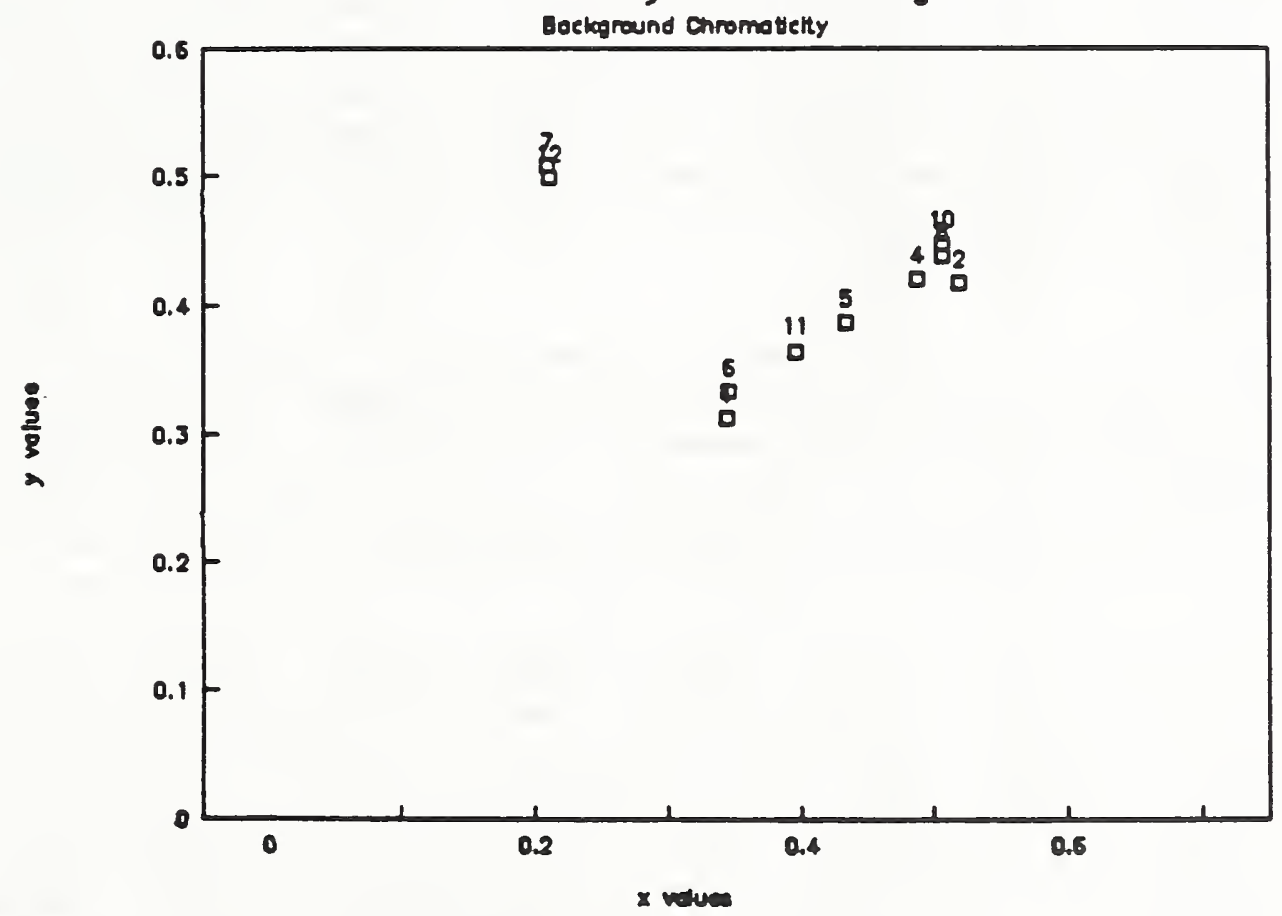

Signs 1, 3G, and 6 were nominally green on white; Signs 2, 3R, 4, 5 and 10 were nominally red on white; Sign 7 red on greenish white; Sign 8 greenish white on blue green; Sign 9 greenish white on red; Sign 11, white on red; and Sign 12 green on greenish white. 
with non-emergency mode - from 4.91 to $24 \mathrm{~cd} / \mathrm{m}^{2}$ for sign 6 ; from 3.29 to $11.03 \mathrm{~cd} / \mathrm{m}^{2}$ for sign 7 ; from 0.64 to $3.5 \mathrm{~cd} / \mathrm{m}^{2}$ for sign 10 ; and from 3.5 to $12.6 \mathrm{~cd} / \mathrm{m}^{2}$ for sign 12 . As a result, they were tested in the visibility portion of the study in emergency mode. This is, of course, the mode they would operate in during a fire or other building emergency. For stencilfaced signs, such as Signs 6 and 10, the maximum luminance is that of the letters while for panel-faced signs, such as 7 and 12 , the maximum luminances refer to the backgrounds. The four EL signs which could be operated only in one mode had generally low mean luminances. Thus, mean luminance for the letters of sign 5 was $5.5 \mathrm{~cd} / \mathrm{m}^{2}$; for $\operatorname{sign} 9$ it was 0.9 $\mathrm{cd} / \mathrm{m}^{2}$; and for sign 11 it was $8.5 \mathrm{~cd} / \mathrm{m}^{2}$. The exception was sign 8 which had a mean luminance of $22.1 \mathrm{~cd} / \mathrm{m}^{2}$. Contrasts for the EL signs were generally high (above 0.9) while the standard deviations were typically low, reflecting the greater uniformity in luminance for these signs. Values from Table 1 obtained with the laboratory quality photometer were averaged to obtain a measure of overall sign luminance. These were used for comparisons for the visibility experiment.

Table 2 presents supplementary photometric data obtained with the handheld luminance meter. (The measures were actually taken with the meter mounted on a tripod, however.) The left-hand columns present mean luminances and standard deviations obtained with the luminance meter in a dark environment, while the right-hand columns present similar data obtained with an illuminance of $5 \mathrm{fc}(53.8 \mathrm{~lx})$ on the face of the sign. The EL signs were operated in emergency mode only for these measurements, while sign 4 was not available for measurement. Examination of the photometric data for each sign in the dark environment indicates relatively good agreement between the luminance meter and the laboratory photometer. The variation is greatest, as might be expected, for the signs with the highest luminance, and is most likely due to the difficulty in measuring exactly the same spot on the sign each time. As a result, no statistical comparisons were made.

Table 2 indicates that the additional illumination provided by the external tungsten source generally increased the luminance for the area that had originally had the lowest measured luminance - typically the background for stencil-faced signs and the letters for the panel-faced signs. The result was a decrease in overall sign contrast which was quite marked for some signs. Thus the calculated contrast for sign 1 decreased from 0.98 to 0.70 , for sign 5 from 0.98 to 0.26 , for sign 7 from 0.95 to 0.53 , for sign 9 from 0.95 to 0.63 , and for sign 10 from 0.98 to 0.58 . This decrease in contrast has potentially serious implications for emergency lighting. If the lighting is improperly placed, so that it shines on the face of the exit sign, it could markedly reduce the contrast of the sign and hence its visibility. Thus, the additional illumination could become a hindrance rather than an aid to emergency egress. These data suggest the importance of locating the emergency lighting correctly with respect to the exit sign and minimizing the illuminance directly on the face of an internally lit sign. Similar concerns were discussed by Rea, et al. (1985). 
Table 2. Photometric Results for Exit Signs Obtained with Hand-held Luminance Meter in Dark and Illuminated Environments.

Dark Environment

$5 \mathrm{fc}(53.81 \mathrm{x})$ Environment

Sign 1 (Incandescent Stencil, Green Letters)

\begin{tabular}{|c|c|c|c|c|c|c|c|}
\hline & $\frac{\text { Letter }}{\mathrm{cd} / \mathrm{m}^{2}}$ & $\underline{B k g}$ & Contrast & & $\frac{\text { etter }}{\mathrm{cd} / \mathrm{m}^{2}}$ & $\underline{\mathrm{Bkg}}$ & Contrast \\
\hline$E-A v g$ & 13.6 & 0.3 & 0.981 & $E-A v g$ & 16.4 & 5.1 & 0.686 \\
\hline E-std & 7.6 & 0.1 & & E-Std & 11.0 & 2.8 & \\
\hline$X-A v g$ & 21.3 & 0.8 & 0.963 & $X-A v g$ & 21.7 & 10.8 & 0.502 \\
\hline X-std & 15.1 & 0.9 & & $\mathrm{X}-\mathrm{std}$ & 15.2 & 10.5 & \\
\hline I-Avg & 31.5 & 0.4 & 0.988 & $I-A v g$ & 29.0 & 5.8 & 0.799 \\
\hline I-Std & 21.1 & 0.2 & & I-Std & 20.5 & 3.4 & \\
\hline$T$-Avg & 25.2 & 0.3 & 0.986 & $T-A v g$ & 18.6 & 3.4 & 0.818 \\
\hline T-Std & 23.2 & 0.2 & & T-Std & 15.4 & 3.0 & \\
\hline Avg & 20.5 & 0.4 & 0.980 & Avg & 20.1 & 5.9 & 0.704 \\
\hline Std & 17.2 & 0.5 & & Std & 15.3 & 6.1 & \\
\hline
\end{tabular}

Sign 2 (Incandescent Panel-Face, Red Letters)

$\begin{array}{rrrllrrr}\text { E-Avg } & 73.0 & 344.9 & & \text { E-Avg } & 76.1 & 329.9 & 0.769 \\ \text { E-Std } & 53.4 & 647.9 & & \text { E-Std } & 51.0 & 614.2 & \\ \text { X-Avg } & 84.5 & 277.7 & 0.696 & \text { X-Avg } & 86.2 & 273.6 & 0.685 \\ \text { X-Std } & 45.4 & 216.9 & & \text { X-Std } & 48.9 & 219.0 & \\ \text { I-Avg } & 118.1 & 109.4 & 0.074 & \text { I-Avg } & 115.1 & 90.1 & 0.218 \\ \text { I-Std } & 78.3 & 44.8 & & \text { I-Std } & 70.4 & 52.0 & \\ \text { T-Avg } & 72.6 & 390.1 & 0.814 & \text { T-Avg } & 76.6 & 76.6 & 0.000 \\ \text { T-Std } & 72.6 & 517.9 & & \text { T-Std } & 58.4 & 58.4 & \\ & & & & & & & \\ \text { Avg } & 82.6 & 313.4 & 0.736 & \text { Avg } & 84.6 & 296.2 & 0.715 \\ \text { Std } & 59.0 & 495.9 & & \text { Std } & 57.0 & 452.8 & \end{array}$

Sign 3 (Fluorescent Stencil, Green Letters)

$\begin{array}{rrrllrrr}\text { E-Avg } & 83.3 & 1.5 & 0.983 & \text { E-Avg } & 98.1 & 9.5 & 0.903 \\ \text { E-Std } & 70.1 & 0.7 & & \text { E-Std } & 89.0 & 4.3 & \\ \text { X-Avg } & 119.4 & 2.2 & 0.981 & \text { X-Avg } & 120.0 & 10.9 & 0.909 \\ \text { X-Std } & 104.0 & 0.9 & & \text { X-Std } & 92.5 & 5.2 & \\ \text { I-Avg } & 202.6 & 1.8 & 0.991 & \text { I-Avg } & 222.3 & 11.4 & 0.949 \\ \text { I-Std } & 188.4 & 0.5 & & \text { I-Std } & 196.3 & 5.3 & \\ \text { T-Avg } & 123.4 & 1.9 & 0.985 & \text { T-Avg } & 118.0 & 7.3 & 0.938 \\ \text { T-Std } & 151.9 & 1.1 & & \text { T-Std } & 128.8 & 4.8 & \\ & & & & & 126.2 & 9.5 & 0.925 \\ \text { Avg } & 118.2 & 1.8 & 0.985 & & 127.0 & 4.8 & \\ \text { Std } & 127.1 & 0.9 & & & & & \end{array}$


Table 2. Continued.

Sign 4 was not measured with this meter

\begin{tabular}{|c|c|c|c|c|c|c|c|}
\hline & $\begin{array}{l}\text { Sign } \\
\text { Letter }\end{array}$ & $\begin{array}{l}\text { (EL T } \\
\text { Bkg }\end{array}$ & $\begin{array}{l}11 \mathrm{n} \text { Pane } \\
\text { Contrast }\end{array}$ & 2 & Letter & Bkg & Contrast \\
\hline$E-A v g$ & 6.7 & 0.1 & 0.982 & E-Avg & 8.4 & 6.9 & 0.185 \\
\hline E-Std & 0.3 & 0.0 & & E-Std & 0.7 & 0.7 & \\
\hline$X-A v g$ & 5.7 & 0.1 & 0.980 & $\mathrm{X}-\mathrm{Avg}$ & 8.5 & 6.6 & 0.232 \\
\hline X-Std & 0.2 & 0.0 & 0.835 & $\mathrm{X}$-Std & 1.1 & 0.9 & \\
\hline$I$ - Avg & 5.6 & 0.2 & 0.974 & $I-A v g$ & 7.8 & 6.2 & 0.205 \\
\hline I-Std & 0.3 & & & - I-Std & 0.7 & 0.9 & \\
\hline$T$ - Avg & 5.6 & 0.1 & 0.985 & $\mathrm{~T}-\mathrm{Avg}$ & 7.4 & 4.2 & 0.432 \\
\hline T-Std & 0.4 & 0.0 & & T-Std & 0.8 & 1.1 & \\
\hline Avg & 6.1 & 0.1 & 0.981 & Avg & 8.2 & 6.0 & 0.269 \\
\hline Std & 0.6 & 0.0 & & std & 1.0 & 1.5 & \\
\hline
\end{tabular}

Sign 6 (EL Stencil-Face, Green letters) Non-Emergency Mode

$\begin{array}{rlll}\text { E-Avg } & 4.4 & 0.1 & 0.985 \\ \text { E-Std } & 0.3 & 0.0 & \\ \text { X-Avg } & 4.4 & 0.1 & 0.984 \\ \text { X-Std } & 0.2 & 0.0 & \\ \text { I-Avg } & 4.6 & 0.1 & 0.979 \\ \text { I-Std } & 0.2 & 0.0 & \\ \text { T-Avg } & 4.5 & 0.1 & 0.987 \\ \text { T-Std } & 0.2 & 0.0 & \\ & & & \\ \text { Avg } & 4.4 & 0.1 & 0.985 \\ \text { Std } & 0.3 & 0.0 & \end{array}$

Sign 6 (EL Stencil-Face, Green letters) Emergency Mode

$\begin{array}{rrrlrrrr}\text { E-Avg } & 21.1 & 0.2 & & \text { E-Avg } & 12.2 & 11.5 & 0.056 \\ \text { E-Std } & 1.4 & 0.0 & & \text { E-Std } & 0.6 & 8.3 & \\ \text { X-Avg } & 19.2 & 0.3 & 0.982 & \text { X-Avg } & 12.2 & 13.0 & 0.064 \\ \text { X-Std } & 1.1 & 0.1 & & \text { X-Std } & 1.1 & 10.0 & \\ \text { I-Avg } & 19.8 & 0.4 & 0.982 & \text { I-Avg } & 12.2 & 13.6 & 0.103 \\ \text { I-Std } & 1.2 & 0.2 & & \text { I-Std } & 1.0 & 8.6 & \\ \text { T-Avg } & 19.3 & 0.2 & 0.990 & \text { T-Avg } & 11.6 & 6.9 & 0.406 \\ \text { T-Std } & 0.8 & 0.0 & & \text { T-Std } & 1.4 & 7.6 & \\ & & & & \text { Avg } & 12.1 & 10.7 & 0.116 \\ \text { Avg } & 20.0 & 0.3 & & \text { Std } & 1.0 & 8.7 & \\ \text { Std } & 1.5 & 0.1 & & & & & \end{array}$


Table 2. Continued.

Dark Environment

$5 \mathrm{fc}(53.8 \mathrm{~lx})$ Environment

Sign 7 (EL Panel-Face, Red Letters and Green Background)

Non-Emergency Mode

$\frac{\text { Letter }}{0.2} \quad \frac{\text { Bkg }}{2.8} \quad \frac{\text { Contrast }}{0.940}$

$\begin{array}{llll}\text { E-Avg } & 0.2 & 2.8 & 0.940\end{array}$

$\begin{array}{llll}\text { E-Std } & 0.0 & 2.4 & \\ \text { X-Avg } & 0.2 & 3.7 & 0.951\end{array}$

$\mathrm{X}$-Std $\quad 0.0 \quad 2.3$

$\begin{array}{llll}I \text {-Avg } & 0.2 & 2.1 & 0.906\end{array}$

I-Std $0.0 \quad 2$.

$\begin{array}{llll}T \text {-Avg } & 0.2 & 4.0 .953\end{array}$

T-Std $\quad 0.0 \quad 2.8$

$\begin{array}{llll}\text { Avg } & 0.2 & 3.2 & 0.945\end{array}$

std $0.0 \quad 2.5$

Sign 7 (EL Panel-Face, Red Letters and Green Background) Emergency Mode

$\begin{array}{rrrllrrr}\text { E-Avg } & 0.5 & 9.8 & 0.947 & \text { E-Avg } & 23.9 & 28.4 & 0.158 \\ \text { E-Std } & 0.1 & 8.3 & & \text { E-Std } & 37.7 & 16.1 & \\ \text { X-Avg } & 0.5 & 11.8 & 0.954 & \text { X-Avg } & 2.7 & 21.4 & 0.873 \\ \text { X-Std } & 0.0 & 7.4 & & \text { X-Std } & 0.3 & 6.1 & \\ \text { I-Avg } & 0.5 & 6.8 & 0.923 & \text { I-Avg } & 2.4 & 18.5 & 0.871 \\ \text { I-Std } & 0.0 & 6.6 & & \text { I-Std } & 0.3 & 7.1 & \\ \text { T-Avg } & 0.5 & 13.6 & 0.964 & \text { T-Avg } & 2.1 & 20.3 & 0.898 \\ \text { T-Std } & 0.1 & 8.0 & & \text { T-Std } & 0.6 & 8.4 & \\ & & & & & & & \\ \text { Avg } & 0.5 & 11.0 & 0.953 & \text { Avg } & 11.0 & 23.4 & 0.530 \\ \text { Std } & 0.1 & 8.1 & & \text { Std } & 26.1 & 11.5 & \end{array}$

Sign 8 (EL Thin Panel, Blue-green Letters)

$\begin{array}{rrrllrrr}\text { E-Avg } & 21.9 & 0.2 & 0.989 & \text { E-Avg } & 26.3 & 0.5 & 0.980 \\ \text { E-Std } & 0.6 & 0.1 & & \text { E-Std } & 0.7 & 0.2 & \\ \text { X-Avg } & 19.9 & 0.3 & 0.985 & \text { X-Avg } & 25.2 & 0.8 & 0.966 \\ \text { X-Std } & 0.7 & 0.1 & & \text { X-Std } & 1.5 & 0.5 & \\ \text { I-Avg } & 19.5 & 0.3 & 0.985 & \text { I-Avg } & 24.7 & 1.0 & 0.959 \\ \text { I-Std } & 0.9 & 0.1 & & \text { I-Std } & 1.5 & 0.5 & \\ \text { T-Avg } & 18.3 & 0.2 & 0.990 & \text { T-Avg } & 23.4 & 0.4 & 0.981 \\ \text { T-Std } & 0.8 & 0.0 & & \text { T-Std } & 1.4 & 0.1 & \\ & & & & & & & \\ \text { Avg } & 20.3 & 0.2 & 0.988 & \text { Avg } & 25.2 & 0.6 & 0.975 \\ \text { Std } & 1.6 & 0.1 & & \text { Std } & 1.6 & 0.4 & \end{array}$


Table 2. Continued.

Dark Environment

$5 \mathrm{fc}(53.8 \mathrm{~lx})$ Environment

Sign 9 (EL Red Background, Green Stenciled Letters)

\begin{tabular}{|c|c|c|c|c|c|c|c|}
\hline & Letter & Bkg_ & Contrast & & Letter & Bkg & Contrast \\
\hline$E-A v g$ & 0.8 & 0.0 & 0.956 & $E-A v g$ & 9.4 & 3.4 & 0.641 \\
\hline E-Std & 0.0 & 0.0 & & $E-S t d$ & 1.2 & 0.8 & \\
\hline$X-A v g$ & 0.8 & 0.0 & 0.954 & $X-A v g$ & 9.8 & 3.8 & 0.605 \\
\hline X-std & 0.0 & 0.0 & & X-Std & 2.1 & 1.4 & \\
\hline I-Avg & 0.8 & 0.0 & 0.946 & $I-A v g$ & 9.4 & 4.0 & 0.571 \\
\hline I-std & 0.0 & 0.0 & & I-Std & 1.3 & 1.1 & \\
\hline $\mathrm{T}$-Avg & 0.9 & 0.0 & & $\mathrm{~T}$-Avg & 8.7 & 3.1 & 0.646 \\
\hline T-Std & 0.0 & 0.0 & & T-Std & 0.8 & 0.7 & \\
\hline Avg & 0.8 & 0.0 & 0.954 & Avg & 9.4 & 3.5 & 0.628 \\
\hline Std & 0.0 & 0.0 & & std & 1.4 & 1.0 & \\
\hline
\end{tabular}

Sign 10 (EL Stencil-Face, Red Letters)

Non-Emergency Mode

$\begin{array}{rlll}\text { E-Avg } & 0.7 & 0.0 & 0.975 \\ \text { E-Std } & 0.0 & 0.0 & \\ \text { X-Avg } & 0.7 & 0.0 & 0.975 \\ \text { X-Std } & 0.0 & 0.0 & \\ \text { I-Avg } & 0.7 & 0.0 & 0.983 \\ \text { I-Std } & 0.0 & 0.0 & \\ \text { T-Avg } & 0.7 & 0.0 & 0.985 \\ \text { T-Std } & 0.0 & 0.0 & \\ & & & \\ \text { Avg } & 0.7 & 0.0 & 0.979 \\ \text { Std } & 0.0 & 0.0 & \end{array}$

Sign 10 (EL Stencil-Face, Red Letters) Emergency Mode

$\begin{array}{rlllllll}\text { E-Avg } & 3.8 & 0.1 & 0.985 & \text { E-Avg } & 7.0 & 15.5 & 0.547 \\ \text { E-Std } & 0.1 & 0.0 & & \text { E-Std } & 0.7 & 13.0 & \\ \text { X-Avg } & 3.9 & 0.0 & 0.986 & \text { X-Avg } & 6.8 & 17.9 & 0.621 \\ \text { X-Std } & 0.3 & 0.0 & & \text { X-Std } & 0.6 & 16.4 & \\ \text { I-Avg } & 3.8 & 0.1 & 0.979 & \text { I-Avg } & 6.3 & 25.0 & 0.747 \\ \text { I-Std } & 0.2 & 0.0 & & \text { I-Std } & 0.6 & 18.2 & \\ \text { T-Avg } & 3.7 & 0.0 & 0.988 & \text { T-Avg } & 5.6 & 11.4 & 0.505 \\ \text { T-Std } & 0.2 & 0.0 & & \text { T-Std } & 1.2 & 15.4 & \\ & & & & & & & \\ \text { Avg } & 3.8 & 0.1 & 0.985 & \text { Avg } & 6.6 & 15.8 & 0.584 \\ \text { Std } & 0.2 & 0.0 & & \text { Std } & 1.0 & 15.2 & \end{array}$


Table 2. Continued.

Dark Environment

$5 \mathrm{fc}(53.8 \mathrm{~lx})$ Environment

Sign 11 (EL Stencil-Face, Green Letters and Red Background)

\begin{tabular}{|c|c|c|c|c|c|c|c|}
\hline & Letter & Bkg & Contrast & & Letter & $\underline{B k g}$ & Contrast \\
\hline$E-A v g$ & 8.1 & $\overline{0.1}$ & 0.986 & $E-A v g$ & 17.2 & 3.5 & 0.796 \\
\hline$E-S t d$ & 0.1 & 0.0 & & E-Std & 1.4 & 0.9 & \\
\hline $\mathrm{X}-\mathrm{Avg}$ & 8.2 & 0.1 & 0.982 & $X-A v g$ & 18.8 & 3.7 & 0.805 \\
\hline $\mathrm{X}-\mathrm{Std}$ & 0.1 & 0.0 & & $\mathrm{X}-\mathrm{Std}$ & 2.9 & 0.8 & \\
\hline$I-A v g$ & 8.2 & 0.2 & 0.980 & $I-A v g$ & 16.8 & 3.4 & 0.796 \\
\hline I-Std & 0.1 & 0.0 & & I-Std & 1.2 & 1.0 & \\
\hline$T-A v g$ & 8.2 & 0.1 & 0.986 & $\mathrm{~T}-\mathrm{Avg}$ & 16.1 & 2.6 & 0.837 \\
\hline T-Std & 0.2 & 0.0 & & T-Std & 2.0 & 0.9 & \\
\hline Avg & 8.2 & 0.1 & 0.985 & Avg & 17.3 & 3.3 & 0.809 \\
\hline Std & 0.1 & 0.0 & & Std & 2.2 & 1.0 & \\
\hline
\end{tabular}

Sign 12 (EL Panel-Face, Green Letters on Green Background) Non-Emergency Mode

$\begin{array}{rlll}\text { E-Avg } & 0.2 & 3.3 & 0.926 \\ \text { E-Std } & 0.0 & 2.4 & \\ \text { X-Avg } & 0.3 & 5.9 & 0.951 \\ \text { X-Std } & 0.0 & 0.5 & \\ \text { I-Avg } & 0.2 & 2.4 & 0.894 \\ \text { I-Std } & 0.0 & 2.0 & \\ \text { T-Avg } & 0.3 & 4.4 & 0.939 \\ \text { T-Std } & 0.0 & 2.8 & \\ & & & \\ \text { Avg } & 0.3 & 4.1 & 0.936 \\ \text { Std } & 0.0 & 2.5 & \end{array}$

Sign 12 (EL Panel-Face, Green Letters on Green Background) Emergency Mode

$\begin{array}{rrrlllrl}\text { E-Avg } & 0.9 & 11.4 & 0.924 & \text { E-Avg } & 2.9 & 19.8 & 0.853 \\ \text { E-Std } & 0.2 & 8.8 & & \text { E-Std } & 3.4 & 10.2 & \\ \text { X-Avg } & 1.0 & 14.5 & 0.929 & \text { X-Avg } & 1.8 & 20.1 & 0.910 \\ \text { X-Std } & 0.1 & 7.8 & & \text { X-Std } & 0.4 & 7.4 & \\ \text { I-Avg } & 0.9 & 8.6 & 0.897 & \text { I-Avg } & 1.5 & 13.9 & 0.893 \\ \text { I-Std } & 0.1 & 8.1 & & \text { I-Std } & 0.2 & 7.8 & \\ \text { T-Avg } & 1.0 & 15.2 & 0.937 & \text { T-Avg } & 1.5 & 17.7 & 0.916 \\ \text { T-Std } & 0.1 & 9.5 & & \text { T-Std } & 0.3 & 10.4 & \\ & & & & & & & \\ \text { Avg } & 0.9 & 12.8 & 0.928 & \text { Avg } & 2.1 & 19.0 & 0.887 \\ \text { Std } & 0.2 & 9.0 & & \text { Std } & 2.3 & 9.1 & \end{array}$


An essential consideration for determining the effectiveness of exit signs is their visibility for human observers in both clear and smokey conditions. For the present paper, visibility is defined as the ability to both see and identify a sign. It is important to realize that signs which are readily detectable and identifiable under clear conditions may not be so in smoke. To assess visibility in the present study, the twelve signs measured photometrically in section 2 were installed in a laboratory facility operated by the Center for Fire Research at the National Institute of Standards and Technology. Their visibility was assessed by 21 adult observers.

\subsection{Experimental Approach}

\subsubsection{Apparatus}

The twelve exit signs.were installed in a facility ( $172.8 \mathrm{~m}^{2}$ or $1860 \mathrm{sq} \mathrm{ft}$ ) in which smoke could be readily created. They were placed in an array of three rows with four signs per row, as shown in figure 3 . The topmost row of signs was located $254 \mathrm{~mm}$ (10 in) from the ceiling; the second row was located $610 \mathrm{~mm}$ (24 in); while the third row was located $1010 \mathrm{~mm}$ (40 in) from the ceiling. The signs were arranged by luminance, with those with the highest luminance located on the top, and those with the lowest located on the bottom. This arrangement was designed to allow for the tendency of smoke to layer from the ceiling down, and meant that the signs with the highest luminance would also receive the greatest smoke density. Signs were also generally arranged to alternate in color from red to green. The array of signs was located approximately $18.9 \mathrm{~m}(62 \mathrm{ft}$ ) from the viewing point. Smoke density was monitored by an array of smoke density meters as described in 3.1.2.

During the experiment, no supplementary room illumination was provided in the smoke chamber. During smokey conditions, however, some illumination was inadvertently provided by the fire which produced the smoke. To the extent possible, the fire was baffled from the observer, although complete baffling would have seriously hampered smoke dispersal. The luminance of the signs as installed was monitored at periodic intervals during the experiment, so the contribution, if any, of the fire to sign luminance is contained in these measures.

\subsubsection{Smoke Production and Optical Density Measurement}

The smoke for the visibility tests was produced by a $100 \mathrm{~kW}$ diffusion flame propane gas burner. The burner was an open top cylinder $0.61 \mathrm{~m}$ (2 $\mathrm{ft}$ ) in diameter by $0.11 \mathrm{~m}(0.4 \mathrm{ft})$ deep. The cylinder was filled with sand, covered by a fibrous refractory material and then topped with expanded metal. The burner was located $6 \mathrm{~m}(20 \mathrm{ft})$ in front of the wall with the exit signs and $0.9 \mathrm{~m}(3 \mathrm{ft})$ to the right of the test area centerline. Shielding was installed around the burner to minimize reflection of the flame on the face of the exit signs and to shield the test subjects and instrumentation from being illuminated by the fire. 
Figure 3. Exit Sign Array for Smoke Tests.

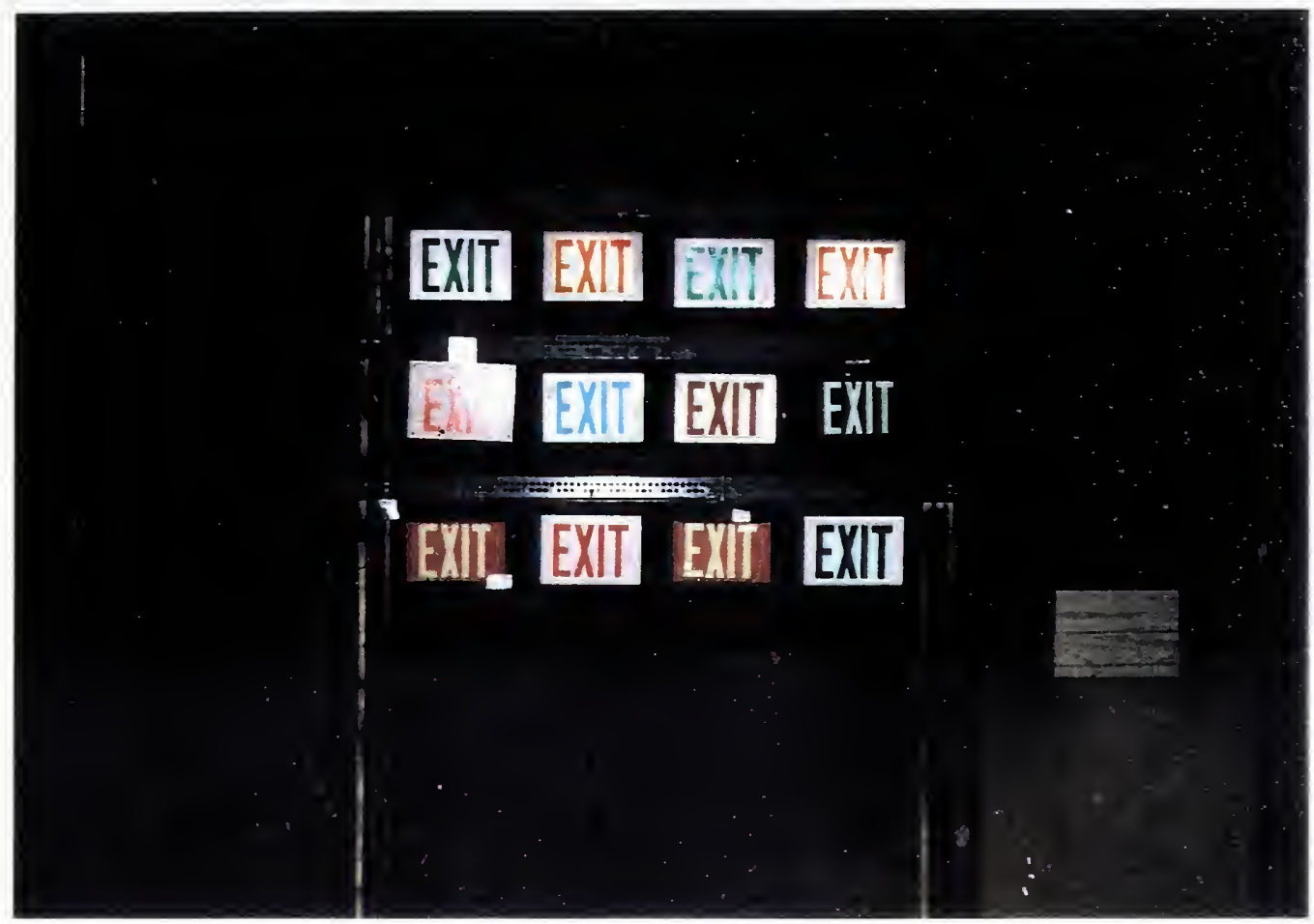


The shielding was composed of two full partitions and two half partitions. The full partitions were $2.4 \mathrm{~m}$ ( $8 \mathrm{ft}$ ) high by $1.2 \mathrm{~m}$ ( $4 \mathrm{ft}$ ) wide and were installed floor to ceiling $1.3 \mathrm{~m}(4.5 \mathrm{ft})$ from the center of the burner (see figure 4 which presents an overhead view of the facility). The half

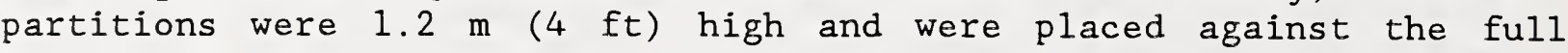
partitions. Hence there was a $1.2 \mathrm{~m}$ ( $4 \mathrm{ft}$ ) gap from the ceiling to the top of the half partition. The shielding, set up in the manner described above, did not seem to have an adverse effect on the smoke distribution in the test area.

Measurements of the optical density of the smoke were made with extinction beam photometers. Optical density is determined by monitoring the attenuation of a beam of white light passing through the smoke. A discussion of the principles of smoke measurement and the extinction beam photometer design can be found in Bukowski (1978). To summarize this measurement technique, the basic components of the extinction beam photometer are a stable light source and a photocell receiver. A fixed path length exists between the source and the receiver. The output from the receiver is used to calculate the optical density of the smoke by the following equation:

$$
\begin{aligned}
& O D=1 / d\left[\ln \left(I_{0} / I_{s}\right)\right] \\
& \text { where: } O D=\text { optical density }\left(\mathrm{m}^{-1}\right) \\
& \mathrm{d}=\text { path length (m) } \\
& I_{0}=\text { receiver output under } \\
& \text { clear conditions } \\
& I_{s}=\text { receiver output under } \\
& \text { smoke conditions }
\end{aligned}
$$

The three extinction beam photometers were positioned in the same horizontal planes as the exit signs at $0.25 \mathrm{~m}(0.83 \mathrm{ft}), 0.6 \mathrm{~m}(2 \mathrm{ft})$ and $1 \mathrm{~m}$ ( $3.3 \mathrm{ft}$ ) below the ceiling. The centerline of the meters was $5.5 \mathrm{~m}$ (18 ft) in front of the exit signs and $1.2 \mathrm{~m}(3.9 \mathrm{ft})$ to the left of the center of the test area. The meters occupied the same vertical plane. The path length of the extinction beam photometers in the present experiment was $1.2 \mathrm{~m}$ ( $4 \mathrm{ft})$.

The output from the meters was read and recorded every ten seconds by the data acquisition system. The measurements were then entered into the above equation to determine the optical density (OD) between the smoke meters and the sign. Optical density between the sign and the observer was not measured, although luminance measures were periodically made of sign 4, the sign with the highest luminance. 
Figure 4. Diagram of Experimental Test Facility.

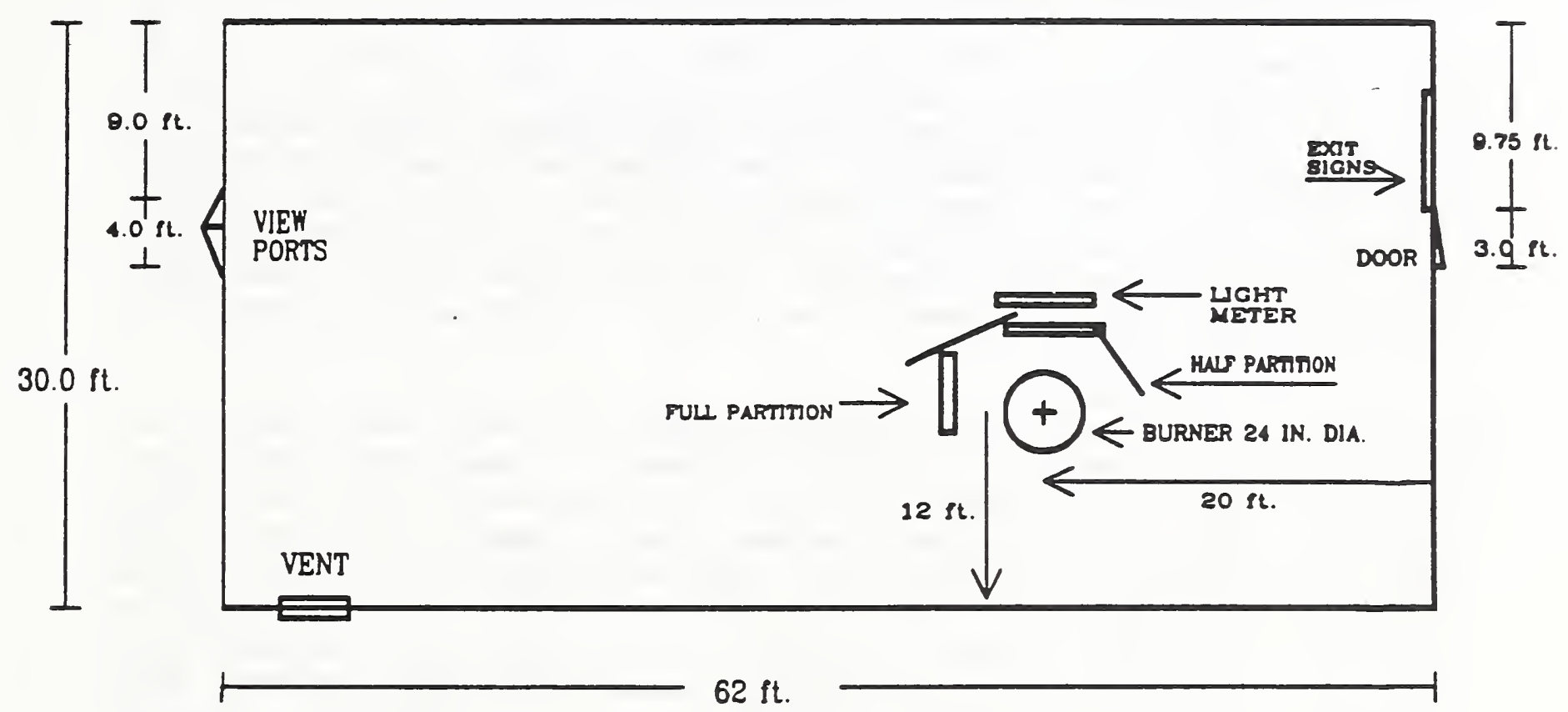




\subsubsection{Observers}

A total of 21 adult observers (NIST employees and visitors) between the ages of 18 and 60 participated in the experiment. Fourteen were males and seven were females. Five observers were between 18 and 30 years of age; six between 31 and 40; nine between 41 and 50; and one between 56 and 60 . Fourteen observers wore some type of corrective lenses - either glasses or contacts, while two reported deutan-type color deficiencies. Each observer individually viewed the signs during the experiment.

\subsubsection{Procedure}

There were three phases to the visibility experiment - clear, smoke, and smoke exhaust. The visibility of the signs was assessed first under clear conditions, then under increasing smoke conditions, and finally under decreasing smoke (exhaust) conditions. The entire experiment took about 45 minutes for each observer. Observers were advised that they could terminate the experiment at any time if they became fatigued or bothered by the smoke.

Observers were brought to the experimental facility and given the instructions and research participant agreement to read (See appendix A). Once they indicated that they understood the procedure to follow in the experiment, they were brought into the viewing chamber and seated at a chair in front of the viewing port. The viewing point consisted of a rectangular opening ( 10.5 in by 15.5 in) covered with clear plexiglas in a door into the smoke chamber. In this way observers were shielded from the smoke. Illumination in the viewing chamber where the observers were located was maintained at about 5-10 $1 \mathrm{x}(0.5-1 \mathrm{fc})$ to simulate emergency viewing conditions. (No reflections from the room lighting were visible on the plexiglas window.) Observers adapted to the ambient illumination for about $5 \mathrm{~min}$. During the experiment, one experimenter recorded the observer's responses, a second experimenter operated the photometer to obtain measures of sign luminance from the viewing port, while a third monitored the fire and optical density measuring equipment.

The experiment began with an assessment of the signs in clear conditions. Each observer rated each sign on a seven point scale of visibility where visibility was defined as "the ability to see and recognize the sign". On this scale a "l" meant "Not at all visible" and a "7" meant "Very visible". Signs were energized individually for this assessment. Once all the signs had been rated, they were all energized and observers then indicated the three best signs (in terms of visibility) and the three worst. They also gave their reasons for their selection. Although initial ratings were given for four electroluminescent signs in both emergency and non-emergency mode, they were operated in emergency mode for this comparison and for subsequent assessments in smoke.

Once all the assessments had been made under clear conditions, the second phase was initiated. In this phase a fire was ignited using a burner fueled with propane. This produced a black smoke which rapidly filled the room. As predicted, it did layer from the top down with the greatest 
obscuration for the top row, and lesser (but similar) amounts for the second and third rows. Figure 5 presents a calibration curve showing optical density as a function of total time following fire initiation. These curves depict the different smoke densities for the three rows of signs. Observers viewed the full array of illuminated signs, and indicated when each sign was no longer visible, using the criterion for visibility developed for clear conditions. Once all the signs had disappeared from view, the fire was extinguished. The time for the complete set of signs to disappear was typically 10 to 12 minutes.

In the last phase, smoke was removed from the room in four stages by an exhaust fan. Observers rated the visibility of each sign using the 7point scale discussed for phase 1: Ratings were made when the overall luminance of sign 4 reached $10 \mathrm{~cd} / \mathrm{m}^{2}, 20 \mathrm{~cd} / \mathrm{m}^{2}, 50 \mathrm{~cd} / \mathrm{m}^{2}$, and $100 \mathrm{~cd} / \mathrm{m}^{2}$. (These corresponded to mean optical densities of $0.103,0.097,0.080$, and 0.071 od m$^{-1}$ for row $1 ; 0.058,0.55,0.49,0.38$ od m-1 for row 2 ; and $0.041,0.27,0.22$, and $0.013 \mathrm{od} \mathrm{m}^{-1}$ for row 3 ). Smoke exhaust was stopped during each rating period. Sign 4 was chosen as the control because it had the highest initial illuminance, and so could be measured more accurately in smoke conditions. At the greatest smoke density, some of the other signs were not visible. The time to reach the final rating period was generally about 15 to 20 minutes after smoke exhaust was initiated. When observers gave their final ratings of sign visibility, they were again asked to select the best and worst signs. They were also asked some demographic questions and for any comments about the experiment.

\subsection{Results of the Visibility Assessment}

Table 3a presents summary data for the psychophysical portion of the experiment. The first column presents the sign number; the second presents the average rating for each sign in clear conditions. Four signs $(6,7,10$, and 12) were tested both in emergency and non-emergency mode.

Inspection of table $3 a$ indicates that the mean rating of visibility under clear conditions for each sign ranged from 2.9 for sign 9 to 6.2 for sign 4 and sign 3 in red ( $3 \mathrm{R})$. Only two signs received mean ratings below 5.0 - sign 1 and sign 9. Figure 6 compares the mean ratings versus average sign luminance as measured in the lab. Luminance for the letters was averaged with the luminance of the background to obtain the average sign luminance in clear conditions in the darkened lab. Of course, luminance of individual areas was higher. Figure 6 indicates that although sign luminance was lowest for the lowest rated sign (9), luminance and ratings of visibility in clear conditions did not appear to be directly related. Thus, the average luminance for sign $3 R$ was substantially greater than that for sign 5, yet, both signs received comparable mean ratings. Figure 6 indicates that in fact, the majority of the signs received favorable ratings (above 5 ) in clear conditions. Yet, table $3 a$ indicates that the four signs tested in non-emergency mode, with lower luminances, received mean ratings below 5, with the dimmest signs ( 7 and 10 ) receiving the lowest ratings. These data suggest that once the luminance of the sign is above some lower limit, the sign tends to be seen as reasonably visible. 
Table 3. Data From the Visibility Experiment

Table 3a. Observer Data (Means)

Clear Smoke Conditions

\begin{tabular}{|c|c|c|c|c|c|c|c|c|}
\hline \multirow{2}{*}{ Sign \# } & \multirow{2}{*}{\multicolumn{2}{|c|}{$\begin{array}{l}\text { Time to } \\
\text { Sec }\end{array}$}} & \multicolumn{4}{|c|}{ Disappear Ratings } & \multicolumn{2}{|c|}{ Overall } \\
\hline & & & Order & First & Second & Third & Fourth & Mean \\
\hline$\ldots$ & $\ldots$ & $\ldots \ldots$ & $\ldots$ & - . . . & $\ldots \ldots$ & $\ldots$ & $\ldots$ & $\ldots \ldots$ \\
\hline 1 & 4.7 & 221.1 & 2 & 2.5 & 2.8 & 3.5 & 4.2 & 3.25 \\
\hline 2 & 5.2 & 432.4 & 10 & 5.2 & 5.5 & 5.9 & 6.1 & 5.68 \\
\hline $3 G$ & 5.6 & 469.2 & 10 & 4.7 & 5.5 & 5.7 & 5.8 & 5.43 \\
\hline $3 R$ & 6.2 & 497.8 & 11 & 6.1 & 6.5 & 6.8 & 6.9 & 6.59 \\
\hline 4 & 5.6 & 570.1 & 12 & 6.1 & 6.4 & 6.6 & 6.8 & 6.49 \\
\hline 5 & 6.2 & 286.1 & 4 & 2.0 & 3.1 & 4.5 & 5.4 & 3.74 \\
\hline $6-E$ & 6.0 & 283.0 & 5 & 2.2 & 3.4 & 4.3 & 5.3 & 3.80 \\
\hline $7-E$ & 5.7 & 254.8 & 3 & 2.0 & 2.5 & 3.3 & 4.7 & 3.12 \\
\hline 8 & 6.0 & 275.8 & 5 & 2.2 & 3.1 & 4.1 & 5.2 & 3.67 \\
\hline 9 & 2.9 & 207.3 & 1 & 1.0 & 1.0 & 1.1 & 1.3 & 1.11 \\
\hline $10-E$ & 6.0 & 313.8 & 7 & 1.9 & 2.7 & 4.1 & 5.0 & 3.43 \\
\hline 11 & 5.9 & 313.4 & 7 & 2.2 & 3.1 & 4.3 & 5.3 & 3.73 \\
\hline $12-E$ & 5.3 & 334.4 & 8 & 2.8 & 3.5 & 4.5 & 5.3 & 4.02 \\
\hline 6 & 4.9 & & & & & & & \\
\hline 7 & 4.3 & & Time & 18.4 & 20.8 & 22.8 & 26.1 & 22.04 \\
\hline 10 & 4.2 & Sign 4 & Luminance & 9.2 & 19.0 & 48.5 & 96.3 & 43.24 \\
\hline 12 & 4.9 & & & & & & & \\
\hline & & & Rating & 3.3 & 4.0 & 4.7 & 5.3 & 4.29 \\
\hline & & & td Dev & 1.7 & 1.6 & 1.5 & 1.3 & 1.49 \\
\hline
\end{tabular}

Table 3b. Summary Data for Smoke Experiment

\begin{tabular}{|c|c|c|c|c|c|c|}
\hline & \multirow{2}{*}{\multicolumn{2}{|c|}{$\begin{array}{l}\text { Luminance of Sign } \\
\text { Measured in Lab } \\
\text { Clear Conditions }\end{array}$}} & & & \multicolumn{2}{|c|}{$\begin{array}{l}\text { Disappearance } \\
\text { In Smoke }\end{array}$} \\
\hline & & & & & Mean & Mean \\
\hline Sign & Letter & Bkground & Overal & & Optical & \\
\hline Number & $\frac{\text { Mean }}{\text { in cd/m }}$ & Mean & Mean & Contrast & $\frac{\text { Density }}{\text { in od } \mathrm{m}^{-1}}$ & $\frac{\text { Time }}{\text { sec }}$ \\
\hline 1 & 21.5 & 0.14 & 10.82 & 0.994 & 0.0714 & 221.1 \\
\hline 2 & 80.6 & 342.63 & 211.59 & 0.765 & 0.1189 & 432.4 \\
\hline $3 G$ & 140.9 & 0.757 & 70.83 & 0.995 & 0.0952 & 469.2 \\
\hline $3 R$ & 324.9 & 2.04 & 163.46 & 0.994 & 0.1652 & 497.8 \\
\hline 4 & 173.8 & 1358.10 & 765.95 & 0.872 & 0.1556 & 570.1 \\
\hline 5 & 5.6 & 0.07 & 2.86 & 0.988 & 0.0569 & 286.1 \\
\hline $6-E$ & 23.5 & 0.19 & 11.85 & 0.992 & 0.0595 & 283.0 \\
\hline $7-E$ & 0.3 & 11.56 & 5.94 & 0.973 & 0.0564 & 254.8 \\
\hline 8 & 22.6 & 0.14 & 11.36 & 0.994 & 0.0579 & 275.8 \\
\hline 9 & 0.9 & 0.01 & 0.47 & 0.988 & 0.0410 & 207.3 \\
\hline $10-E$ & 3.5 & 0.03 & 1.76 & 0.990 & 0.0815 & 313.8 \\
\hline 11 & 8.5 & 0.07 & 4.28 & 0.992 & 0.0506 & 313.4 \\
\hline $12-E$ & 0.8 & 13.09 & 6.96 & 0.936 & 0.0538 & 334.4 \\
\hline
\end{tabular}


Figure 5. Optical Density as a Function of Time Showing the Dispersal Between the Three Sets of Signs.

\section{CALIBRATION CURVE}

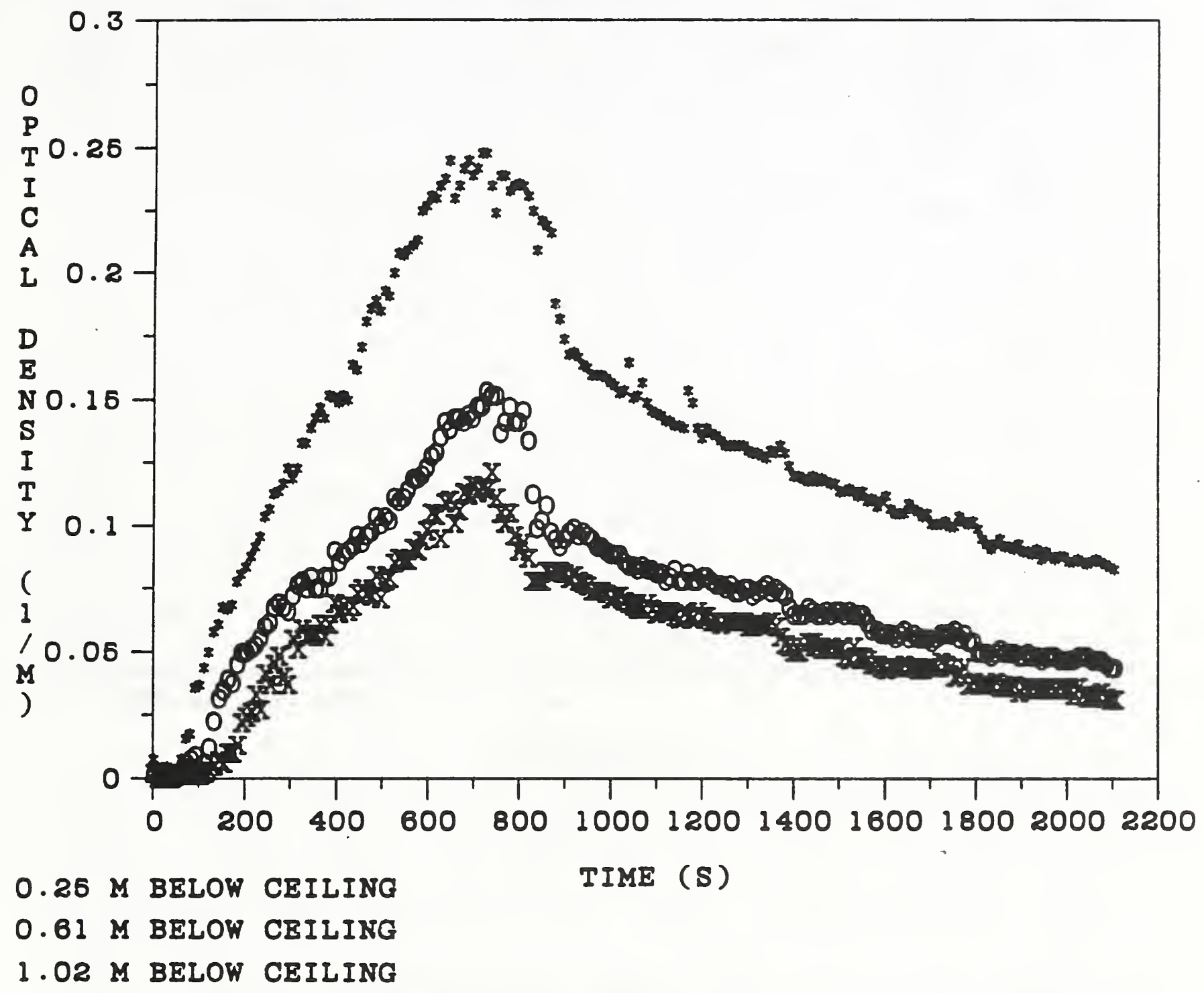


Figure 6. Comparison of Mean Sign Luminance and Visibility Ratings for Clear Conditions.

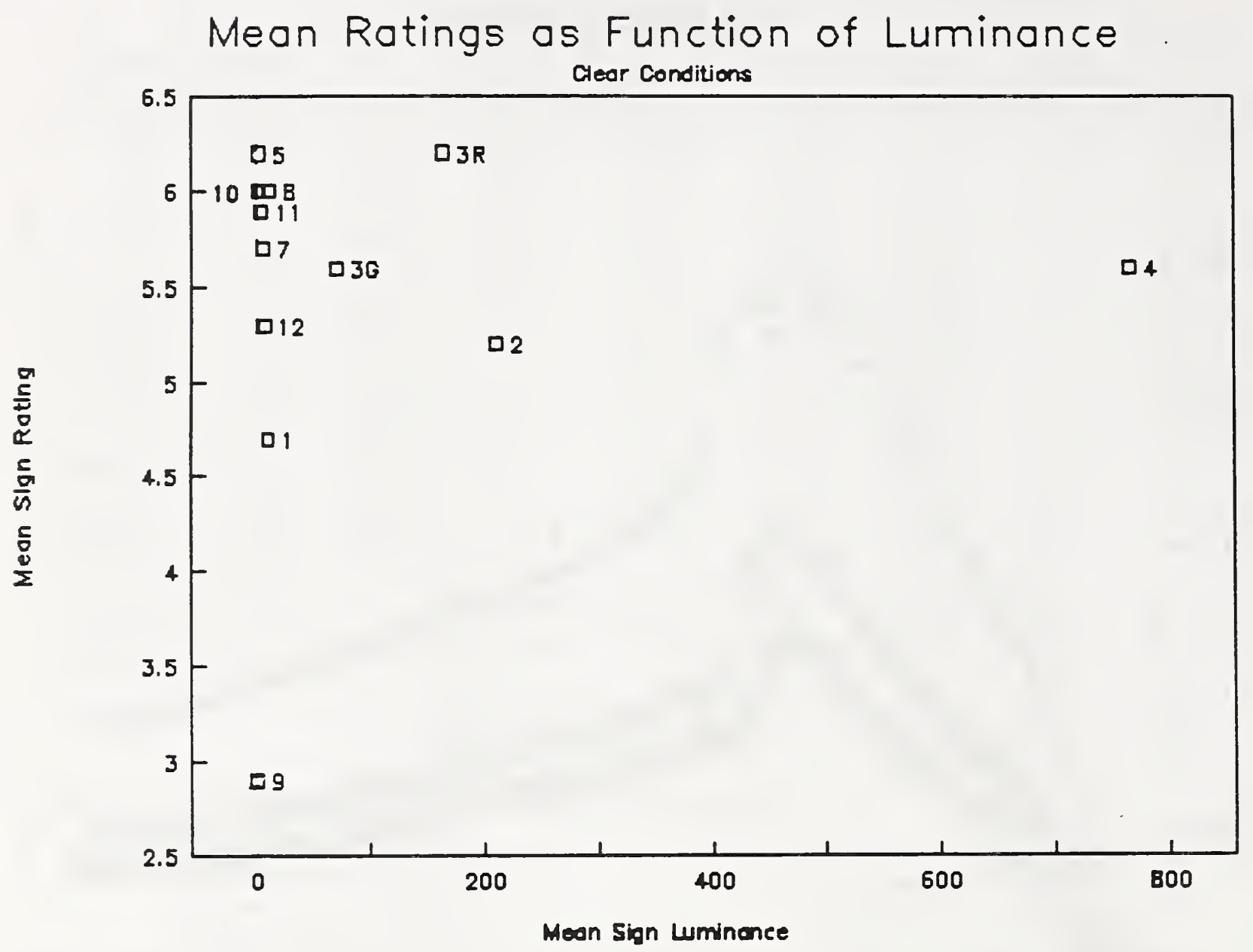

Sign numbers refer to the sign numbers used in Tables 1,2 and 3. Signs 1 and 2 were incandescent, 3 and 4 were fluorescent, while 5 through 12 were electroluminescent. Sign 3 was evaluated in both a red (3R) and green (3G) configuration. Signs 2 to 4 had the highest luminances of the signs evaluated. Electroluminescent signs (6E, 7E, 10E, and 12E) were operated in emergency mode. 
Other characteristics of the sign which may influence the visibility rating will be discussed later.

In the next portion of the experiment, the time for each sign to disappear in smoke was determined. Column three of table $3 a$ presents the average time in seconds for each sign to disappear. Inspection of this table reveals that sign 9 disappeared first, while sign 4 disappeared last. Figure 7 indicates clearly that signs with higher initial average luminances, namely $2,3 R, 3 G$, and 4, also took longer to disappear. These signs all had average luminances above $70 \mathrm{~cd} / \mathrm{m}^{2}$. As figure 8 indicates, these signs also required greater smoke density to obscure them. Table $3 \mathrm{~b}$ presents the summary photometric data obtained in the laboratory, along with the calculated contrast, mean sign luminance, mean optical density of the smoke at disappearance, and mean time to disappearance. This table indicates that signs with luminances below $20 \mathrm{~cd} / \mathrm{m}^{2}$ were no longer visible by $350 \mathrm{sec}$, and had mean optical smoke densities below $0.08 \mathrm{~m}^{-1}$, while signs with luminances above $70 \mathrm{~cd} / \mathrm{m}^{2}$ were visible between 430 and $570 \mathrm{sec}$, even with mean optical densities of 0.09 to $0.17 \mathrm{~m}^{-1}$. Of course, time to disappearance would have been substantially longer for these signs had they been located in the lower rows of the sign layout which received lower smoke densities. Figure 9 compares sign luminance measured from the viewing port during the experiment with optical density for both clear and smokey conditions. The upper graph presents data for signs 2, 3R, and 4, while the lower graph presents data for signs 1 and 5 to 12 (which had substantially lower luminance.) On each plot, sign luminance as measured from the observer's viewing port under clear conditions is presented on the ordinate $(o d / m)$. Inspection of these graphs reveals that the luminance of all signs had dropped to near zero by the time an optical density of $0.14 \mathrm{od} / \mathrm{m}$ was reached and the sign had disappeared. The graphs also provide an indication of the sign luminances seen by the observers during clear and smokey conditions.

In the final portion of the experiment, the fire was extinguished and the smoke exhausted from the room. Observers rated the visibility of the signs using the 7-point scale discussed earlier at four times during smoke exhaust. These ratings were taken when the luminance of sign 4 reached four levels: $10 \mathrm{~cd} / \mathrm{m}^{2}, 20 \mathrm{~cd} / \mathrm{m}^{2}, 50 \mathrm{~cd} / \mathrm{m}^{2}$, and $100 \mathrm{~cd} / \mathrm{m}^{2}$. Ratings from the 21 observers were averaged for each sign. Ratings between 1 and 3 indicate that the signs were "not at all visible" or "not very visible". Table 3 a reveals that signs $1,5,6,7,8,9,10,11$, and 12 were not visible (received mean ratings below 3 ) when the first set of ratings were made - about 18 minutes after fire initiation (and about 8 minutes after smoke exhaust began.) At this point, the optical densities for the smoke were greater than those measured for when those sizes disappeared. reinforcing the idea that they were not likely to be visible to the observers. The second series of ratings were taken about two minutes later, when the luminance of sign 4 reached $20 \mathrm{~cd} / \mathrm{m}^{2}$. Again, only signs 2,3 ( $R$ and $G$ ), and 4 received mean ratings above 5.5. Ratings for all other signs were lower than 3.6, although the mean rating for signs 5, 6 , 8 , and 11 had increased to between 3.1 and 3.5 . By the third series of ratings, the mean ratings for signs $5,6,8,10$, and 12 had.increased to between 4.1 and 4.5, while those for signs 2, 3, and 4 had increased to 
Figure 7. Boxplot Comparing Time to Disappear in Smoke with Initial Sign Luminance.

TIME TO DISAPPEARANCE

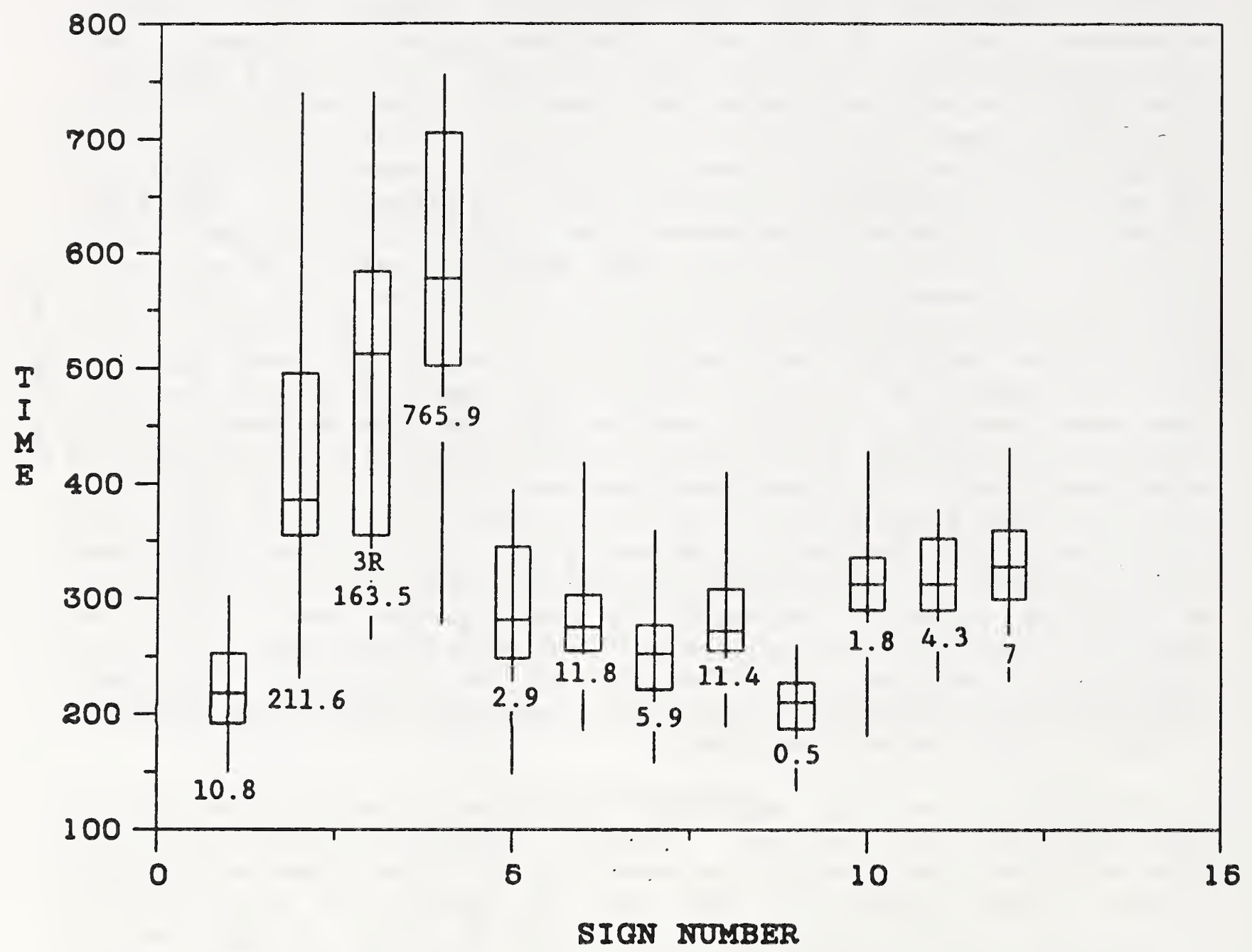

The boxplot graphs the entire data set, with the midrange of the data represented by the box, the horizontal line representing the median, and the vertical lines representing the top and bottom points of the total range. The numbers below each box refer to the mean sign luminance as measured in the laboratory. 

Figure 8. Time to Disappearance as a Function of Optical Density of
Smoke.

Time to Disoppeorance

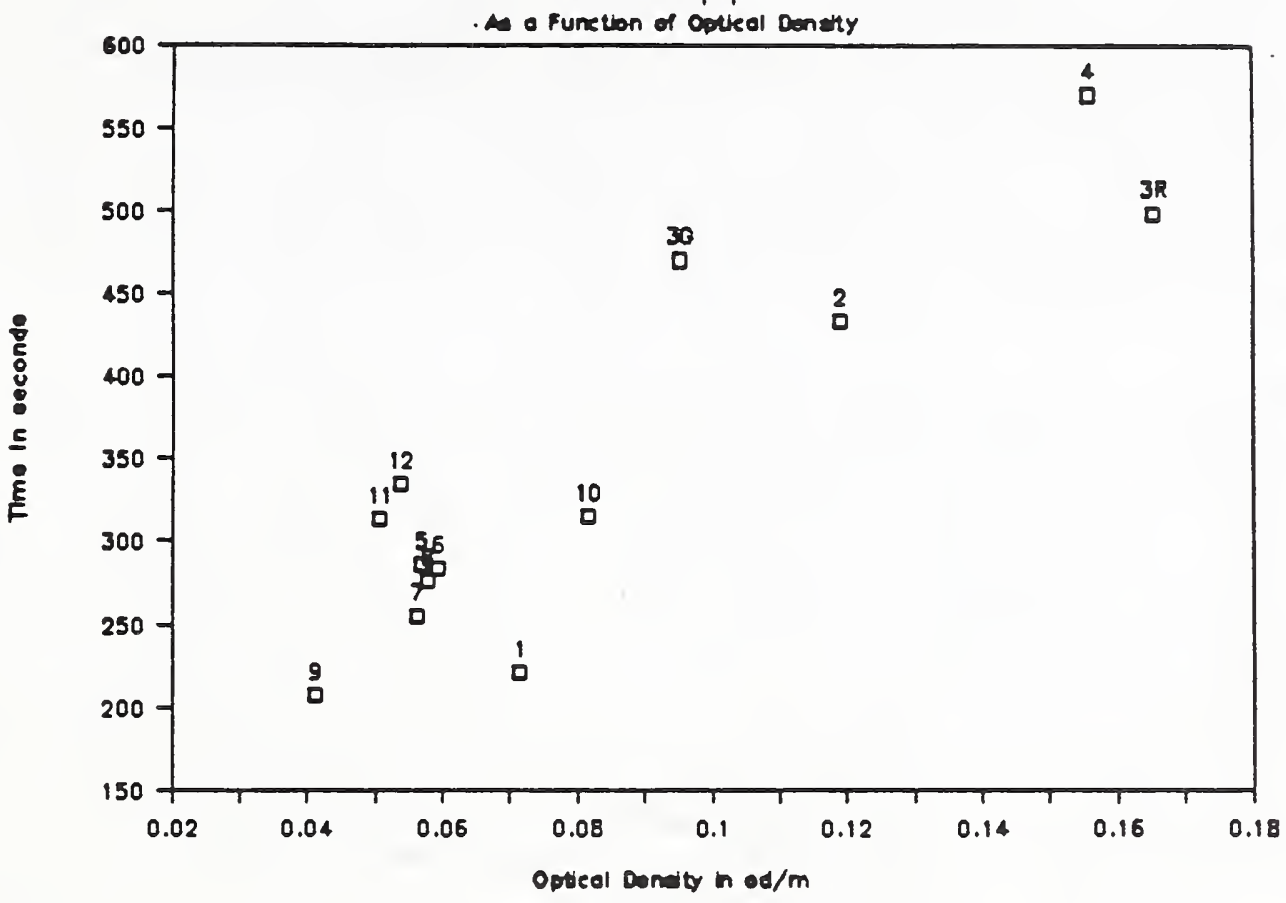

Time to Disoppeorance

a o Funetion of cotieal andity

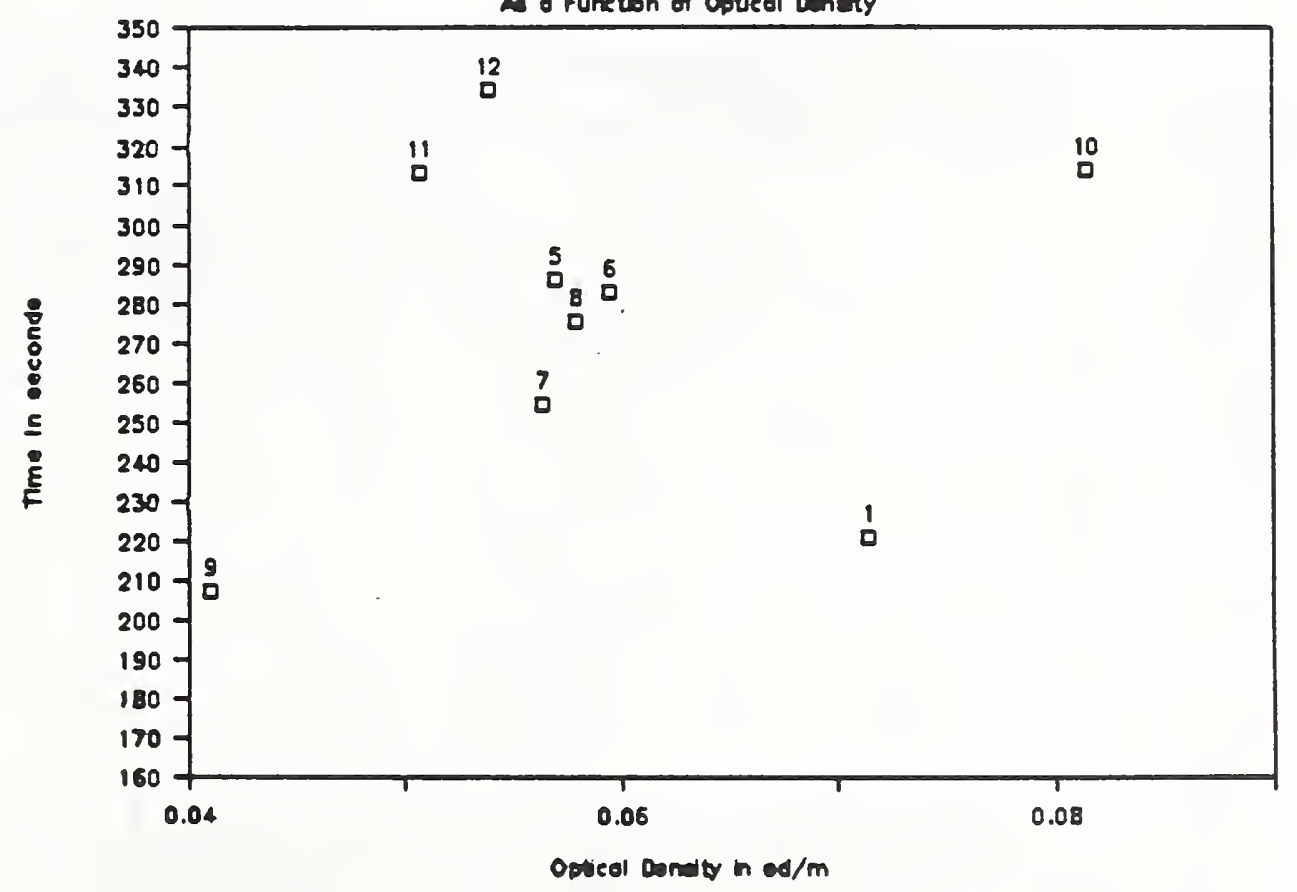

The upper plot presents all the data, while the lower plot presents only the data for the signs which disappeared before $350 \mathrm{sec}$. These latter signs had mean luminances below $12 \mathrm{~cd} / \mathrm{m}^{2}$. 
Figure 9. A Comparison of Optical Density and Luminance for all Signs as Measured During Clear and Smoke Calibration.
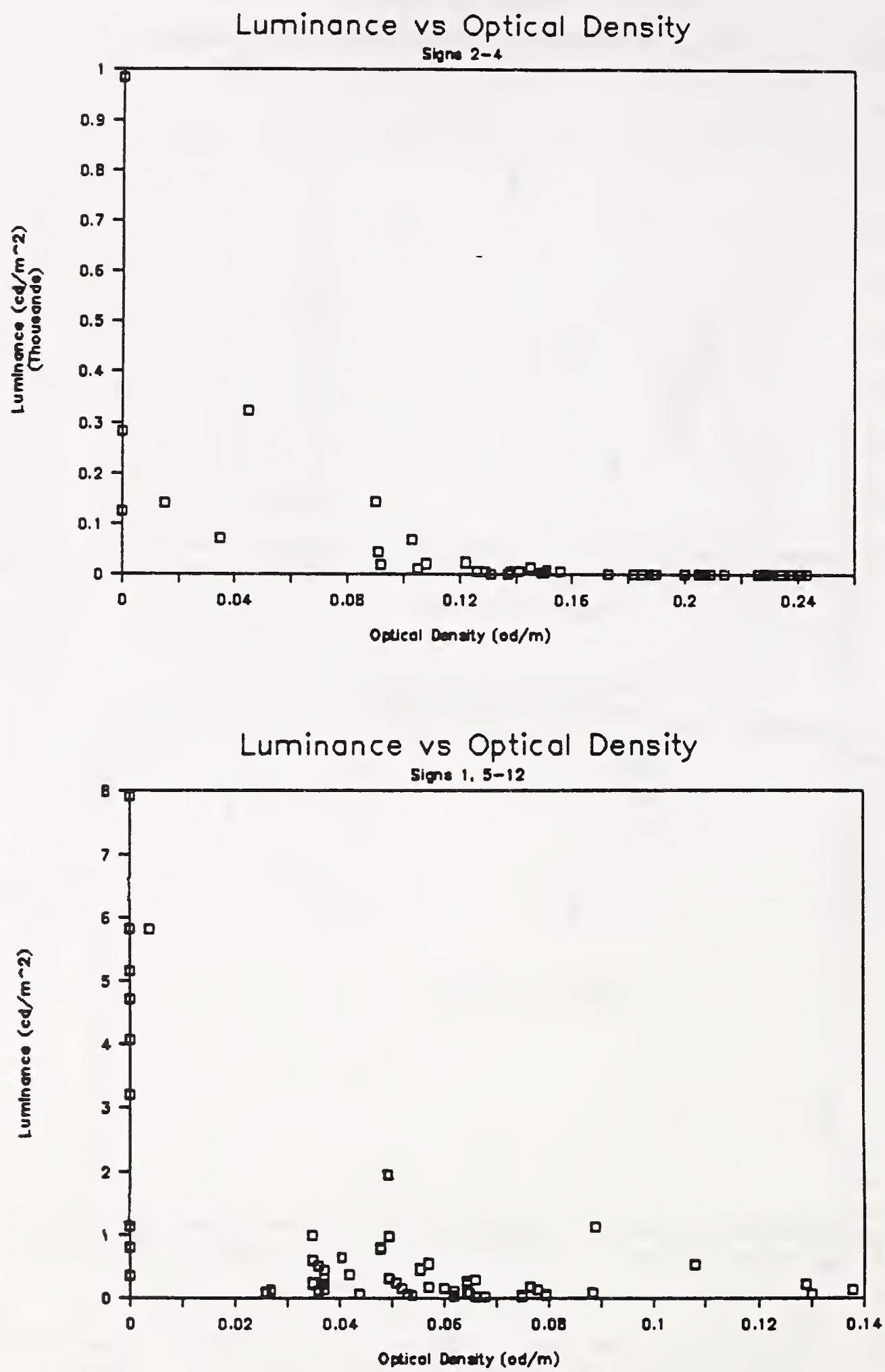
between 5.7 and 6.8 - or above their initial rating in clear conditions. By the fourth series of ratings, all signs received mean ratings above 5 , except signs 1,7 , and 9 . Signs $3 R$ and 4 , in fact, received mean ratings of 6.9 and 6.8 , respectively, indicating almost perfect visibility. Over this series of four ratings, the optical density of the smoke gradually declined. Figure 10 compares high ( 5 to 7 ) and low ( 1 to 3 ) ratings for each sign for the first (upper graph) and fourth (lower graph) rating periods in smoke. This figure makes it clear that the change in ratings from the first to last rating was greatest for the EL signs -. particularly 5, 7, 10 and 11. It also makes it very clear that sign 9 never received high ratings, while sign 4 always received high ratings.

It is also instructive to compare the mean ratings for clear conditions with those for the final smoke condition. Table $3 a$ indicates that signs $2,3 R, 3 G$, and 4 received higher ratings for the final smoke condition, Sign 12 received the same rating, while all other signs received lower ratings, some markedly lower. These data suggest that three of the conventional signs were viewed as more visible in smoke. Only sign 12, of the electroluminescent signs, was rated as having the same visibility for the two comparisons. Sign 9, the EL sign with the lowest luminance, received the lowest ratings for smoke, being rated as "not at all visible" for all four sessions. In addition, it had the shortest time to disappearance in smoke and the lowest optical density. The performance of signs 7 (EL) and 1 (conventional) was also marginal with no initial mean ratings above 3.3 , and rapid times to disappearance. By comparison, signs 10, 11, and 12, all EL signs, were somewhat slower to disappear, and received higher initial and final mean ratings.

In the experiment, sign luminance was not the only predictor of visibility performance, however. The configuration of the sign -. panel-face vs. stencil-face - also played an important role. This is demonstrated most clearly by a comparison of the performance of sign $3 R$ with sign 4. Sign $3 R$ was a stencil-faced sign with red letters on a non-luminous background, while sign 4 was a panel-faced sign with red letters on a white luminous background. The optical density required to obscure sign $3 R$ was actually higher than that for sign $4(0.1652 \mathrm{vs} 0.1556 \mathrm{od} / \mathrm{m})$. Yet the overall mean luminance of sign 4 was $765.9 \mathrm{~cd} / \mathrm{m}^{2}$ as compared with $163.5 \mathrm{~cd} / \mathrm{m}^{2}$ for sign 3R. (Sign 4 took longer to disappear, however). Sign $3 R$ received the highest mean visibility ratings throughout the experiment, with only sign 5 receiving the same high mean rating in clear conditions. Observer comments revealed that they considered $3 R$ sign to be sharper with less blur than sign 4. Several observers stated that sign 4 tended to blur and not be legible in clear conditions even though it was "brighter". In smoke, it became a bright white spot rather than the word EXIT.

Throughout the experiment, there was a slight tendency for stencil-faced signs to perform better than panel-faced signs at comparable luminances. Thus sign 10, a stencil-faced sign, required greater smoke density $(0.0815$ vs. $0.0569 \mathrm{od} \mathrm{m}^{-1}$ ) and longer time to disappear ( $313.8 \mathrm{vs} .286 .1 \mathrm{sec}$ ) than sign 5 even though its luminance was slightly lower $\left(1.76 \mathrm{vs} 2.86 \mathrm{~cd} / \mathrm{m}^{2}\right)$. Similar comparisons of greater smoke density for obscuration and longer time to disappear also apply to sign $7 \mathrm{vs}$. sign 11 (with luminances of 
Figure 10. Rated Visibility Comparing Low and High Ratings for the First and Fourth Smoke Condition.
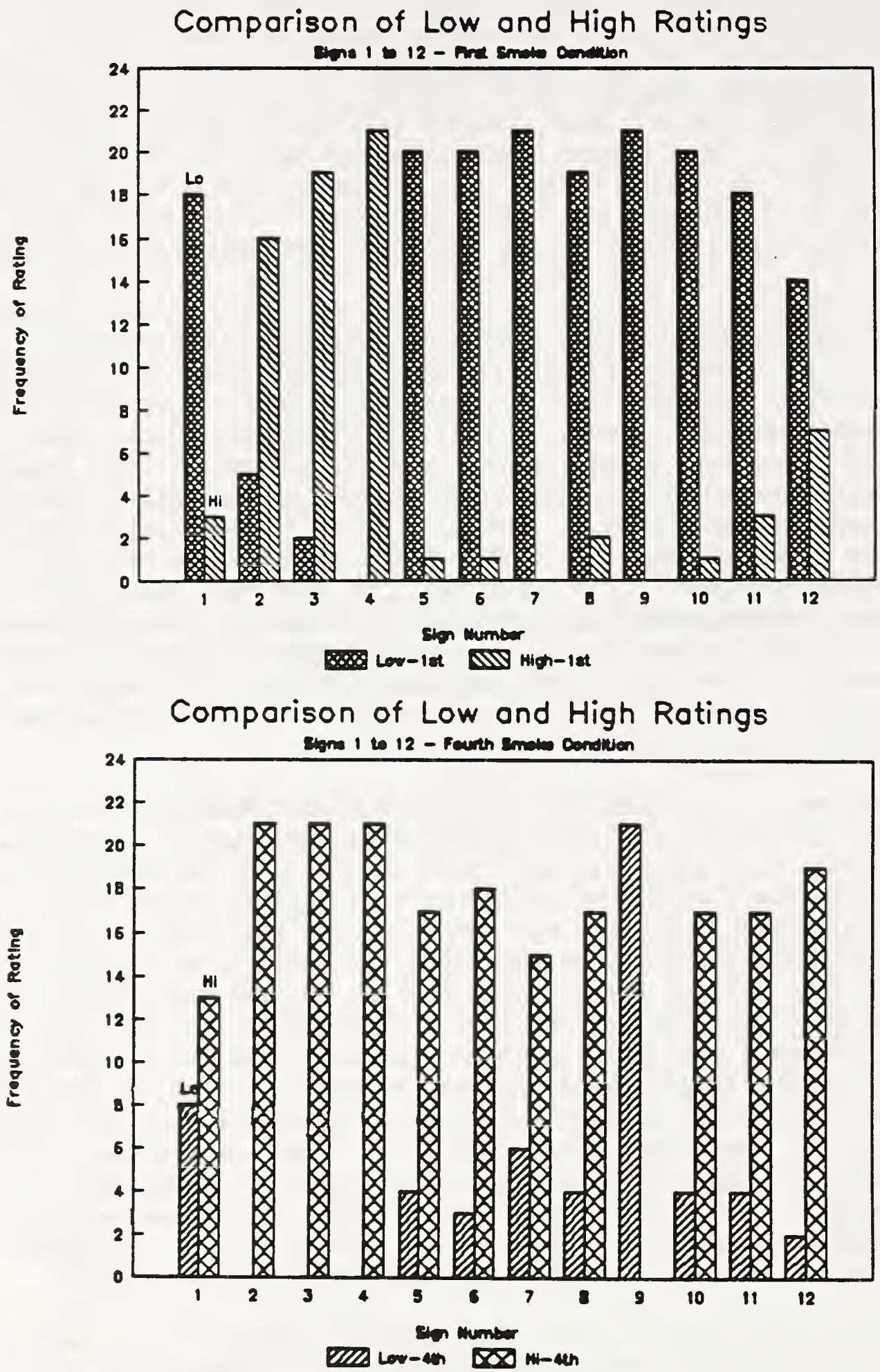

In this plot the frequency with which ratings of 1 to 3 (low) were given is compared with the frequency with which ratings of 5 to 7 (high) were given for the first (upper graph) and fourth (lower graph) smoke condition for each sign. 
5.94 vs. $4.28 \mathrm{~cd} / \mathrm{m}^{2}$, and optical densities of $0.0564 \mathrm{vs} 0.0506 \mathrm{od} \mathrm{m}^{-1}$ ). In both cases the stencil-faced sign required greater smoke density and longer time to disappear. Even for signs 1 vs. $3 G$ and 4 vs. $3 R$, the stencil-faced sign took longer to disappear ( 1 vs. 3R) and/or required greater optical density ( 4 vs. 3R). The data suggest that configurations which used illuminated letters and opaque background resulted in a "more visible" sign especially in smoke.

During the course of the visibility assessment, observers also selected the "best" sign, the "best three" signs, the "worst" sign, and the "worst three" signs for both clear and smokey conditions. Table 4 summarizes these selections. Inspection of this table indicates that sign 9 was almost unanimously selected as "worst" for both clear and smokey conditions, with all but one person selecting it as "worst". Choices for the "best" sign were less straightforward, although there was some consensus that signs 3 (both red and green), 4, and 10 were the best in clear conditions with selection by 6,7 , and 4 people, respectively. This distribution changed significantly when the selections for smoke were considered, with signs 3 ( $3 G$ and $3 R$ ) and 4 selected by all but one person. Signs that were considered among the three best in clear conditions included sign 2, 3, 4, 5, 6, 8, and 10 - a mix of EL and conventional signs. When smoke was a consideration, only signs $2,3,4,5$, and 6 were included in this category. Inspection of table 4 reveals that signs 3 and 4 were also included in the selection of the three worst for clear conditions (probably because of their high luminance). Other candidates for the three worst (in clear as well as smokey conditions) included signs 1 and 7 , as well as sign 9 .

Table 5 presents the reasons given by the observers for their selections. Data for the choices in clear conditions are considered first. Inspection of these data reveals that the reasons for selecting sign 10 included sharpness and good contrast. Reasons for selecting sign 4 included its brightness and color. Reasons for selecting sign 3 included its color, brightness and sharpness. Sign 3 was selected only after its color was changed to red, however. Once it was changed, six of the eleven people who viewed it selected it as the best. Signs 2 and 12 were each selected because they were readable, while 5 and 10 were selected for their distinctive letters. Reasons for selecting the best three signs were much less numerous but included color, sharpness (distinctiveness), and contrast. Reasons for selecting the worst sign, sign 9, were straightforward; it was considered to be too dim. Signs that were considered to be among the three worst included those that were missing portions or that were not very bright.

The reasons for selecting signs for smokey conditions appeared to be largely based on brightness and contrast considerations. Thus signs 3 and 4 were selected as best, while sign 9 continued to be selected as worst. The reasons for selecting signs as best in either smoke or clear conditions included brightness, but also clarity and contrast - or the ability to distinguish individual letters easily. Observer comments about stencil-faced signs suggested that they were sharper, with less tendency to blur. This suggests that the background luminance in panel-faced signs 
Table 4. Frequency of Selection of Specific Signs as Best and Worst in Both Clear and Smokey Conditions.

\section{Sign Numbers}

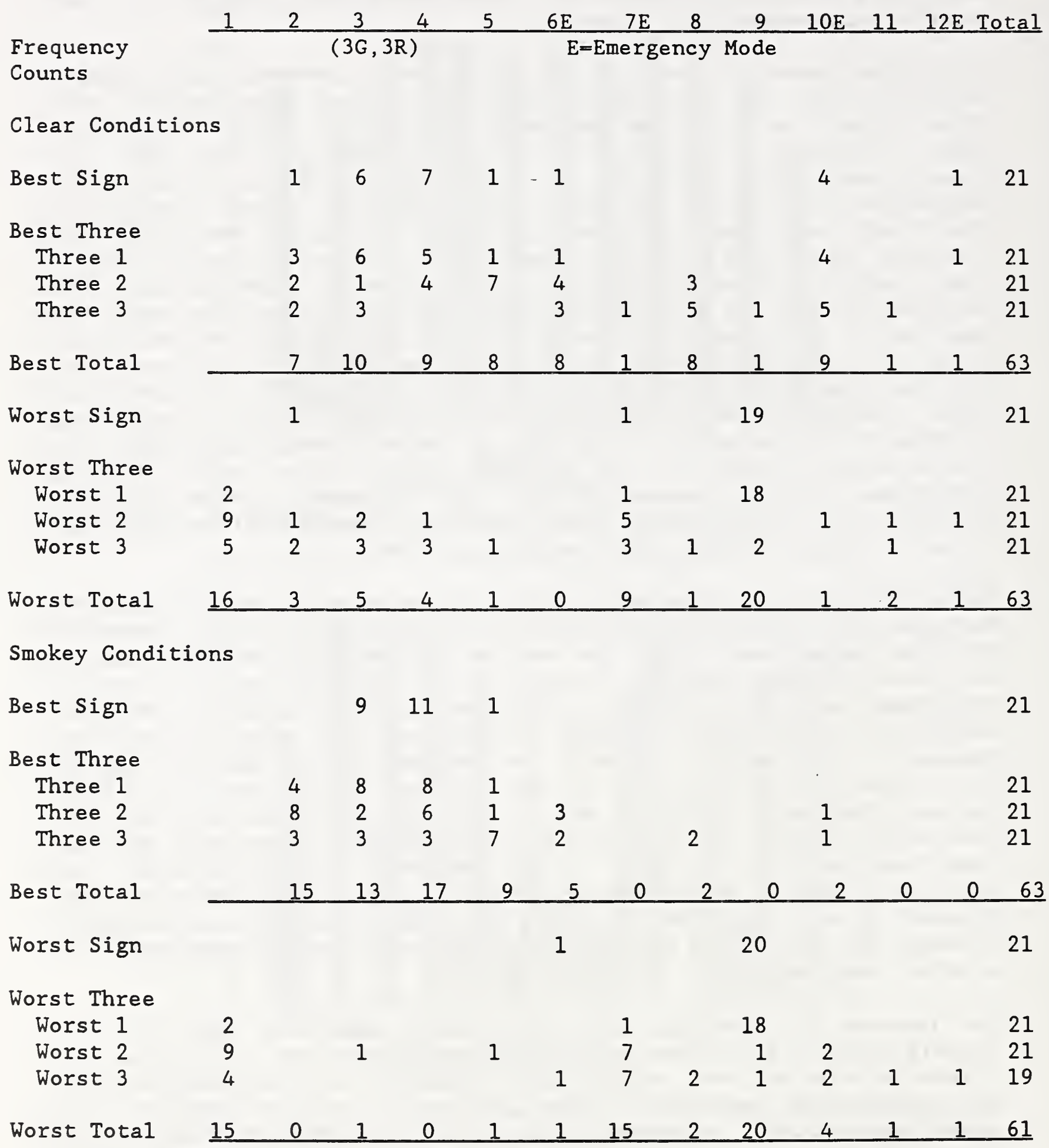


Table 5. Reasons for Selecting Signs Given By All Observers

Sign 3 was green for $1 \mathrm{~A}-9$ and Red for 10-20

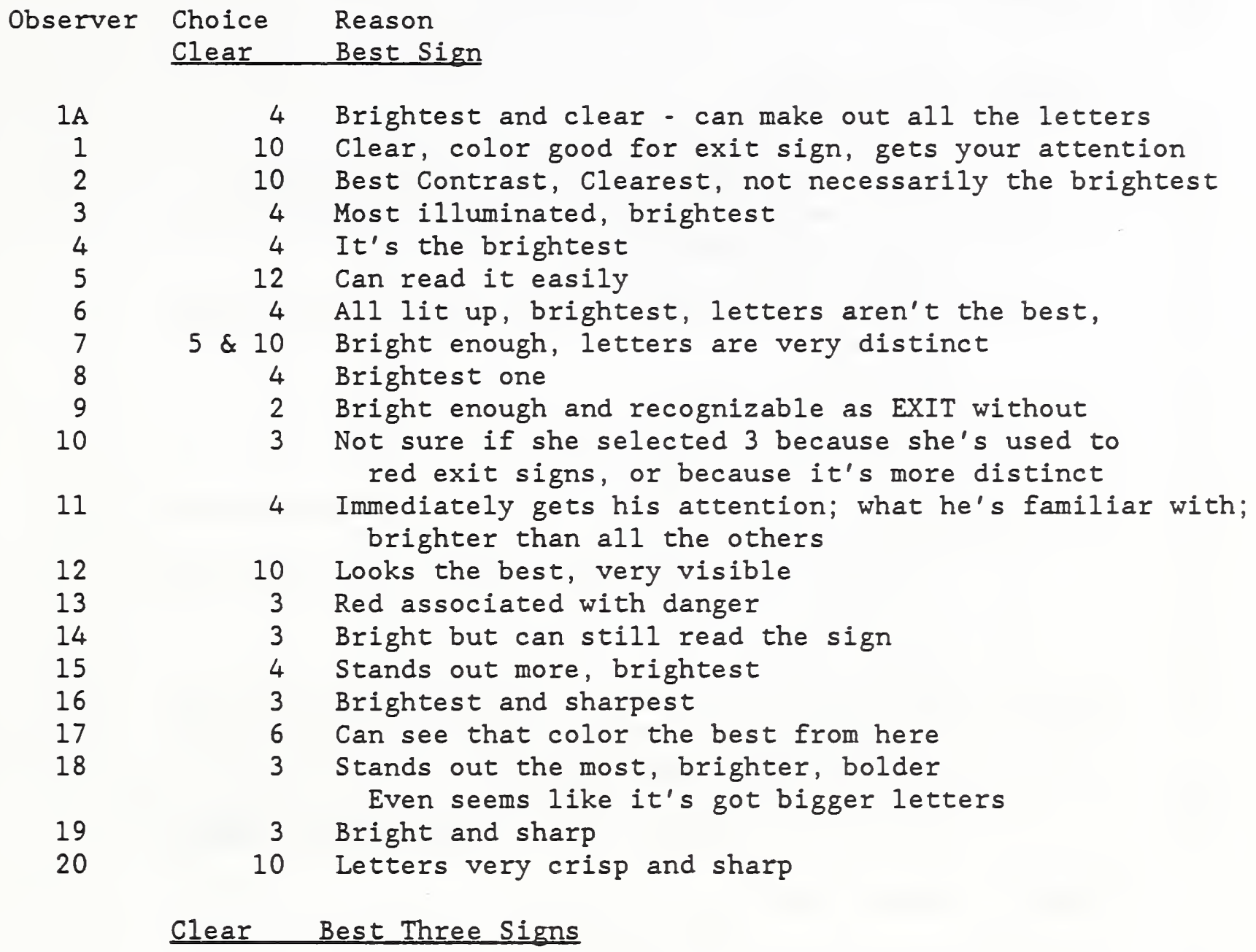

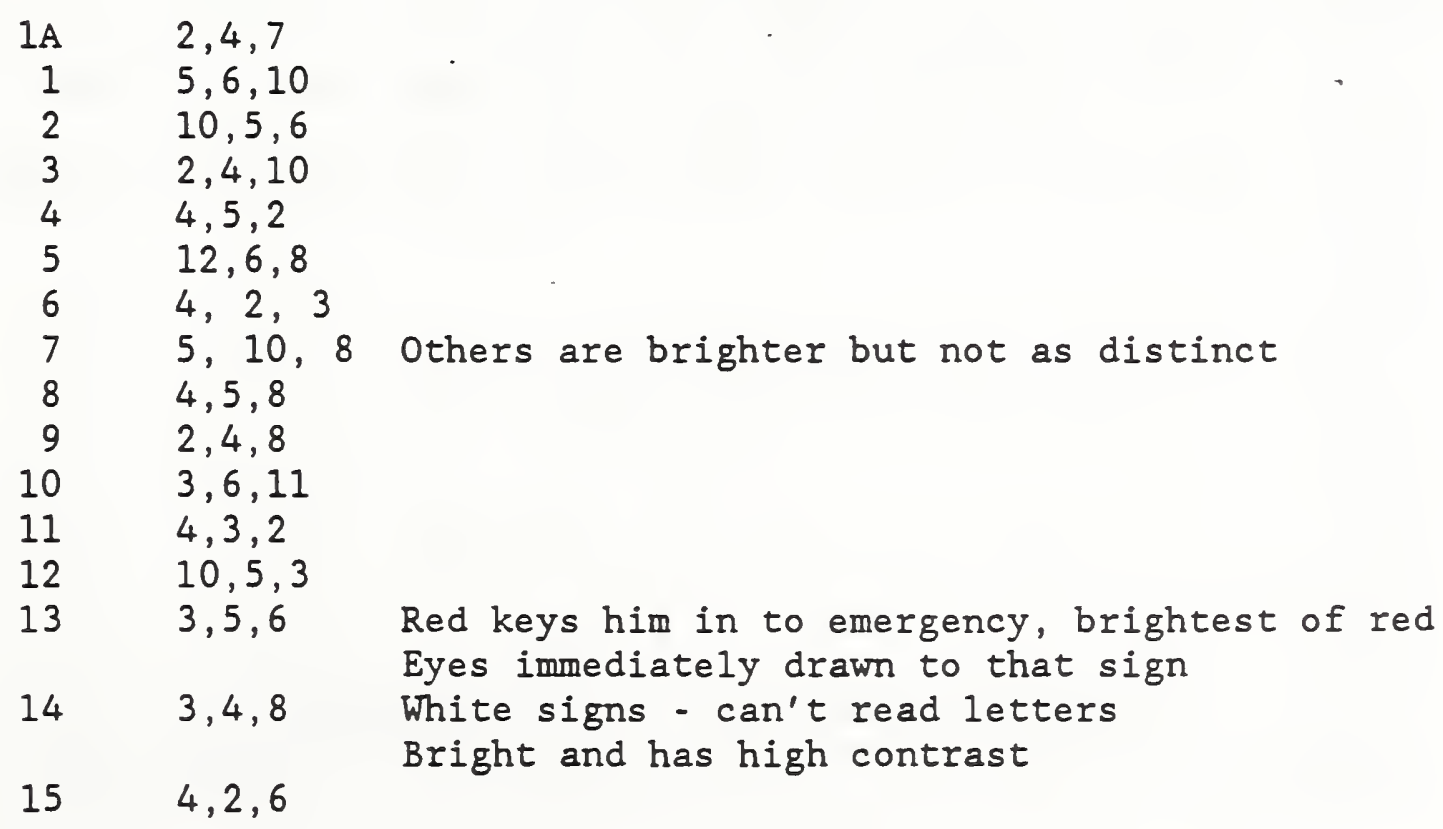




\section{Clear Worst Sign}

9 Not as defined

9 Color, very dim, can't make it out plainly

9 Very poorly lit, barely distinguishable at all

9 Very difficult to see

9 Very very dim

2,4 Awful, can't read clearly, bulbs are too bright

9 Darkest

9 Very dim

9 Dim, can't read it

9 Can barely see it, difficult to read

9 Can hardly see it

9 Dark, closest to being black there; almost washed out

9 Can't hardly see it

9 Illumination is so poor that you can't even see it

9 Very dim, low contrast

9 Can barely see it

9 Can't see it

7 Has hard green background; hard to focus on let

9 Very light, doesn't stand out, not very visible should have more light bulbs or something

9 Can't hardly see it; very dim - really washed out

9 Letters not legible - hard to distinguish what

\section{Clear Worst Three}

$9,7,1$

$1,3,9$

Others stand out more

$9,1,3$

$9,1,3$

$9,1,7$

$9,2,4$

$9,7,8$

$9,1,7$

$9,3,1$

$9,1,3$

$9,4,2$

$9,7,1$

$9,1,4$

$9,1,7$

$9,10,5$

$9,1,7$

$9,7,1 \quad 1$ bright but not clear; 7 not very bright

$7,12,9 \quad 7 \& 12$ because of green background; 9 is really dim
1 and 3 difficult to read; Green wrong color for EXIT

Top parts of sign 1 are missing, even though it's bright 
Table 5. Continued.

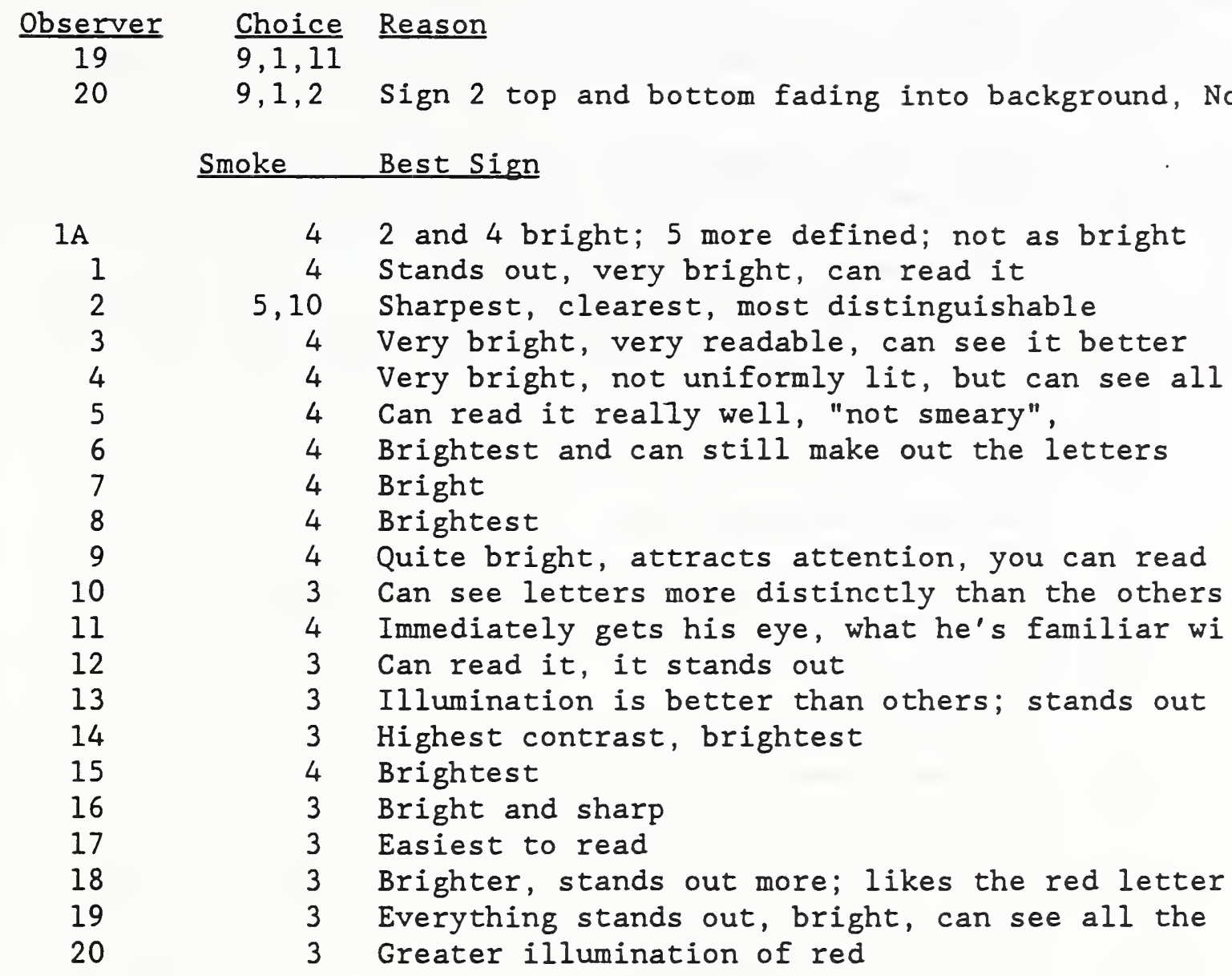

Smoke Best Three

$\begin{array}{rrl}\text { IA } & 2,4,5 & \\ 1 & 2,4,5 & \text { Stood out the whole time } \\ 2 & 5,10,6 & \text { Two and four brightest but letters are not well } \\ 3 & 4,2 & (5 \& 6 \text { equal) } \\ 4 & 4,2 & (5 \& 12) \\ 5 & 4,2,3 & \text { Red and white are really clear } \\ 6 & 4,2,3 & \\ 7 & 4,2 & (5 \& 10) \\ 8 & 4,2,3 & \\ 9 & 4,2,6 & \\ 10 & 3,6,8 & \text { Stands out; brighter } \\ 11 & 4,3,2 & \text { Very bright traditional exit sign } \\ 12 & 3,5,10 & \\ 13 & 3,4,5 & \\ 14 & 3,4 & \text { (2 \& } 6) \\ 15 & 2,3,4 & \\ 16 & 2,4,2 & \\ 17 & 3,6,8 & \\ 18 & 3,2,4 & \\ 19 & 3,4,5 & 4 \text { is bright, but it washes out the letters } \\ 20 & 3,6,4 & \end{array}$


Table 5. Continued.

Observer Choice Reason

Smoke Worst Sign

IA

1

9 Black, can't even see it

9 Can't see it

9 Can't see it

9 Cannot see it, just barely glowing

9 Can't see it; not visible at all

9 Can just barely see it, almost like a purple blob

9 Can hardly tell it's there

9 Can't see it

9 Can't see it

9 Can't see it

9 Can barely see the light

9 Can't see it

9 Can't make out any of the letters; hardly any 1

9 Can't see it, can tell it's there, but can't re

9 Can't see it

9 Can't see it

9 Wouldn't know it was there if hadn't seen it be

9 Can hardly see it

9 Can hardly see it

9 Totally blocked out

Smoke Worst Three

1 A $6,7,10,12$ Can't see anything (not even light)

$11,9,11$

$21,3,9$

$39,7,1$

$4 \quad 9,1,7$

$5 \quad 9,7,8$

$6 \quad 9,1,8$

Tops are blocked, letters are not distinguishable

$9,1,7$

$10 \quad 9,5,10$

119,10

$129,7,1$

$139,1,7$

$14 \quad 9,7,10$

$159,1,7$

$16 \quad 9,7,1$

$17 \quad 9,1,7$

$18 \quad 9,7,1$

$19 \quad 9,1,7$

$20 \quad 9,1,7$

The rest all seemed in the middle

$1,6,7,10,11$ al1 equal

\section{(rest tied or better) Can't read exit at all}

Not even a decent blur 
may have tended to mask the lettering by producing a veiling luminance. Only one reason was given for selecting the worst sign (sign 9) for either condition; namely, that it was the dimmest. Lack of clarity and sharpness entered into the selection of the three worst signs, however.

Additional information about sign effectiveness was obtained from the observers in the form of spontaneous comments about the signs at the end of the experiment. These comments are summarized in table 6 . Inspection of these reveals some indication among the observers that red is the appropriate color for exit signs. Of course, red is the color of choice in the local community, as well as at the NIST site where the experiment was performed. Several observers claimed that they have never "seen" a green exit sign. This feeling may be one reason why sign 3 was preferred only after it had been switched from green to red. (In addition, however, its luminance increased from 70 to $160 \mathrm{~cd} / \mathrm{m}^{2}$ which may have also accounted for the increase in performance and observer preference.) Although two observers had deutan-type color defects, meaning that the green signs may have been less effective for them, they viewed sign 3 in its red configuration. Thus the differences observed between the green and red versions of this sign were not due to difficulties with the green version for the deutan observers.

Observers also commented on sign clarity and uniformity, noting that signs 1,2 , and 4 were not uniformly lit. Still others commented that sign 4 was "too" bright and tended to blur out in clear conditions, but be more visible in smoke. These comments indicate that some observers found the lack of uniformity for the conventional signs, particularly the panel. faced ones to be disturbing. By comparison the uniformity of the EL signs appealed to some observers, although others were troubled by their generally lower brightness, especially in smoke conditions. 
Table 6. Comments by Observers in Smoke Experiment

Sign 3 was green for observers 1 A-9 but red for 10-20

\section{Observer $\underline{\text { Comments }}$}

1 Sign 4 was 12 times better than the other ones

Red is the color for exit signs

2 Green seems to be the wrong color for an exit sign

Would rather see a sloppy red one than a green one

Two and four brightest but letters are not well defined

Tops of 1 and 3 are blocked, letters are not distinguishable

3 Based visibility assessment on how bright the sign was

4 \#5 - letters very clear but not as bright

\#6 - clear and as bright as \#5, but green color not as "bright"

\#8 is clear but can't really tell because it's under \#4

\#l is fairly bright, but can't really make out the tops of the letters

\#2 is not as bright but can see letters

Some of them not illuminated over all the letters

\#5 was pretty good, but if it had been under \#4, he's not sure that he would have rated it that way.

54 has too much white

5 black behind is good w/red

7 red is better

In the smoke, really the red and white are easier to see

Maybe green on white wouldn't be bad

Subject doesn't recall seeing many green exit signs in real situations

6 Brightness and clearness are two important factors

Signs 2 and 4 are not as distinct but brightness overall makes them the best

7 Wonders if letters would be more readable if the bulbs were horizontal behind the "vertical" letters

If light (in clear conditions) is too bright it's hard to read but when smoked up - want it as bright as possible

Dark letters on green backgrounds are not great

Red letters on dark backgrounds are easier than green on dark background

Most familiar with red letters on white background

\#4 so white it's hard to see 'exit'

\#1 lettering unclear 
Table 6. Continued.

\section{Observer Comments}

8 Illumination is not consistent (on some signs)

Makes the signs difficult to read (clarity of the letters)

"Bright spots"

Some tended to "wash out" on the top and the bottom Makes it difficult to read the letters

9 For \#1 and \#3 the back lighting is not very uniform even under good conditions can't really see the top of the "T". Can tell it's an exit sign because the most common sign you see that starts with an ' $E$ ' is an exit sign.

\#7 and \#12, black letters on a lighted green background aren't very good

\#2 and \#4, red letters on white lighted background seem to be the best

\#9 isn't very 'good even under clear conditions

lA No Comments

Switched to red for Sign 3 for Subjects 10-20

10 \#3 expected to be the best in the smoke, because it's best

in clear conditions, but \#4 turned out to be the best in the smoke Maybe because of the white light behind the red letters (also maybe because \#4 is the "traditional" exit sign

Red predominates over green;easier to see red than green

She likes red better than green

\#6, 7, 8 look almost blue

11 Most important thing for him is what he's used to as an exit sign i.e. \#2 and \#4, the red letters on white background

12 No Comments

13 \#7 and \#12, dark letters on 1ight, letters blur with the border (frame)

doesn't have that problem with 2 and 4 because of brighter light \#7 and \#12 like a picture frame where the frame overpowers the picture

Blue especially but also green blurs more readily than red letters Brightness of the red

\#5 is better than 10 because of contrast difference subject noticed \#5 is brighter

14 White backgrounds (such as 2 and 4 ) are noticeable as being signs but the light keeps you from being able to read them

(too bright, poor contrast)

Red sign on black (\#3) has a better contrast, both bright, and letters are clear 
Table 6. Continued.

\section{Observer Comments}

15 \#3 would be great if the $x$ were totally lit up

\#2 would be better if more evenly lit

Most are kind of dull, should be brighter

Light doesn't seem to be even

16 \#1 bright but not clear; 7 not very bright

\#2 not uniformly bright;

\#12 is sharp but dim

Trouble with some is that they're falling off the edge

\#3 \& 4 fading at the top

Brightness and sharpness important

Don't like uneven illumination

Can't make out letters clearly

Surprised at how clear \#3, \#5, \#10 (red signs) are

17 Black background where there's not a lot of smoke -

makes the letters easier to read

White background was more visible in the smoke

although the letters still weren't very clear

Red and green letters are more visible

18 Red lettering and doesn't have whiteness that makes it hard to read '\#3 is good

Red letters seem to stand out more than the green/blue letters

19 He's not sure he would walk towards a bright light only

Sees the red ones the best - 3, 5, 10

Noticed flicker from fire

If in a smokey room he'd look for red light whether he could

read it or not; white lights. might just be a light bulb

He's been in so many fires that he's sure he would head toward red

light.

Might see white light, but he's not sure he'd head for a white light

(It might just be a light bulb or a light over a door) under smokey condition

Switched \#3 from red to green panel

Top 3 choices became 5, 10, 12

The switch makes \#4 look a lot clearer

Couldn't tell that \#2 was red on white when \#3 was red

but could tell when \#3 was switched to green

20 Illuminated letters far superior to non-illuminated letters 
Results from the present experiment indicate the importance of sign luminance in determining the visibility of exit signs in smoke. Signs with mean luminances above $70 \mathrm{~cd} / \mathrm{m}^{2}$ required substantially greater optical density for disappearance. Time to disappearance was also longer (by a factor of two -. and this with greater optical density). The optical density required to obscure these signs was between 0.07 and $0.16 \mathrm{od} \mathrm{m}^{-1}$, in line with the densities observed by Rea, et al. (1985). Rea, et al. and Jin and Yamada (1985) also determined that signs with higher luminances were more visible in smoke.

Conversely the poor performance of the signs with low luminance, particularly sign 9 , is of concern. This sign had the lowest mean luminance $\left(0.47 \mathrm{~cd} / \mathrm{m}^{2}\right)$ with an average letter luminance of $0.92 \mathrm{~cd} / \mathrm{m}^{2}$ and background luminance of $0.01 \mathrm{~cd} / \mathrm{m}^{2}$. Smoke at a mean optical density of $0.04 \mathrm{~m}^{-1}$ obscured this sign in a mean of only 206 seconds - almost a minute earlier than any other sign. This sign also received the lowest visibility ratings in both clear and smoke conditions. Comments by the observers revealed that they did not consider it to be at all effective. The data suggest that signs with low luminances, below $0.5 \mathrm{~cd} / \mathrm{m}^{2}$, are likely to be less effective in smoke -. particularly when located near the ceiling. In the present experiment, optical densities in excess of 0.04 od/m were reached in the first one to three minutes, meaning that this sign, if located above a door, would not have been visible. Other EL signs such as 5,10 , and 11 with somewhat higher mean luminances ( 1.7 to $4.3 \mathrm{~cd} / \mathrm{m}^{2}$ ) required higher optical densities and/or longer times to disappearance (260 to $300 \mathrm{sec}$ ). Such signs may be more useful when located near the floor, as Keating (1984) has suggested.

Sign luminance was not the only predictor of visibility performance, however. The configuration of the sign -- panel-face vs. stencil-face -. also played an important role. As noted earlier, the optical density of smoke required to obscure sign 3, particularly $3 R$, was actually greater than for sign 4, even though the overall mean luminance of sign 4 was higher. Observer comments revealed that they considered sign $3 R$ to be sharper with less blur than sign 4 which tended to blur in both clear and smokey conditions. As discussed earlier, there was a slight tendency for stencil-faced signs to perform better than panel-faced signs at comparable luminances. Typically, the stencil-faced signs required greater smoke density and longer time to disappear than the panel-faced signs. These comparisons suggest that the use of illuminated letters with an opaque background resulted in a "more visible" sign. Observer comments about them indicated that they were sharper, with less tendency to blur. This suggests that the background luminance in panel-faced signs may tend to mask the lettering by producing a veiling luminance. Certainly, the stencil-faced signs tended to have higher contrasts, again suggesting that the perception of crispness was rooted in reality. Ouellette (1988 a,b) also reported a tendency for signs with transilluminated (stencil-faced) letters to perform somewhat better in smoke. The data suggest, then, that signs that are more visible in smoke are likely to have higher luminances and be stencil-faced (have transilluminated letters). 
In the present experiment, there was also a tendency for red signs, particularly $3 R$, to be more visible than comparable green signs such as 3G. This tendency, however, was confounded with luminance since virtually all the red signs had somewhat higher luminances than comparable green signs. Thus sign $3 R$ outperformed sign $3 G$ on all visibility criteria but also had a substantially higher mean luminance $\left(163.5 \mathrm{vs} .70 .8 \mathrm{~cd} / \mathrm{m}^{2}\right)$. Observer comments, of course, indicated a preference for red signs, perhaps because of their familiarity.

When the performance of conventional and electroluminescent signs was compared, the conventional signs with higher sign luminance were superior in terms of the smoke density needed for sign obscuration and rated visibility particularly in smoke. - When the performance of the two sign types for similar sign luminances was compared, as for signs $1,8,6$ and 12 , somewhat different findings emerged. The EL signs ( 8,6 , and 12) received higher initial and final mean ratings of visibility ( 5.3 to 6 vs . 4.7) and took longer to disappear (about $60 \mathrm{sec}$ ) than sign 1, which used incandescent lamps. These data suggest that for signs of comparable luminance, EL signs may be superior in terms of time to disappear in smoke and visibility ratings. The worst performance, of course, was also by an EL sign, sign 9, which had markedly lower sign luminance. The performance of EL signs may be improved by increasing power to them under emergency conditions and increasing their luminance.

The data obtained in the visibility portion of the present experiment are, of course, subjective. They are critically dependent on each person's criterion for visibility. While observers were instructed that visibility is the ability to both identify and recognize the sign as an exit sign, individual observers clearly interpreted these instructions differently. Thus, some defined it as the ability to read every letter easily; others defined it as the ability to read enough of the sign that they could reasonably interpret it to be an exit sign; and still others felt that any light located above a door would obviously indicate exit and so the ability to identify individual letters was less important. While there were undoubtedly variations in visibility criteria between observers, individual observers tended to be consistent in their own criteria throughout the experiment. Therefore, it is the relative ratings of the signs between the observers that is important. Thus, sign 9 was always worst, while signs $3 R$ and 4 were generally best. Similarly, sign 9 disappeared first in smoke; signs $3 R$ and 4 were last. These differences appear to relate meaningfully to sign luminance, configuration, uniformity, and contrast.

The results of the present experiment tend to confirm those of recent experiments at NRC Canada (Rea, et al., 1985; Ouellette, 1988 a,b), in Japan (Jin and Yamada, 1985), and in Australia (Wilson, 1990). In contrast to Schooley and Reagan (1980 b) and Beyreis and Castino (1974), these more recent studies indicate the importance of sign luminance in determining visibility in smoke. They also raise questions about the likelihood of reduced sign visibility due to ambient illumination. The present study also suggests that stencil-faced signs with transilluminated letters may be superior as Ouellette found. Unlike Rea, et al., the 
present experiment did not confirm the idea that green signs are more visible, perhaps because the luminance of green signs tested was lower and because the observers were more familiar with red exit signs.

The research presented in the preceding pages raises almost as many questions as it answers. For example, the data suggest that the characteristics of an exit sign which determine its effectiveness in clear conditions may be somewhat different than in smoke conditions. In clear conditions, uniformity and contrast were considered important, while in smoke, luminance became more critical - although the combination of luminance and uniformity was considered to be the most visible. In fact, the "best" sign actually had lower average luminance but greater uniformity than the "brightest" sign. The study raises questions about sign configuration by hinting that stencil-faced signs are more visible than panel-faced, even though the latter frequently had slightly higher overall luminance. Questions also arose about minimum and maximum specifications for sign luminance. Certainly, the sign with the lowest luminance $\left(0.9 \mathrm{~cd} / \mathrm{m}^{2}\right)$ was ineffective in this experiment in both clear and smokey conditions. Yet, NFPA 101 currently provides an exclusion for self-luminous signs such as EL or tritium by allowing a minimum luminance of $0.06 \mathrm{fL}\left(0.21 \mathrm{~cd} / \mathrm{m}^{2}\right)$ for these signs. The data in the present experiment question the effectiveness of such low luminances for visibility especially in smoke conditions. On the other hand, while NFPA provides no maximum specification for sign luminance, the British standard does, again somewhat in contradiction to the current findings of greater visibility with higher sign luminances. Finally, the role of color remains uncertain. While Rea, et al. (1985) suggested that green might be a more effective color for exit markings, the present study indicated that red might be more effective, at least for the observers studied. In the present study, however, all the red signs had somewhat higher luminances, while the observers were accustomed to red exit signs. These findings suggest the need for a study in which the effects of exit sign luminance and color are studied parametrically, along with sign configuration and uniformity. The role of smoke type (white versus black), sign position, and ambient illuminance should also be examined critically in the same parametric experiment.

In conclusion, the present study indicates that some electroluminescent signs can be effective in clear conditions and in smoke, particularly if their average luminance is above about $10 \mathrm{~cd} / \mathrm{m}^{2}$. The data clearly indicate, however, that overall sign luminance is a primary determinant of visibility with higher luminance being associated with greater visibility. The data also suggest that sign configuration is an important contributor with stencil-faced signs - signs with illuminated letters and opaque backgrounds - being somewhat more visible than panel-faced signs. 
Australian Standards Association, Emergency Evacuation Lighting in Buildings: Part 1 - Installation Requirements. AS 2293, Part 1, 1983.

Beyreis, J.R. and Castino, T.G. Safety in Sight. Labdata, Winter, 1974 , Pp. $14-19$.

Bono, J.A. and Breed, B.K. Study of smoke ratings developed in standard fire tests in relation to visual observations. Underwriters' Laboratories, Bulletin of Research. April, 1965, 56, pp. 5-59.

Boyce, P.R. Movement under emergency lighting: the effect of illuminance. Lighting Research and Technology, 1985, 17, Pp. 51-71.

Boyce, P.R. Movement under emergency lighting: the effects of changeover from normal lighting. Lighting Research and Technology, 1986, 18, Pp. 118. also see Electricity Council, Capenhurst Research Memorandum, ECRC/M1 973, October 1985.

Bukowski, R.W. Smoke Measurements in Large and Small Scale Fire Testing. National Bureau of Standards. NBSIR 78-1502, October 1978.

Bullen, A.A. Emergency Lighting: Legislation and Application. Lighting Research and Technology, 1988, 20, Pp.61-62.

Clark, F.R.S. Strategies for improving visibility in fires. Canadian Building Digest, CBD 246, January 1988.

Clark, F.R.S., Rea, M.S., and Ouellette, M.J. Visibility of exit signs through smoke. Proceedings of the International Conference on Building Use and Safety Technology. 1985, Pp. 75-80.

Cohn, B.M. Study of human engineering considerations in emergency exiting from secure spaces. Gage-Babcock \& Associates, Inc. Report \#7762-2. March, 1978.

Collins, B.L. and Lerner, N.D. An Evaluation of Exit Symbol Visibility. NBSIR 83-2675, April, 1983.

Commission Internationale de l'Eclairage (CIE). Guide on the Emergency Lighting of Building Interiors. CIE No. 49 (TC4-1). Paris, 1981.

Demaree, J. Examination of Aircraft Interior Emergency Lighting in a Postcrash Fire Environment. U.S. Department of Transportation, Federal Aviation Administration. DOT/FAA/CT-82/55, June, 1982.

Department of the Army, Corps of Engineers. Lighting Fixtures. Standard Drawing No. 40-06-04, Feb 1985; Change 2, January 1986. 
Edmondo, P.M. and Macey, H.T. An investigation of lighting and directional signs for emergency egress from ship's compartments. Naval Ship Research and Development Center. Report 2661, November 1968.

Howett, G.L. Size of Letters Required for Visibility as a Function of Viewing Distance and Observer Visual Acuity. NBS Technical. Note 1180, July 1983.

Hurvich, I. M. Color Vision. Sunderland, MA: Sinauer Associates, 1981.

Japanese Standards Association. Self-Luminous Safety Signs. JIS Z 9115. 1979.

Japanese Standards Association. Phosphorescent Safety Sign Boards. JIS Z 9100. 1987.

Jaschinski, W. Conditions of emergency lighting. Ergonomics, 1982, 25, pp. $363-372$.

Jin, T, and Yamada, T. Irritating effects of fire smoke on visibility. Fire Science and Technology, 1985, 5, Pp. 79-90.

Kaufman, J.E. and Christensen, J.F. (Eds.). IES Lighting Handbook; Application Volume. New York: IESNA, 1987, Pp. 246-250.

Keating, J.P. A Feasibility Study on the Placement of Egress Signage at Lower Positions than is Currently Common. A report to the California State Legislature by the Office of the State Fire Marshal in response to SCR 32, 1984.

National Fire Protection Association. Life Safety Code, NFPA 101. Section 5-8, Illumination of Means of Egress; 5-9 Emergency Lighting; 5-10 Markings of Means of Egress. 1988 Ed.

National Research Council, Canada. National Building Code of Canada. Sections 3.2.7, Lighting and Emergency Power Systems; and 3.4.5, Exit Signs. 1990 Ed.

Nikitin, V.D. Svetotekhnika, 1973, 6 (no.).

Ouellette, M.J. Design parameters for more visible exit signs in smoke. Proceedings of the National Lighting Conference. Cambridge, UK, March, 1988. (a)

Ouellette, M.J. Exit signs in smoke: Design parameters for greater visibility. Lighting Research and Technology, 1988, 20, Pp. 155-160. (b)

Ouellette, M.J. and Rea, M.S. Illuminance Requirements for Emergency Lighting. Journal of the Illuminating Engineering Society, 1989, Pp. 37 42 . 
Rasmussen, P.G., Garner, J.D., Blethrow J.G., and Lowrey, D.L. Readability of Self-illuminated Signs in a Smoke-obscured Environment. U.S. Department of Transportation, Federal Aviation Administration. FAAAM-79-22, FAA-ARD-79-108., Nov., 1979.

Rea, M.S. How good are emergency lighting systems. Lighting Design and Application, 1985, Sept., Pp. 26-27.

Rea, M.S., Clark, F.R.S., and Ouellette, M.J. Photometric and Psychophysical Measurements of Exit Signs Through Smoke. National Research Council Canada, Division of Building Research, DBR-1291, NRCC 24627, June 1985 .

Rea, M.S., Ouellette, M.J., and Clark, F.R.S. Design considerations for egress signs based on visibility through smoke. Proceedings of American Institute of Architecture Conference on Research and Design, Los Angeles, 1985, Pp. 295-277.

Schooley, L.C. and Reagan, J.A. Visibility and legibility of exit signs. Part 1: Analytical predictions. Journal of the Illuminating Engineering Society, 1980, 10, Pp.24-28.

Schooley, L.C. and Reagan, J.A. Visibility and legibility of exit signs. Part II:Experimental Results. Journal of the Illuminating Engineering Society, 1980, 10, Pp. 29-32.

Sime, J.D. Movement towards the familiar: Person and place affiliations in a fire entrapment setting. In Duerk, D., and Campbe11, D. (Eds). The Challenge of Diversity: Proceedings of EDRA/15. Washington, D.C: EDRA, 1984, Pp. 100-109.

Sime, J.D. Perceived Time Available: The Margin of Safety in Fires. School of Architecture, Portsmouth Polytechnic. Proceedings First International Symposium on Fire Safety Science, National Bureau of Standards, Oct 9-11, 1985. (a)

Sime, J.D. The Outcome of Escape Behaviour in the Summerland Fire: Panic or Affiliation? Proceedings of the International Conference on Building Use and Safety Technology. Los Angeles, March 1985. (b)

Simmons, R.C. Illuminance, diversity and disability glare in emergency lighting. Lighting Research and Technology, 1975, I, Pp. 125-132.

Teal, M. Improved Interior Emergency Lighting Study. U.S. Department of Transportation, Federal Aviation Administration. DOT/FAA/CT-83/31, MDC J9838, September 1983.

Taylor, L.H. and Sucov, E.W. The movement of people towards lights. Transaction. Journal of the Illuminating Engineering Society, 1974, 13, Pp. 237-241. 
Underwriters Laboratories (UL) Inc. Emergency Lighting and Power Equipment. UL 924, Exit Fixture and Exit Light Visibility. March 2, 1989. copyright $1973,1989$.

Underwriters Laboratories Inc. Report of Determination of Shape, Size and Visibility of Directional Arrows for Exit Signs (Report No. 1988-1, Subject 924). Underwriters Laboratories, Santa Clara, CA. March 1988. Report No. 1988-2, Subject 924), March 1988.

U.S. Army Corps of Engineers. Lighting Fixtures. Standard Drawings No. 40-06-04. Feb 1985, January 1986.

Webber, G.M.B. Emergency lighting recommendations. Proceedings of the International Conference on Building Use and Safety Technology. 1985.

Webber, G.M.B., Hallman, P.J., and Salvidge., A.C. Movement under emergency lighting: Comparison between standard provisions and photoluminescent markings. Lighting Research and Technology, 1988, 20, Pp. $167-175$.

Webber, G.M.B. Way out lighting. Building Services, August, 1987, Pp. $39-40$.

Webber, G.M.B. and Hallman, P.J. Emergency lighting and movement through corridors and stairways. Proceedings of the Ergonomic Society's Annual Conference, Swansea, U.K., April, 1987.

Webber, G.M.B. and Hallman, P.J. Movement under various escape route lighting conditions. Proceedings of the International Conference on Safety in the Built Environment. Portsmouth, U.K., July 1988.

Webber, G.M.B. and Hallman, P.J. Photoluminescent Markings for Escape Routes. BRE Information Paper, IP 17/89, September 1989.

Wilson, I. The effectiveness of exit signs in smoke. Lighting in Australia, February 1990, Pp. 14-19. 
Appendix A. Instructions and Research Participant Agreement Form. Subject *

File \#

Date

Instructions

\section{Visibility of Exit Signs}

The purpose of the present experiment is to determine the visibility of different types of exit signs under both clear and smokey conditions.

You will see a total of twelve internally lit exit signs in the experiment. First, you will view each sign individually under clear conditions, and give a rating of its visibility. Next you will see all the signs under smokey conditions and indicate when each sign disappears from view. At the end of the experiment, you will be asked to rate the visibility of each sign again, for a given level of smoke in the room.

In the first part of the experiment, you will be asked to rate the visibility of each sign by itself under clear conditions using a 7-point scale of visibility. By visibility, we mean your ability to see and recognize an individual sign. In this scale, a "l" means "Not at all Visible", while a "7" means "Very visible". Next, we will turn all the signs on, and ask you to indicate the best and the worst exit sign, and tell us why you selected each sign.

Next the chamber will be filled with smoke until you indicate that the signs are disappearing. Please state the order in which each sign disappears from view using the grid shown in the window to locate the sign.

Finally at the end of the experiment, you will be asked to rate the visibility of each sign from the fixed viewing distance for four different smoke densities, again using the 7-point scale of visibility.

We would also like to know if you wear glasses, contacts or bifocals, and if you have any color deficiency. The total experimental time is expected to be less than 30-min but you may quit at any time if you become tired. The smoke will be confined to the chamber in which the signs are located you will view the signs from a seated position through a clear plexiglas shield, between you and the smoke. To minimize exposure to the smoke even further, we will give you a smoke mask to wear for the smokey conditions.

Do you have any questions? Thank you very much for your cooperation. 


\section{Rating Sheet - Exit Sign Visibility}

Please give the rating that best represents the visibility of each sign using a scale of 1 to 7 .

$\begin{array}{lllllll}1 & 2 & 3 & 4 & 5 & 6 & 7\end{array}$

Not at all visible

Very Visible

1 Not at all Visible

2 Barely Visible

3 Not very Visible

4 Neutral

5 Somewhat visible

6 Quite Visible

7 Very Visible

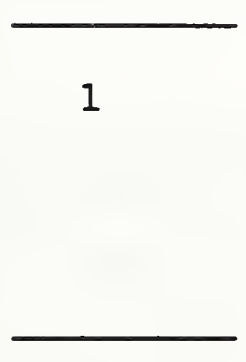

5

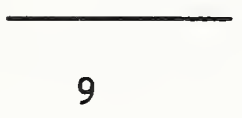

2
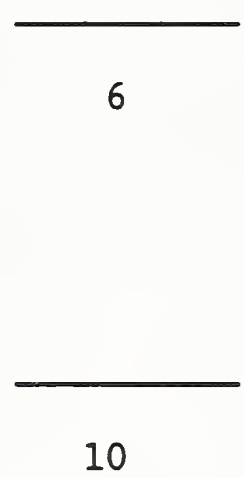

3
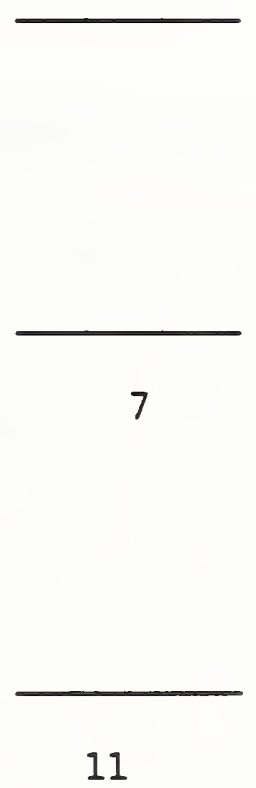

4
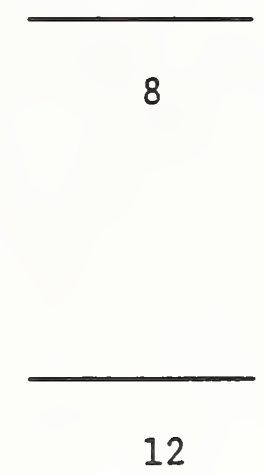

Best sign

Best Three

Why?

Worst sign

Worst Three

Why? 


\begin{tabular}{|c|c|c|}
\hline \multirow[t]{4}{*}{$\begin{array}{l}\text { NIST-114A } \\
\text { (REV. 3-00) }\end{array}$} & \multirow{4}{*}{$\begin{array}{l}\text { U.S. DEPARTMENT OF COMMERCE } \\
\text { NATIONAL INSTITUTE OF STANDARDS AND TECHNOLOGY } \\
\text { BIBLIOGRAPHIC DATA SHEET }\end{array}$} & $\begin{array}{l}\text { 1. PUEUCATIOM ON REPONT MUMDEN } \\
\text { NISTIR } 4399\end{array}$ \\
\hline & & 2. PERFORMING ORQAMIZATION REPOAT MUMAEA \\
\hline & & . \\
\hline & & $\begin{array}{l}\text { 2. PUEUCATION DATE } \\
\text { AUGUST } 1990\end{array}$ \\
\hline
\end{tabular}

4. TII AND SUETIU

Evaluation of Exit Signs in Clear and Smoke Conditions

5. AUTHOR(3)

Belinda L. Collins; Mubarak Dahir; Danfel Madryzkowsk1

6. PERFOAMING ORQAMIZATION (IF JOIMT OR OTHEA THAN MIST, SEE INSTRUCTIONS) U.S. DEPATTMEATT OF COMMERCE MATIONAL IHSTTUTE OF STANDARDS AND TECHHOLOOY CATTHERSEURG, MD 20000

7. CONTAACT/ORANT MUMBER

Q. TYPE OF REPORT AND PERIOD COVERED

9. SPONSOAIMO ORGAMIZATION MAME AND COMPLETE ADOAESS (STRERT, CTY, STATE, ZP)

10. SUPPLEMEMTANY MOTES

11. ABSTRACT (A 2OO-WOAD OA LESS FACTUAL SUMMAAY OF MOST SIOMIFICANT IMFORMATIOH. IF DOCUMENT IMCLUDES A SIOMIFICANT BIBUOOAAPHY OA UTERATURE SURVEY, MEMTIOH IT HERE)

The present paper provides a short review of the research literature on the visibility of exit signs, directional markings, and emergency lighting. It also presents a study which assessed the visibility of several types of exit signs including conventional and electroluminescent (EL) in both clear and smokey conditions. A two-part evaluation was performed. In the first, signs were measured photometrically in clear conditions with two different photometers in a laboratory to determine their luminance under dark conditions and with an ambient room illuminance of $54 \mathrm{~lx}$ ( $5 \mathrm{fc}$ ). Analysis of these data indicated very wide variations in luminance (from about 0.9 to $1350 \mathrm{~cd} / \mathrm{m}^{2}$ ) as a function of sign type. In the second part of the study, the visibility of the signs in both clear conditions and smoke was assessed psychophysically. A total of 21 observers participated ix the assessment of visibility. Analysis of the data indicated that overall sign luminance was one of the primary determinants of visibility in smoke conditions, while uniformity was also an important contributor. The data indicated that some EL signs can be effective in clear conditions and in smoke (particularly if their luminance is above about $10 \mathrm{~cd} / \mathrm{m}^{2}$ ). Consideration of the results indicated that somewhat different characteristics of the signs seemed to determine their visibility for clear conditions than smoke, with uniformity (or sign configuration) playing a larger role in clear conditions, and luminance being more critical in smoke. Finally, the data indicated the need for further research in which the effects of color, sign configuration, and luminance are varied parametricaliy.

12. KEY WORDS (6 TO 12 EMTRIES; MLHABETICAL ORDER; CAPTTALZE ONLY PROPEA MUMES; AND SEPARATE KEY WOADS BY SEMICOLONS) color; contrast; electroluminescent; exit; luminance; smoke; optical density; uniformity; visibility

13. AVALATIUTY

\begin{tabular}{|c|c|}
\hline $\mathrm{X}$ & 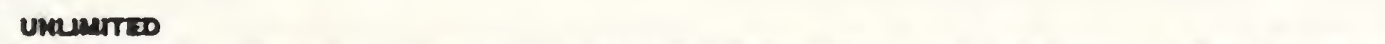 \\
\hline & FOR OFFICUL DISTAIEUTION. DO NOT RESASE TO MATIONLL TECHMICNL MFONMATION SEMVCE (MTIS). \\
\hline & 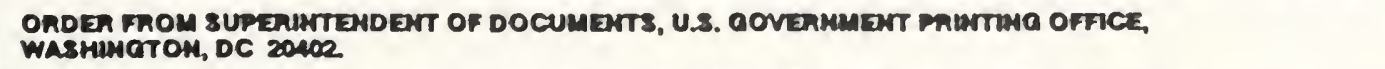 \\
\hline $\mathrm{x}$ & ORDER FROM MATIOMLL TECHMICAL IMFORMATIOH SERMCE (MTS), SPAMOFEED, VA $2 O 161$. \\
\hline
\end{tabular}

\begin{tabular}{l} 
14. HUMBEN OF PAIHTED PAQES \\
80 \\
\hline 18. PAICE AOS \\
\hline
\end{tabular}






\section{IR 4400}

\section{CANCELLED 08/03/90}


